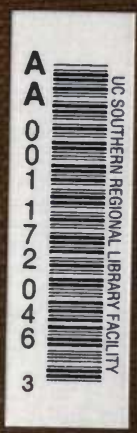


UNIVERSITY OF CALIFORNIA AT LOS ANGELES
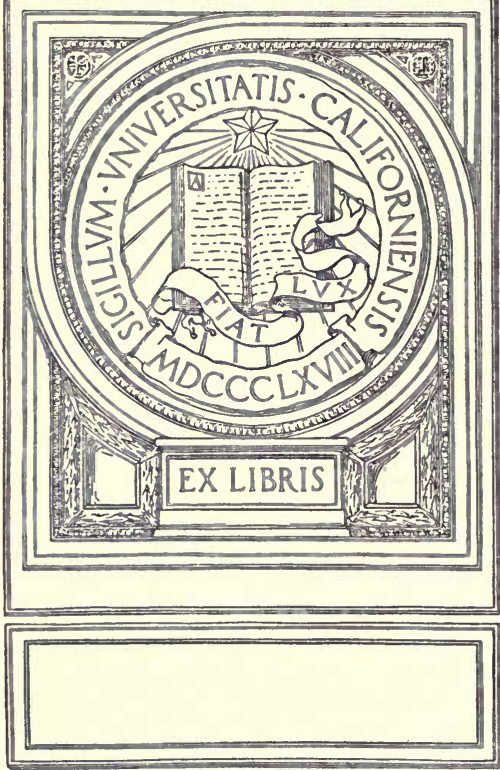

The RALPH D. REED LIBRARY $\diamond$

DEPARTMENT OF GEOLOGY UNIVERSITY OF CALIFORNIA LOS ANGELES, CALIF. 






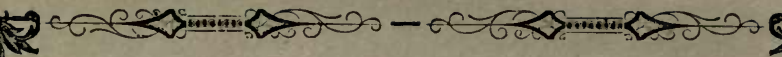

\section{E M O I R S}

OF THE

\section{GEOLOGICAL SURVEY}

or

\section{THE UNITED KINGDOM.}

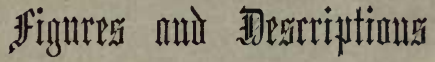

ILLUSTRATIVE OF

BRITISH ORGANIC REMAINS.

MONOGRAPH I.

PURLISIIED BY ORDER OF THE LORDS COMMISSIONERS OF MER MAJESTE'S TREASURT.

LONDON :

PRINTED FOR HER MAJESTY'S STATIONERY OFFICE:

PUBLISUED BY

LONGMAN, BROWN, GREEN, LONGMANS, \& ROBERTS. 1859. 


\section{N 0 T I C E.}

The Session of the Government School of Mines and of Scrence applied to the Arts commences early in October in each year, during which the following Courses of Lectures are delivered :-

Chemistry, with special reference to its applications in the Arts and $\}$ A. W. Hofmann, LL.D., F.R.S. Manufactures

General Natural History - $\quad$ - T. H. Huxley, F.R.S.

Physics - - - - G. G. Stokes, M.A., F.R.S.

Applied Mechanics - - Robert Willis, M.A., F.R.S.

Metallurgy - - - ～- John Percy, M.D., F.R.S.

Geology - - - - A. C. Ramsay, F.R.S.

$\left.\begin{array}{ll}\text { Mining } & - \\ \text { Mineralogy } & -\end{array}\right\} \quad-\quad-\left\{\begin{array}{l}\text { Warington W. Smyth, M.A., } \\ \text { F.R.S. }\end{array}\right.$

The Chemical Laboratory, under the direction of Dr. Hofmann, and the Metallurgical Laboratory, under the direction of Dr. Percy, are open for the instruction of Students.

A Prospectus and Information may be obtained on application to

Trenham Reeks, Registrar.

Jermyn Street, London. S.W. 


\section{E M O I R S}

OF TIIE

\section{GEOLOGICAL SURVEY}

OF

\section{THE UNITED KINGDOM.}

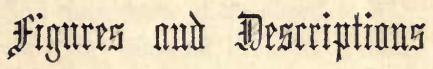

ILLUSTRATIVE OF

\section{BRITISH ORGANIC REMAINS.}

MONOGRAPH I.

PCBLISHED BY ORDER OF THE LORDS COMMISSIONERS OF HER MLJESTY'S TREASCRT.

\section{LONDON :}

PRINTED FOR HER MAJESTY'S STATIONERY OFFICE:

PEBLISHED BY

LONGMAN, BROWN, GREEN, LONGMANS, \& ROBERTS. 1859. 


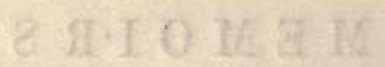

\section{TMVRUR ThOLDOJORD}

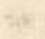

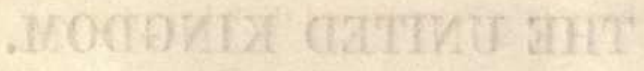

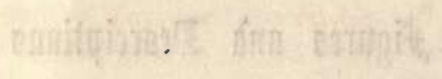

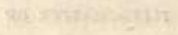

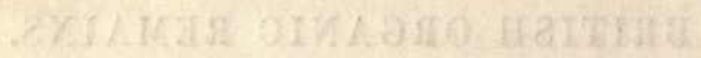

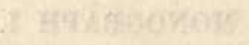

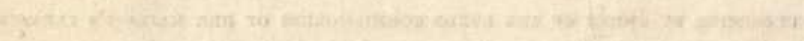

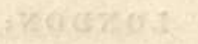

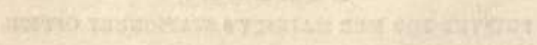

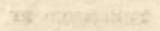

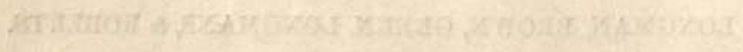

औ औ o

आ 


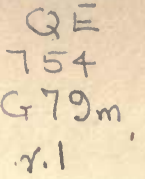

\section{NOTICE.}

THE accompanying Monograph, by Professor Huxley and Mr. Salter, shows the advantage accruing to geological science from the combined efforts of the Naturalist and the Palæontologist.

Having devoted many years of my life to the establishment of the true order of those strata which are characterised by the genus Pterygotus, i.e. the Upper Silurian Rocks of Britain and Russia, and the Lower Old Red Sandstone of Scotland, it is peculiarly gratifying to me to announce the issue of a work which, whilst it throws fresh light on the organic remains of those deposits, and must be valued by all naturalists, will at the same time sustain the usefulness of the study of fossil remains, in developing the true geological structure of the British Isles.

The figures and descriptions of British Organic Remains having been hitherto, in great measure, confined to the illustration of isolated genera and species, it was found convenient to publish them, at intervals, in fasciculi of Ten, under the term of Decades. That title is, however, obviously inapplicable to Memoirs like the present, and to other Monographs containing a variable number of plates, which are in preparation.

RODERICK I. MURCHISON,

December 31, 1858.

Director-General. 


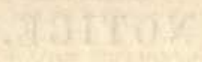

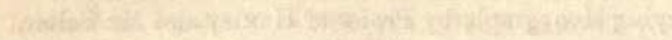

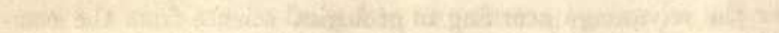

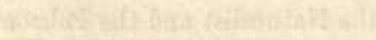

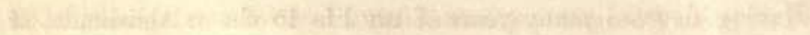

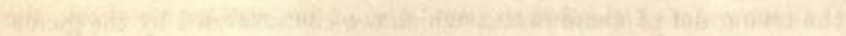

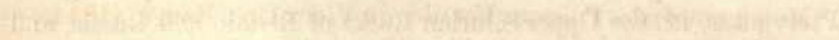

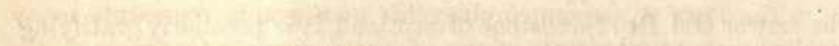




\section{BRITISH FOSSILS.}

\section{MoNograph the First.}

Part I.-On the Anatomy and Affinities of the Genus Pterygotus.-By Thomas H. Huxley, F.R.S., Professor of Natural History, Government School of Mines.

The genus Pterygotus was established by Professor Agassiz, in the following note appended to page xix. of his well-known work, the "Monographie des Poissons Fossiles du Vieux Grès Rouge" (1844):-

"The Plate A, accompanying this monograph, represents many well preserved fragments of one of those gigantic Crustacea of the Old Red, collected by Mr. Webster in the neighbourhood of Balruddery, in Scotland. Deceived by the scaly aspect of a portion of the carapace, $I$ at first believed that this might be the type of a peculiar genus of fishes, and to that class I referred Pterygotus, in my enumeration of the fossil fishes of the Silurian system, published in Murchison's great work. This genus, founded upon very imperfect fragments from the Ludlow rocks, is now well known, from the investigations which I have been enabled to make of a new species from the Old Red, discovered by Lyell, in Forfarshire, and of which Mr. Webster has found more characteristic remains at Balruddery. The specimens collected by Lyell are those large scutes, of which I have spoken in my 'Recherches,' vol. i. p. 26, and which, in the absence of the means of rigorous determination, have been seriously taken for the remains of superhuman beings.

" Dr. Buckland and I, on examining them carefully, convinced ourselves that they must be the carapaces of Crustacea ; but it was only in 1840 that I obtained direct proof that such was the case. In fact, among the specimens collected and communicated to me at that time by Mr. Webster, are fragments of carapaces, segments of the tail, the natatory palettes with which the extremity of the latter was provided, legs, and chelæ. These remains remove all doubt as to the zoological position of the fossil. It is a crustacean of colossal size, having a carapace of more than a foot and a half in width, and a tail about a foot wide. The dimensions of the cephalothorax, 
represented in the right-hand figure of the second row, Plate A,* forbid its arrangement among the Decapoda, notwithstanding the form of the chela figured in the middle of the lower series of the same plate.t I am rather inclined to believe that this singular animal will become the type of a family, intermediate between the Trilobites and the Entomostraca, in which perhaps the Eurypteri and the Eidotheoe will some day be included. The carapace is ornamented throughout with a squamose sculpture, which confers upon its surface the aspect of a fish's cuirasse; in the middle it presents an impression like that of a lance-head, corresponding, without doubt, to the gastric and cardiac regions of ordinary Crustacea. The divisions of the chela are provided with large obtuse teeth; the longer point of these levers is strongly arcuated. The arm which carried the chela (figured on the left in the lower series) is very large; the articulations which immediately precede the pincer are short, and wider than they are long. The ordinary legs (figured on the left in the middle series§) are simple, and end in a point; the segments to which they are attached are sensibly longer than they are wide.

"The segments of the tail, $\|$ (represented in the right-hand figure of the upper series,) reduced to half their natural size, are broad plates, provided with articular processes at their superior extremities, Lastly, the natatory palettes of the tail (the two figures at the superior left-hand and inferior right-hand corners 9 ) are rounded plates, fringed along their edges, and scaly on the surface, like the carapace. This curious fossil does not seem to be very rare in the Old Red of Scotland. I have conferred upon this species the name of Pterygotus anglicus, which at once suggests its origin and the singular view which was once entertained as to its nature."

Although the parts figured by M. Agassiz have, as I have taken occasion to point out in successive notes, in no single case the nature attributed to them, his sagacious indication of the affinities of Pterygotus deserves thankful recognition.

The views of Professor Agassiz respecting the affinities of Pterygotus are adopted and expressed still more strongly by $\mathbf{M}$. von

- This is in fact the epistoma.

$\uparrow$ The part thus figured is one of the antennæ.

‡ The figure here referred to represents a part of the palp of the ectognath, which has nothing to do with the chela.

$\S$ This is an endognath with its palp; no segment is represented in the figure.

II The figure represents one of the most anterior segments of the body.

T The part shown in the superior left-hand figure is part of the basal joint of an ectognath. The inferior right-hand figure represents the terminal joint of the palp of the same organ. 
Eichwald, in his Memoir on the Grauwacke of Livonia and Esthonia.* "It appears at first sight," says he, "that this (Pterygotus) was a colossal Eurypterus, at least the genera are very closely allied." M. von Eichwald differs from Agassiz only in considering the latter's "caudal segment" to have been thoracic. His specimen, which he ascribes to P. anglicus, was found in the Limestones of Rootsikülle.

In the Annals and Magazine of Natural History for 1849,'series 2, vol. iv. pp. 393, 394, Professor M'Coy gives an account of the remains of a new species of Pterygotus, $P$. leptocheles. In his preparatory remarks, Professor M'Coy erroneously states that Agassiz has " in his work on the Fishes of the Old Red Sandstone referred it (Pterygotus) to the Entomostraca, without indicating any particular division." The fact being, as is proved by the quotation just given, that he does not consider Pterygotus to be entomostracan at all, but to be intermediate between "Trilobites and Entomostraca."

Following Agassiz and Eichwald, Professor M'Coy indicates the close relations which obtain between Pterygotus and Eurypterus; but he unites Pterygotus, Eurypterus, and Bellinurus, and makes of them a family of the Pacilopoda. Professor M'Coy considers that he has found evidence of the existence of more than one pair of didactyle feet.

Professor M'Coy's views are further expressed in the restored figures of Pterygotus, which he has furnished to the fifth edition of Sir Chas. Lyell's "Manual," (1855,) and in the following passage of that work (p. 420):-

"The carapace of this buge crustacean, which must have rivalled, if not exceeded in size, the largest crab, is furnished at its hind part with two short prongs, and has two large eyes near the middle, much like those of the Eurypterus found in the coalformation of Glasgow. The body consists of ten or eleven moveable rings (the exact number is not ascertained), and was terminated by an oval pointed tail. The whole surface is covered by the scale-like markings before mentioned as ornamenting the head. Professor $\mathbf{M}^{\prime} \mathrm{C}$ coy, to whom I owe these notes on the general structure, has kindly furnished me with a restoration of the entire animal (fig. 543), which he believes to be closely allied to the great Eurypterus before mentioned, if not of the very same genus, and moreover of the same family as the living king crab or Limulus."

The restorations exhibit, in figs. 542, 543, 544, the chelæ fitted on to the ends of the mutilated ectognathary palp, in accordance

* Die Grauwacke Schichten ron Liv-und Esth-land, von Ed. von Eichwald. Bulletin de la Société Impériale des Naturalistes de Moscon. 
with Agassiz's idea of their position; while, in fig. 543, the epistoma is represented as the carapace, and a transversely elongated eye is made to appear on either side of its median lobe, about midway between the middle line and the margin! The chelate appendages are made to arise from behind this supposed carapace, and are succeeded by two or three pairs of articulated appendages. In short, wherever Professor M'Coy departs from M. Agassiz's conception of the structure of Pterygotus, the alteration is not an improvement.

In $1852 \mathrm{Mr}$. Salter published a "Description of the Pterygotus problematicus," in the "Quarterly Journal of the Geological Society," in which the following passage occurs :-

"It is probable that there are numerous species of the genus in the old rocks. Fragments, with the characteristic markings, occur in Upper Silurian shale at Gaspé, Lower Canada; and portions of the limbs of a Bohemian species have been figured by the late M. Corda as the feet of Brontes, a genus of Trilobites."

Mr. Salter expresses his concurrence in the systematic views of Professor M'Coy.

The Report of the British Association for 1855, "Transactions of the Sections," (pp. 89-91), contains the abstract of a paper by Mr. D. Page, "On the Pterygotus and Pterygotus Beds of Great Britain." The following passages show what views were then entertained by Mr. Page with respect to the structure of these animals :-

"The Pterygotus, of which there appeared to be three distinct species, - the gigantic problematicus, the anglicus, and the punctatus, - was altogether different in its general structure from any crustacean living or extinct. The portions chiefly found (and of these capital specimens are in the collections of Lord Kinnaird, the Watt Institution, Dundee, \&c., all originally from Balruddery,) were the frontal cephalic shield, the posterior cephalic or thoracic shield, with its lunar-like epimera, the abdominal segments, generally from seven to eleven in number, the huge prehensile claws with their curious denticulated edges attached to limbs of great length, the shorter swimming limbs with their paddle-like appendage, and several semi-oval detached plates which evidently belonged to the breast or under side of the animal. Putting all these portions in place as nearly as could be determined, we had a huge lobster-like crustacean, but only lobster-like in general contour, for in its true generic relations it belonged to no existing family of the order. Partly phyllopod and partly pæcilopod, in its abdominal segmentation macrourous, and in its thoracic appa- 
ratus resembling the existing Limulus. The Pterygotus could be classed with no living family, and was in aspect more like the larvæ than the adult forms, of any Crustacea with which we are acquainted. This peculiarity, indeed, ran throughout the whole of the Crustacea, (and there were several new forms he would notice on another occasion,) which had hitherto been found in this geological horizon, - a horizon that would yet be found to be marked peculiarly by its strange Crustacea. From the portions he now exhibited to the section, the members eould perceive at a glance that the restoration by Professor M'Coy was altogether erroneous, and bore scarcely any resemblance to what the creature must have been when alive, and acting the part of a scavenger along the muddy shores of the Old Red Sandstone seas. The figures on the walls (Mr. Page here exhibited what he conceived to be a near approach to a complete restoration) would afford some idea of the general features of the animal, which he had found of all sizes from ten or twelve inches up to full five or six feet in length. Such was the Pterygotus, and looking at its complex structure, as well as the similar structure of other Crustacea of the period, there could be no doubt that no existing classification of the order embraced them in its subdivisions. The fact was, that the existing Crustacea were by no means well worked out as a group, and the discovery of these strange fossil forms rendered the study still less perfect."

The comparative anatomist acquainted with the labours of Milne Edwards, Dana, Bell, Baird, Schaeffer, Darwin, and a host of other workers, will hardly be disposed to agree with the opinion expressed in the commencement of Mr. Page's last paragraph, though doubtless a good deal remains to be done. In Mr. Page's reference of the Pterygoti to a distinct group, he has, as we have seen, been anticipated, and his restoration of their structure is hardly more fortunate than that of his predecessors. His " posterior cephalic or thoracic shield " is the epistoma, and has a wholly different place from that assigned to it; like Agassiz and M'Coy he places the chelæ at the end of the ectognathary palps, and considers them to terminate thoracic appendages.

Mr. Page's paper was read before the British Association at its meeting in 1855. In November of the same year Mr. Salter communicated a paper to the Geological Society "On some new Crustacea from the Uppermost Silurian Rocks," to which I added a note on the structure and affinities of Himantopterus.

Mr. Salter points out the differences between Himantopterus 
and Eurypterus, and establishes six species of the former genus, whose structure and affinities are discussed in my own note. Subsequent investigation has confirmed the riews therein taken of the carapace, its eyes, the chelate antennæ, the swimming feet, the general structure of the body, and the absence of abdominal or thoracic appendages ; nor has it, as yet, been absolutely proved that there were more than three pairs of cephalic appendages; but the basal joints of the ectognaths were mistaken for mandibles, and their connexion with the long palp-like swimming foot was not observed. Neither the epistoma nor the metastoma (the latter is figured in the restoration as a "scale-like appendage") were determined. In inquiring into the affinities of Himantopterus, I compared it successively, with the Phyllopoda, the Pocilopoda, the Copepoda, and the grounds on which I objected to refer it to either of these orders seem to me still, substantially, to hold good. I then proceeded to compare it with the Cumoid Crustacea, with certain Stomapoda, and with the embryonic forms of the higher Crustacea, and I concluded by expressing the opinion, that " the nearest approach to Himantopterus which could be constructed out of the elements afforded by existing Crustacea, would be produced by superinducing upon the general form of a Cumoid crustacean, such a modification of the appendages as we find among the Zociform Macruran larvæ."*

In his "Advanced Text-Book of Geology," p. 135 (1856,) Mr. Page gives a figure of one of the specimens on which Himantopterus was based, and provisionally admits that genus, adopting the "Cumoid" affinities which I had suggested. He considers that those palæozoic Crustacea and their allies exhibit, "as it were, an interfusion of phyllopod, pæcilopod, and decapod-of brachyurous, macrourous, and xiphosurous forms," and figures and names "Slimonia" and "Stylonurus," which he considers to be new genera, but which are not as yet proved to be other than species of Eurypterus and Pterygotus.

Mr. Salter communicated to the meeting of the British Association, in 1856, a paper "On the great Pterygotus (seraphim) of Scotland, and other Species," containing his opinion as to the identity of the genera Himantopterus $\dagger$ and Pterygotus, and some of the farther anatomical facts which had at that time been elucidated.

- Mr. Salter has misunderstood me, when he says at the end of his memoir (l.c.) that I consider Himantopterus to be "one of the Stomapoda." On the contrary, I have always been prepared to admit the ordinal distinctness of the Eurypterida.

† The name Himantopterus could in no case have been retained, as it has been already used for a genus of lepidopterous insects. 
And, lastly, I stated the results of the same inquiries still more fully in my ". Lectures on General Natural History," published in the Medical Times and Gazette for 1857.

The evidence upon which the following attempt to give a connected account of the structure of Pterygotus is based, is both positive and negative. Numerous specimens testify to the existence of certain characteristically formed parts, and to the arrangement or these in a definite order in the body of the animal, so that its general configuration may be very confidently restored. On the other hand, the large number of fragments of many species of Pterygotus which have been inspected, without revealing anything new, leads me to entertain a strong impression that no structures of any very great importance remain to be discovered.

With regard to the nature of the positive evidence, I may premise that of the fifteen distinguishable species of the genus, the remains of only five, viz., anglicus, acuminatus, punctatus, perornatus, and bilobus have yielded facts of capital importance in a structural point of view; I shall, therefore, confine myself to these species, referring the reader to the systematic portion of this monograph for information respecting the rest, and indeed for all details of no anatomical importance concerning even these.

Of the species named, the only entire specimens yet discovered belong to $P$. bilobus, but the large size and comparatively perfect condition of the detached parts of $P$. anglicus, added to the fact that the genus was originally founded on this species, render it convenient to commence with a description of them.

1. The Carapace.-In Lord Kinnaird's collection there is a large flattened plate, figured in Plate III. fig. 1, which appears to have possessed a trapezoidal form when perfect, but is at present very irregular (though by no means distorted), one of its angles and a considerable portion of the margin of the longest side having been broken away. The shortest or anterior side is very slightly convex, the opposite and parallel longest side is a little concave; that lateral margin which is entire is nearly straight, but is rounded off where it joins the posterior edge. The surface of the fossil is slightly concave, and exhibits neither sculpture nor distinct granulation, but it is marked by a great number of sinuous elevations and depressions. At the outer extremities of the anterior edge are two large and deep depressions of an oval form, having their long axes directed obliquely forwards and inwards.

The surface of each concavity presents a great number of minute, but regular and close-set depressions (Figs. 1a, 1b), which appear 
quite distinct when viewed from a little distance, but whose form is by no means easily defined on closer inspection. On the inner side of one of these concavities a broad longitudinal depression traverses the surface for some distance. Prima facie, one would be inclined to take this great plate for a carapace, and the lateral, peculiarly sculptured, concavities for the vestiges of eyes; and any doubt on the subject will be at once removed on comparing it with the carapaces of Pterygotus bilobus or perornatus (Plate I. figs. 1,13); but it is somewhat difficult to decide whether the fossil is merely the impression of the dorsal surface of a carapace, or whether we really see the inner face of the carapace itself. The absence of the characteristic sculpture is not conclusive against the former determination, as, with the exception of its anterior edge, the dorsal surface of the carapace of $P$. perornatus is equally devoid of ornament.

However this may be, the long margin must clearly be posterior, and the entire lateral edge, the right, while the piece broken off is the left posterior lateral angle. If a line be drawn so as to continue the direction of the anterior part of the left edge backwards until it meets the line of the posterior edge, it will represent the general course of the broken margin, and the carapace will then be found to have had a trapezoidal form, the posterior edge being nearly twice as long as the anterior, and the antero-posterior diameter being about equal to the length of the anterior margin. The right lateral edge is more or less crushed and distorted.

This is the only known example* of the carapace of $P$. anglicus ; the fossil described as such by Professor Agassiz must therefore have a totally different nature.

2. The Epistoma.-It is this remarkable structure which is figured in a state of greater or less perfection in Plate III. figs. 2, 7.

The most perfect specimens (figs. 2, 5, ) reveal a broad plate having one edge nearly straight, but presenting a slight median emargination, while the opposite edge inclines from the middle line on each side outwards towards the straight margin, which it would, if continued, cut at a considerable angle.

In the middle line a slight longitudinal depression passes along the face of the plate for a short distance, from the straight margin towards the convex one, and then divides into two diverging grooves.

From the extremities of these, two others, slightly convex towards one another and the median line, are continued as far as the convex edge, and thus the plate becomes divided into three

* Mr. Salter informs me that there are two more in Lord Kinnaird's collection, which I have not seen. 
regions,-a narrow "median lobe" and two wide "lateral alæe." The inner angles of the alæ are rounded off; the median lobe projects beyond them and ends in a sharply defined, well-rounded, free edge. The outer fourth of the transverse diameter of the median lobe on each side is overlapped by the corresponding ala, a considerable amount of matrix being occasionally interposed between the two. The general plane of the median lobe, in fact, lies behind that of the alæ, whence it arises that impressions of the plate present the aspect figured by M. Agassiz, and reproduced in Plate III. fig. 2, and the median lobe, while covered by the alæ, appears spoon-shaped, whereas its end is in reality but little expanded (fig. 7).

The alæ present, very well developed, the peculiar sculpture so characteristic of Pterygotus and its allies, multitudes of little semilunar facets, with their convex edges raised and all turned towards the convex margins of the plate, being thickly scattered over its surface.

The facets of the sculpture on the middle of the median lobe are greatly elongated, but have the same general direction. The rounded end of the median lobe is marked by radiating striæ, while its sides, where overlapped by the alæ, are smooth. From the thinness and sharp definition of its edge, the median process would seem to have been quite unconnected with the alæ laterally; and it appears to have very readily yielded to force along the diverging grooves. The impressions of median lobes detached, in consequence of having broken away from the alæ along these lines, are figured in Plate III. figs. 3, 4.

No crustacean, living or extinct, is known to have a carapace presenting the least approximation to the structure here described, and the true carapace of Pterygotus has already been described. I shall endeavour to prove by-and-bye that this singular plate is in fact the homologue of the epistoma and labrum of other Crustacea.

3. The Body Segments. - Numerous oblong plates and impressions of such, ornamented more or less extensively with the peculiar sculpture, have been discovered (Plates IV. and V.). Of these, some are much elongated transversely, and, if we may be guided by the analogy of $P$. bilobus and perornatus, belonged to the anterior part of the body. Others are longer than they are broad, and it may be concluded, on similar grounds, that they represent posterior segments. In the specimen figured in Plate IV. fig. 6, two such segments remain in their natural relation to one another, but it is, unfortunately, impossible to ascertain whether they simply overlapped one another and were merely connected by membrane, or 
whether their union was effected by a more definite articulation. In Plate IV. fig. 1, a segment is seen to send a strong process forward from its anterior and external angle, and a similar structure appears to have obtained in the specimen figured by Professor Agassiz, in the right-hand upper corner of his Plate A (loc. cit.) This process may have served to articulate the segment with its predecessor, or it may have given attachment to muscles.

The specimen figured in Plate V. fig. 2, would at first appear to indicate that the segment had a sub-circular or elliptical section, but it is so much crushed and distorted, that I am not inclined to lay any great stress upon the conclusions which may be drawn from it, the more especially as all the other specimens which give a view of the thickness of the body rather lead to the belief that it was considerably depressed, at any rate, posteriorly. The segment, probably penultimate, figured in Plate V. fig. 3, for example, exhibits no sign of having undergone any very considerable compression, and yet its thickness does not equal more than one-fourth of its breadth. It is quite possible, and indeed probable, however, that the proportions of the antero-posterior and transverse diameters may have been different in the anterior and posterior segments.

It is probable that the segments were sculptured on the ventral, as well as on the dorsal surface, in all cases, as that last referred to certainly is so. No segment has as yet exhibited any trace of an appendage or of an articular surface for one.

A specimen in the possession of Mr. Lightbody exhibits at least. eight segments connected together, but there is no evidence as to the total number composing the body of $P$. anglicus.

4. The Telson.- Reasoning from the analogy of P. acuminatus, \&c., the part figured in Plate V. fig. 6, must be the telson, or terminal segment of the body, of $P$. anglicus. It is particularly described in the systematic portion of this Monograph (p. 72). I will merely remark, therefore, that it is oval, truncated anteriorly, mucronate posteriorly, and serrated along the lateral edges. It presents traces of a median ridge, and appears to have been very flat.

5. The paired Appendages. - The remains of three distinct kinds of paired limbs, besides single appendages, have been discovered in the same beds with the carapace and body segments of $P$. anglicus. These are :-

(a.) The chelate organs figured in the most perfect state in which they have yet been discovered in Plate VI. figs. 4, 5. Three joints at least may be observed in this member. The first is an elongated subcylindrical stem, flattened by pressure. The next, 
short, enlarged, and swollen, is produced into a long slender process, pointed and incurved at its extremity, and beset with very strong and numerous, unequal, striated teeth. The third joint is articulated with the enlarged basal part of the second, so that its similarly incurved extremity is opposable, like a thumb, to the latter. It possesses teeth of a similar structure to those in the other ramus of the chela, and opposed to them as the canine teeth in the upper jaw of a mammal are opposed to those in the lower, passing, that is, behind the others, or on their proximal side.

(b.) The second kind of appendage (Plate VII. figs. 4, 5, 6, 7, presents a large flattened basal joint, produced at one extremity, and truncated obliquely to its long axis at the other. The truncated margin is slightly curved, and is beset with long and strong, curved and pointed teeth, which are longer at one end of the series than at the other; and are so constricted at their bases, as to appear to be articulated with the basal joint.

Of the two longest margins of the latter, the one has a general convexity, while the other is concave. The outer part of the former exhibits a sort of notch or step, in which is lodged the basal joint of a long palpiform appendage. This joint $(c)$ is very short and somewhat swollen.

The next articulation ( $d$ ), longer and subcylindrical, is broader distally than proximally. The third $e$ ), twice as long as the last, has a nearly equal breadth throughout. It is exhibited in situ, and in its whole length, by only one specimen (Plate VII. fig. 4), and here the distal extremity is rounded and slightly emarginate.

In the same specimen (and only in this) a fourth joint $(f)$ may be observed. It is as long as the third, but of a different form, the distal end being much wider than the rod-like proximal extremity. The internal edge of the distal extremity is rounded and slightly serrated, and is apparently the natural edge of the part; but there are appearances which lead one to suspect that the continuation of the outer angle has been broken away.

The characteristic sculpture is visible upon the surface of the basal joint of this appendage, more particularly towards the anterior edge of its inner region, and the convexities of the facets are here directed towards the convex long margin. The outer wall of its outer region in fig. 4 is broken away, and the matrix contained in the interior has become detached, so as to show the inner surface of the opposite wall, which is perfectly smooth.

In the recent state a considerable interval, doubtless filled by muscular and tendinous soft parts, must have existed between the 
two walls, as, even in the compressed fossil, the thickness of the matrix filling the cavity sometimes amounts to one-sixteenth of an inch. The third and fourth joints also had a considerable thickness.

(c.) Of the third kind of paired appendages the most complete specimens are those figured in Plate VI. fig. 1, and Plate VII. figs. 1, 2. It consists of an exceedingly large and expanded, quadrate, basal joint, produced at one angle into a broad curved process, which is obliquely truncated at its extremity. The truncated edge is nearly straight, and is serrated, broad notches separating a number of strong flattened pointed denticles, which are continuous with the substance of the joint, and not articulated with it.

The denticles or serrations form a single series, and diminish in size from one end of the series to the other. The smallest is succeeded by the rounded corner in which the truncated edge and the concave margin of the serrated process meet.

The surface of the joint, and of its process, is covered with the squamiform ornamentation, and presents in the middle of the margin, opposite to the serrated process, a deep notch, which receives the first joint of the long palpiform remainder of the appendage.

The form of these joints is particularly described below (p. 75). I will only remark here that there are six of them, and that the penultimate, much larger than any of the others, is elongated, broad, flattened, and widely emarginate at its distal extremity, where it articulates with an oval palette-like plate, with serrated edges. A brief comparison of the figures will satisfy the reader that this is the part represented by Professor Agassiz in the lower right-hand corner of Plate A (loc. cit.)

From the form of the articulating edges of the joints of the palpiform part of this appendage, I am inclined to think that, as in the chela of the lobster, the plane of motion of each joint formed a considerable angle with that of its predecessor and successor, the result of which would be a sort of feathering, or screw-propeller motion, of the ultimate and penultimate joints during flexion of the limb.

The Metastoma.-The last kind of appendage (Plate VI. fig. 7) I have to describe is perfectly symmetrical, and hence, even if there were no other means of determining its real nature, its single or azygos character might be divined.

It is an oval plate with margins much thinner than the centre, and presenting a median notch at one extremity. It is richly sculptured, the facets having their convexities turned towards the rounded entire end; and it is worthy of notice that the facets are 
singularly close set around the apex of the emargination. It is as if the plate had been once completely oval and evenly ornamented, and had then been folded in at the emargination.

The part represented in Plate VII. fig. 7, closely resembles the basal joint of the appendage described under the head $(b)$ in general aspect, but differs from it in the excavation of the more convex margin, in the length of the latter, and in the fact that the longest tooth arises considerably behind the junction of the curved with the truncated margin. If these appearances do not arise from mutilation or other alteration, this part is probably a fourth paired appendage.

The carapace of Pterygotus anglicus has not been found in connexion with the body, nor the epistoma with the carapace, nor any of the appendages with any other part of the body. A peculiar value consequently attaches to those entire specimens of a crustacean formerly denominated Himantopterus, but which the further information yielded by the extensive materials on which this Monograph is based, shows to be of doubtful generic distinctness from Pterygotus.

A well-preserved specimen of $P$. (Himantopterus) bilobus is represented in Plate I. fig. 1. It presents an elongated body, rounded anteriorly and posteriorly, and much narrower in its posterior, than in its two anterior, thirds. Assuming that the dorsal surface of the animal is exhibited, there lie, on its right side, the remains of two appendages, the anterior disposed so that its long axis crosses that of the body nearly at right angles, and passing by its inner extremity into the middle of the anterior margin of the head; the posterior, lying more nearly parallel with the axis, and traceable forwards, only so far as the posterior margin of the anterio segment or carapace.

The latter has a nearly semicircular outline, but is more produced than a true semicircle would be. On the right side the margin is interrupted by a much elongated oval depression, having its long axis directed forwards and inwards. This is the impression of the eye, and in some specimens it shows a sculpture very similar to that seen upon the eye of $P$. anglicus.

The carapace is succeeded by a number of segments, of which the best preserved specimens exhibit twelve. The anterior ones are transversly, the posterior longitudinally, elongated, and the hindermost, or telson, is oval and deeply emarginate posteriorly. In front of the head, in the specimen figured in Plate I. fig. 1, and apparently connected with its anterior boundary, lies a semicircular plate with [1.] 
its convex edge turned forwards (a). The plate is as broad as the head, but not quite half so long, and its longitudinal axis is oblique to that of the body. In the middle line, it presents a flattened area, bounded by a longitudinal ridge on each side, and rounded off in front. Although the structure of this part is somewhat obscure, I have little doubt that it corresponds with the epistoma of $P$. anglicus, and that it has been thrust out of place and thrown forward.

To the right-hand side of the carapace, opposite the anterior half of the eye, two curved, serrated, linear impressions, convex inwards, appear (fig. 1a). The anterior and inner of these is not more than half the length of the posterior and outer, and cuts the latter about its middle. I find no corresponding impressions upon the left side. When the impressions are viewed very carefully with a magnifying glass, in a good light, they present minute but important differences The serrations of the short impression are concave and striated, and constricted at their bases. Those of the long impression, on the other hand, are flattened and not constricted, and their series is terminated, posteriorly, by a rounded lobe which forms the posterior angle of a broad process whose boundaries become lost externally. Sufficient, however, remains to show the correspondence between this part and the serrated process of the appendage (c) of $P$. anglicus, while the teeth of the inner and shorter line are strikingly similar to those which beset the edge of the basal joint of the appendage (b) in that species.

That the impressions in question are in fact the remains of appendages similar to $(b)$ and $(c)$ becomes a matter of certainty when we examine such specimens as those figured on Plate I. figs. $3,4,8,9$.

In fig. 8. is represented an organ, certainly belonging to $P$. bilobus, whose basal articulation has as nearly as possible the same form as that of the appendage $(c)$, and presents, along its free edge, the same continuous serration and posterior rounded lobe. The like resemblance is traceable in the joints of the palp-like appendage, except that in this specimen a structure was observable, not visible in any other, whether of the same or of different species. This is a long taper filament, nearly as long as the ultimate and penultimate joints, lying on their surface, and apparently attached by its thicker end to the distal extremity of the antepenultimate articulation. . There are indications that this filament was itself jointed. In figs. 3, 4, 9, the whole appendage, or at any rate its basal joint, is seen in situ, and on comparing the serrated edge of any of these with the outer 
linear impression first described, the source of the latter will be obvious.

The base of this great limb is attached to the hinder part of the carapace; it therefore, without doubt, lay behind the mouth, and as it is the outermost pair of buccal appendages, it will be useful to call it the "ectognath," a term more convenient than "maxilla," " maxillipede," or "swimming-foot," as it involves neither a morphological nor a physiological hypothesis.

The organ which caused the shorter linear impression, lying internal to and in front of, that of the cutting edge of the ectognath is, I doubt not, similar to that which lies detached in two specimens, and is figured in the woodcut, p. 40. It is unfortunately impossible in either of these examples to trace, as distinctly as might be wished, the precise form of this appendage, but enough is visible to satisfy me that this species was provided with one, if not two, organs on each side similar in general structure to the appendage $(b)$ of $P$. anglicus, and quite competent to produce the impression in question.

From its general character I entertain very little doubt that the appendage $(b)$ is the homologue of the mandible of other Crustacea, but as there is some reason to suspect the existence of a third buccal appendage, and as it is impossible as yet, supposing this third jaw to exist, to say whether any given appendage similar to $b$. was first or second in order, it will be better to term an oral limb in front of the ectognath, an "endognath." The specific name of " mandible" must be assigned to whichever of these endognaths further research proves to be anterior.

The position and general nature of two of the three pairs of appendages of Pterygotus having thus been determined, the third presents no difficulty. In the specimens of $P$. bilobus, represented in Plate I. figs. 1, 3, indeed, the pair of long anterior appendages are so much distorted and damaged that their structure cannot be satisfactorily made out. There is abundant evidence, however, to show that they were similar to the detached chelæ figured in Plate I. fig. 6, and these are obviously identical with the pincer-like appendage $(a)$ of $P$. anglicus.

The epistoma has already been recognized in the plate lying in front of the head, in Plate I. fig. 1; it remains only to discover the representative of the metastoma, and the position which it occupied in the organism. The form and sculpture of the part represented in Plate I. figs. 10,10a, testify that it answers to the organ sought, and a careful examination of most well preserved carapaces of 
$P$. bilobue, shows a corresponding plate, or its impression, in situ. When undisturbed, in fact, the metastoma occupies the middle of the under surface of the carapace, the cutting edges of the basal joints of the gnathites overlapping, or being overlapped by, its lateral margins, and its emarginated extremity being turned towards the anterior end of the head, which it nearly reaches. The posterior rounded margin is in contact with the posterior boundary of the carapace.

A part, having this form and occupying this position, might be regarded as a labrum or as a metastoma. My reasons for giving it the latter appellation are the following:-It may be regarded as pretty certain that in Pterygotus, as in other Crustacea, a sculptured surface was free and uncovered by other parts, in which case the plate could not have been attached to the inner surface of the epistoma by its sculptured anterior and outer surface; nor, for the same reason, could it have been attached by its inner surface to the sculptured outer surface of the epistoma. The anterior margin of the plate reaches so far forwards that it could not have been attached by that margin to the posterior margin of the epistoma; and, furthermore, when the latter is detached or thrown out of place the metastoma is never found connected with it, but, as in fig. 1, Plate I., remains in its own proper position.

I have little doubt, therefore, that this plate was attached by its posterior extremity to the under surface of the hinder half of the carapace; that it lay behind the mouth, and had all the relations of a metastoma, and it will be seen by-and-bye that certain existing Copepoda possess a metastoma very like it, except in its very great proportional size.

Putting together the different facts furnished by the remains of the two species of Pterygotus, which have been described, it results,-

1. That the body in this genus was composed of a number or segments, which might be thirteen in number.

2. That these segments exhibit a peculiar ornamentation.

3. That the terminal segment, or telson, is liable to considerable specific variation.

4. That the anterior segment is larger than the rest, and forms a carapace, on whose antero-lateral margin two large oval convex eyes are seated.*

* Notwithstanding the peculiar character of the markings upon the corneal surfaces of these eyes, I wait for better evidence than I have hitherto met with, before deciding that they were really compound, and that these markings indicate corneal facets. 
5 . That, attached to the under surface of the carapace, there are eight (or ten) distinct organs, two single and median, and three or four pairs.

6. The former are, in front, the great epistoma; behind, the metastoma ; between these lay the oral aperture.

7. The latter are, anteriorly, the chelate organs (antennæ); posteriorly, the ectognaths, immediately in front of which lay one or two pairs of endognaths.

8. That there is no good evidence of the existence of any other appendages.

Almost all the remains certainly assignable to Pterygotus, which have passed through my hands, are easily referable to one or other of the classes of organs mentioned above, and exhibit no anatomical peculiarities worthy of comment, but a few specimens present difficulties to whose discussion I will now proceed.

1. Pterygotus punctatus.-The only representative of the endognaths of this species which I have examined (Plate XI. fig. 5) exhibits a structure somewhat different from that of the perfect endognath of $P$. bilobus and anglicus. The anterior and internal angle is rounded off ; the series of teeth commencing behind, and not at the anterior extremity of, the inner edge. The straight inner portion of the anterior margin is spinose, and forms a considerable angle with the outer portion, which bears the palp. The latter is four-jointed, the proximal articulation being large, quadrate and setose along its anterior margin, and provided with a large and strong curved spine towards the outer extremity of that margin. The next joint is elongated and curved, its posterior margin being slightly convex, the anterior similarly concave, and towards the distal extremity bearing a curved spine, like that in the preceding joint.

The third joint and the fourth are much shorter. The former carries a spine on its anterior edge. The latter has two spines, one anterior and one terminal. Is this the homologue of that endognath of Pterygotus anglicus represented in Plate VII. fig. 4, or does it, as the structure of its basal joint would seem to indicate correspond with the apparently different part shown in fig. 7 ?

2. Pterygotus acuminatus.-On the same slab with a large portion of the body and one of the ectognaths of this species, is seen the remains of an appendage whose basal joint clearly resembles the corresponding part in $P$. anglicus (Plate XIII. figs. 2, 3.) It consists of a broad, flattened, quadrate plate, having a series of curved and striated teeth articulated with its well-defined, nearly straight, 
edge. These teeth, however, do not form one even series, either as regards their size or their position. They commence large, near to what I will term the anterior margin of the plate, but not close to it, the antero-lateral angle being rounded off and giving rise to no tooth. In this respect it represents the corresponding part of the endognath of $P$. punctatus just described. After four or five large ones, the teeth rapidly diminish in size and become indistinguishable. The free edge of the plate then makes a slight curve, so that it projects beyond its former line and then gives rise to two teeth of the same size as the most anterior ones, after which it becomes lost beneath the matrix. A depression runs from the commencement of this projecting edge into the crushed and transversely folded, middle part of the plate. In front of this crushed portion, the anterior region of the plate is, in its outer half, richly sculptured; behind and internally, the substance of the organ is for the most part broken away, but shows the remains of a similar sculpture outside the broken edge. The opposite half of the specimen exhibits the impression of the sculpture over this broken part, but in neither half can the ornamentation be satisfactorily traced continuously over the middle crushed region.

The outer part of the joint, just described, is continued into a broad mass, so divided into two portions externally, as to appear like two palps. Each palp-like division appears to possess at least three joints, and the distal margins of the outer of these joints in the anterior "palp" are produced into strong curved processes or setæ.

The part represented in Plate XIII. fig. 4, apparently consists of these palpiform appendages detached from their basal joint. Four or five gradually tapering joints are here distinguishable, and each is produced into setæ along it distal edges, while the terminal articulation resembles a curved claw.

The same kind of basal plate, apparently provided with similar appendages, is shown in another specimen (Plate XIII. fig. 3), but the parts are here overlapped by the broken ectognath, and are so crushed and confused that I can arrive at no satisfactory conclusion regarding them.

A valuable example of $P$. acuminatus from Lesmahago (Plate XV. fig. 1), although greatly crushed, and at first sight very unpromising, yields a great deal of valuable information on patient investigation, and shows, among other things, that the organs under discussion belong to the mouth and to the endognathary series. In fact, in both halves of this specimen, the ectognath and the metastoma are very clearly traceable, and are evidently almost undis- 
turbed. The palps of the ectognaths are displayed in situ on each side ; the cutting edges of these appendages are seen on each side of the middle line and are turned towards one another, while the large metastoma lies between them, overlapping their respective inner margins. Internally to their serrated edges, a series of articulated teeth $\left(c^{\prime}\right)$, like those connected with the free edge of the basal joint of the organ described above, can be seen upon each side, but the rest of the basal joint cannot be made out.

On the left-hand side of the head, bowever, the remains of two palpiform bodies (c), evidently of the same nature as those described. above, and provided with similar strong curved setæ, are visible. On the right side is an impression of a similar character, but its minutiæ cannot be satisfactorily deciphered.

The facts I have detailed may be variously interpreted. Either the two palps belong to one basal joint, or there are two basal joints, each with a palp. In the former case there would be one endognath on each side, with a double palp; in the latter, two endognaths, each with a single palp. As the evidence stands at present, I see no means of arriving at a well-grounded opinion on this subject, and I prefer to abstain from conjecture.

3. Pterygotus perornatus. - The opposite impressions of part of an example of this species are exhibited by two slabs, each of which shows more or less distinctly the carapace and one of the body segments.

On the larger slab (Plate XV. fig. 2), the impression of the metastoma is distinguishable within the outline of the carapace, but it is thrown out of place, so that its long axis is directed obliquely forwards and to the right side, at an angle of forty-five degrees to that of the body. Close to the anterior extremity of the metastoma, but projecting beyond the boundary of the carapace, lies the basal joint (c) of an appendage with articulated, curved, pointed and striated, teeth, like those of the endognaths of the preceding species.

The dentated edge of this organ lies almost parallel with the longaxis of the metastoma; but beyond it, and more towards the middle line of the body, there is another curved edge $\left(c^{\prime}\right)$, similarly provided with striated and articulated teeth, but cutting the first at a large angle. Is this part of a second endognath of the same side, or is it that of the other side turned round? In any case the parts are thrown far out of their natural position.

On the left-hand side, between the base of the metastoma and the middle of the lateral margin of the carapace, the imperfect impression 
of part of the toothed edge of another appendage $\left(c^{\prime \prime}\right)$ is discernible. It is turned backwards (so that it is certainly displaced), and the teeth are somewhat curved and striated. If there are two endognaths on each side, this might well be one of the left pair turned round.

On the left-hand side, the palp (e) of the ectognath is in position, but nothing is to be seen of its basal joint. On the right-hand side, the large basal joint of an ectognath lies detached and turned round, so as to have its cutting edge directed backwards. A confused mass occupies the place of its palp.

Where the antennæ should be there is, on the left side, a long and broad dark impression (b) fading away externally. On the right side there is a somewhat similar marking which continues the line of that on the left hand, but is very broken and irregular. However, it divides distally into two branches, on the opposed edges of which the remains of the characteristic antennary teeth can readily be discovered $\left(b^{\prime}\right)$.

Whether these impressions represent one antenna, or portions of both, I cannot say, but between them, and in front of them, a dark sculptured area $(f)$ presents itself, which is cut off anteriorly by the fractured edge of the stone. On the right side, this area is bounded by a well-defined margin, which runs between the posterior boundary of the antenna, and the inner of the two endognaths. On the left side, its well-marked curved boundary is distinguishable between the antenna and the broken edge of the stone.

Towards the junction of the middle and anterior thirds of the left lateral edge, a long, flattened, filiform appendage $(c)$ comes off from the carapace. On the right side, the remains of two such appendages, with, perhaps, traces of a third, are visible $(x)$. They come off close to the two endognaths, and one might be inclined to suppose them all organically connected with the latter, were it not for the independent appendage on the opposite side.

In the other, smaller, half of the specimen the only points to be noted are, the greater distinctness of the right boundary of the "sculptured area" in front of the carapace, and of the right (here left) filiform appendages. I am strongly inclined to think that the "sculptured area" in this fossil is the epistoma. The interpretation of the filiform impressions is more difficult. That on the left side seems to be attached directly to the carapace, and in that case might be a secona antenna. If this be its nature, the impressions on the other side may be the corresponding appendage and the palps of the endognaths. On the other hand, it must be remembered that there. 
is no independent evidence of the existence of a second antenna in the genus, and that the position of the filiform appendage on the left side may be purely accidental.

4. The two singular fossils figured in Plates XII. fig. 16, and Plate XIII. fig. 16, are the only remains, which, from their sculpture, may be, with every probability, referred to Pterygotus, but which are not as yet referable to their proper place in the organization.

These parts present, at first sight, a striking resemblance to the terminal palette of an ectognath, with a portion of the penultimate articulation. They are described at length in the systematic portion of this Monograph (p. 97); and I will, therefore, only remark in this place that, as the ectognaths of $P$. problematicus and arcuatus (the species to which these remains probably belong) have not yet been observed, it is possible that they may be their distal joints. Pending sufficient proof that such is the case, however, it must be borne in mind that they differ in several important respects from any ultimate and penultimate joints of an ectognath at present known. The only alternative which suggests itself is that these parts may have been thoracic or abdominal appendages.

5. The fossil figured in Plate XIII. fig. 17, is evidently crustacean, but it exhibits no character by which it can be identified as a part of a Pterygotus. It is a broad quadrate plate, abruptly truncated on two of its opposite sides, one of which is much longer than the other, and having the other two margins equal and rounded. Two folds or ridges run from one truncated edge to the other, and divide the plate into three lobes, a median and two lateral. The median lobe presents a series of curved lines or ridges disposed symmetrically on either side of the median line. Similar folds in the one lateral lobe are more or less symmetrically arranged with regard to those on the other lobe.

The shorter truncated margin of the plate presents two impressions, like the remains of articular surfaces, and there are similar impressions at the outer extremities of this margin. Of these, that on one side gives attachment to a long jointed appendage presenting six distinct articulations. The basal joint is short and much wider than the others. The distal edge of the fourth presents a series of strong spines, the sixth has the form of a curved claw.

I know of only two crustacean structures with which this body can be compared, the one is a carapace, the other the swimming limb of a copepod with its coalesced, lamellar, basal joints greatly developed (compare, Plate XVI. fig. 7). 
Systematic Position of Pterygotus.-In comparing Pterygotus with other crustaceans, for the purpose of determining its systematic position and relations, several of the largest and best defined orders of the Crustacea may at once be left out of consideration. Pterygotus is clearly not one of the Trilobita, Cirripedia, Ostracoda, Edriophthalmia, or Stomapoda (if we restrict this order to these Crustacea which have pedunculate eyes, and distinct and moveable ophthalmic and antennulary somites). Nor are there any known Branchiopoda to which these great extinct crustaceans have relations of affinity, so that if they are to be referred to any existing order, it must be either that of the Podophthalmia, that of the Copepoda, or that of the Pacilopoda.

The first step towards determining the systematic place of Pterygotus, therefore, is to consider the reasons for and against the assignment of a position in either of these orders to them.

To those who are acquainted only with the ordinary Podophthalmia, the discussion of the affinities of Pterygotus, with forms in every way so distinct, may seem superfluous ; and there is assuredly little enough in common between a crab or a shrimp and their palæozoic congeners ; but there are one or two sections of the Podophthalmia which, while they still hold fast by the typical characteristics of their order, become so modified in many important particulars, as to require careful consideration in relation to the forms at present under consideration. These are the Diastylidac or cumoid Crustacea.

The typical genera of this group were first described by Mr. H. Goodsir, and they have since been the subjects of excellent essays by Kröyer and Spence Bate.

Cuma Rathkii (Plate XVI. figs. 17, 18) may be selected for description as a good representative of the family. The animal presents anteriorly a short and broad carapace, having its outer and lateral edges rounded and sloping into a bifid, median, anterior, rostrum-like prolongation. The longitudinal fissure of this process divides posteriorly on the carapace, so as to embrace the anterior part of a more convex median lobe, which represents the tergal region of the head. The bifid median prolongation is not, as it appears to be, a frontal rostrum, but it is formed by two lateral processes of the carapace, which come forward and are applied to one another in front of the head.

The carapace is succeeded by five broad thoracic somites, and these by six, narrower and longer, abdominal somites and a telson. The sixth abdominal somite has styliform appendages, but in the 
female there are no other abdominal limbs, and in the male such as exist are few and rudimentary.

Of the appendages, the eye is median, sessile, and not easily made out in spirit specimens; there are a pair of antennules, a pair of antennæ and of mandibles, two pairs of maxillæ, and eight pairs of thoracic appendages; there is a a small labrum and a bifid metastoma; but these parts have too little resemblance to any of the organs of Pterygotus to need description in this place.

The most interesting feature about this crustacean in reference to the present inquiry, however, is the ornamentation with which the body and many of the appendages are covered. The surface of the integument appears in many parts irregularly reticulated, but elsewhere the reticulations assumes the form of a regular squamous sculpture, singularly like that upon Pterygotus, but on a very much smaller scale.

The general form of the body and the paucity of abdominal members, combined with the peculiar sculpture exhibited by the Diastylida, attracted my attention strongly when, on a former occasion,* I endeavoured to trace the affinities of Pterygotus. Following the line of inquiry thus suggested, I pointed out that in many Schizopoda and Stomapoda, such as Mysis, Phyllosoma, and Erichthys, either the abdominal or some of the posterior thoracic members, or both, became abortive, and that in the larval condition of some Podophthalmia, even the sixth pair of abdominal appendages remains undeveloped, and the abdomen is wholly devoid of limbs. In the larval Brachyura or Zoeoe all the appendages but the gnathites and antennæ are rudimentary, and the long palpiform maxillipedes are (in addition to the abdomen) the only organs of propulsion. The larval lobster (before hatching) is similarly deprived of abdominal appendages, it possesses a disproportionately large labrum, and a metastoma, which is only slightly emarginate anteriorly, and very large in proportion to the other buccal organs, as compared with its adult state.

In the paper referred to, I laid considerable stress upon the analogies, which, from what has been said, may be readily enough apprehended, between Pterygotus and the Diastylidce and larval Podophthalmia. Renewed examination of the specimens and of the far more extensive materials which have since presented themselves, aided by a careful investigation of the characters of the recent Copepoda has shown me, however, that at least as strong a

* Quarterly Journal of Geological Science, vol. xii. 1855. 
case might be made out for the relegation of the Pterygoti to the latter order. (See p. 36, note.)

The evidence which has led me to this conclusion can only be appreciated when the structure of the Copepoda is fully understood. I will, therefore, proceed to give a brief account of that structure, and I am the more willingly led to do this as I have found it difficult, notwithstanding the valuable labours of Milne Edwards, Baird, Dana, and others, to arrive at a clear and connected view of the anatomical characters of this difficult group.

The genus Calanus, containing a large number of marine species, is perhaps best fitted to furnish a typical illustration of copepod anatomy. The species represented in Plate XVI. fig. 1, was taken in the North Atlantic. It is about one-eighth of an inch long, and (after preservation in spirit) has a lightish brown colour. The body presents a large carapace anteriorly, succeeded by a number of thoracic and abdominal segments. The cephalo-thorax has the form of a long oval, truncated and slightly excavated behind, the posterclateral angles of its last segment being but very slightly produced. The abdomen has not a third the length of the head and thorax, and is terminated by two elongated lobes provided at their extremities with long setæ. The antennules are as long as the body. The cephalo-thorax consists of six segments, the anterior of which is about equal to the three following ones in length, and forms a carapace. The abdomen presents four obvious segments, but the first appears to consist of two somites united together, and it is probable that the two terminal styliform lobes may represent a somite, in which case there would be six somites in the abdomen. The anus opens between the bases of the terminal processes.

The carapace is not prolonged, either along its posterior margin or laterally, but merely overlaps the tergum of the succeeding somite in the ordinary manner. Anteriorly, it extends beyond the bases of the antennules, and is produced forwards and downwards, between them, into two delicate pointed processes, slightly constricted at their bases, which are about equal in length to the two basal joints of the antennules. The latter are slender, of even thickness, and divided into twenty-four setose joints.

An endophragm, or inflexion of the chitinous integument, distinctly separates the sternum of the antennulary, from that of the antennary, somite. Viewed laterally, the former appears concave, its posterior portion sloping backwards and downwards at an angle with the anterior. The anterior half of the antennary sternum, on 
the other hand, is very convex, while its posterior half is produced into an abrupt conical protuberance, behind which it passes into a broad plate, with a free, convex, posterior edge. This projecting mass developed from the antennary sternum appears to me to represent both the epistoma and the labrum of decapod Crustacea.

Viewed from below (Plate XVI. fig. 2) the part described has the aspect of a very broad, almost triangular plate, occupying nearly the whole width of the antennary sternum, and presenting a prominent median portion and two lateral alæ, which slope away backwards and upwards. The posterior portion of the median lobe is rounded and somewhat expanded at its extremity, and the lateral edges of the expanded end are provided with fine setæ, which extend over its superior face for a short distance. This conjoined epistoma and labrum forms the anterior boundary of the oral vestibule; its inner face is beset with short setæ, and a short median tooth, rounded at its extremity, projects backwards in the middle line.

Posteriorly, the oral vestibule is bounded by a quadrate plate, the metastoma, directed forwards and downwards, and having about two-thirds of the width of the labrum. As the sterna of the two somites which immediately succeed the mouth, viz., the mandibular and the first maxillary, are not distinctly separated from one another; it is difficult to say from which this plate arises. I am inclined to think, however, that it is really a production of the maxillary sternum, as its posterior boundary lies behind the level of the anterior margin of the base of the maxillæ. The free anterior extremity of the plate is deeply divided, by a wide median excavation, into two lobes, which are provided with many short and fine setæ. A little, accessory, setose, lobule is also developed from the inner surface of the plate on each side.

A well-developed endophragm separates the sternum of the first maxillary, or second post-oral, somite from that of the rest. From the mouth to the posterior edge of this, the third post-oral somite, the sternal surface slopes gradually downwards; but beyond this point, or in the fourth post-oral somite, the sternum makes an abrupt projection downwards and then passes backwards, with a general parallelism to the axis of the body, for the rest of the extent of the cephalo-thorax.

The antennæ are about as long as the proximal nine or ten joints of the antennules. They consist of a short basal portion supporting two branches of about the same length. The basal portion is threejointed, the inner branch two-jointed, the outer-multiarticulate. 
Neither antennules nor antennæ are chelate or sub-chelate in either sex.

The mandible (fig. 3 ) consists of a basal joint and a palpiform appendage. The outer half of the former is quadrate, convex inferiorly, and presents, posteriorly and externally, a curved articular process; the middle of the basal joint is a little constricted and flattened, while its internal portion widens again, and ends in a truncated, toothed edge. The teeth are continuous with the blade of the mandible, not articulated with it. The palp springs from an excavated surface on the anterior and superior face of the quadrate outer division. Its proximal joint is short and rounded. The next is the longest, and as broad as or broader than the basal joint, and wider distally than proximally. At the distal end it supports two branches, the outer of which is obscurely five-jointed; the inner two-jointed. The toothed and cutting extremities of the basal joints of the mandibles pass between the labrum and the metastoma, and bite against one another in the middle line. Those of the maxillæ lie behind the metastoma. The first maxilla (fig. 4) is nearly of the same size as the mandible. Its basal joint is produced internally into a large curved process, whose inner edge is beset with strong articulated setæ, which might almost be called elongated teeth, were they not setose along their edges. Succeeding this articulation is a broad joint produced internally into a narrow, transversely elongated, flattened process, terminated by elongated setigerous setæ externally, into a broad flat plate bearing eight or ten extremely long and strong setigerous setæ; five other obscurely marked joints follow these two.

The next appendage (fig. 5) is not quite so long as that just described; it is obscurely divided into seven joints and tapers to its extremity, which, like its inner edge, is provided with very long and strong setæ. The inner setæ are by far the stronger, and are directed forwards so as nearly to reach the mouth.

The fourth post-oral appendage (fig. 6) is more than twice as long as the third. It consists of a short and strong, subcylindrical, basal joint, beset along its inner margin with a row of very long setigerous setæ, and having a rounded projecting inner distal angle. One long and five short gradually diminishing articulations follow this.

To this appendage succeed the five pairs of swimming feet (fig. 7), of which the first and the last are smaller than the intermediate ones. Each natatory limb consists of a stem (protopodite) and two 
branches (endopodite and exopodite). In the former a long proximal and a short distal joint are distinguishable. The proximal joint is united, for a considerable part of its length, to its fellow on the opposite side by a flattened plate, continuous above with the sternum, and thickened by a spatulate ridge in the middle line.

The distal joint has the inner half of its terminal margin more produced than the outer. The former bears a shorter (endopodite), and the latter a longer, three-jointed branch (exopodite). The terminal articulation is the largest, and is provided with long and strong setæ.

The inner edges of the basal joint of the protopodite of the fifth pairs of these feet are beset from their distal extremities to the uniting plate with a series of short, but strong and pointed teeth.

On considering the structure of Calanus with reference to the general plan of the Crustacea, I may observe, in the first place, that of the twenty typical somites, only eighteen, at most, appear to be represented. We may reckon one, for the eyes ; two, for the antennules and antennæ; four, for the four pairs of post-oral appendages ; and five, for the swimming feet, making, in all, eleven, provided with moveable appendages. Then, if the first segment of the abdomen be really formed, as there is much reason to believe it is, by the coalescence of two somites, and if the two caudal styles really represent another, we shall have six somites in the abdomen, making up the sum total to eighteen.

This number cannot by any means be made out in all Copepoda, but I know of no members of the order which exceed it. Different opinions have been entertained with respect to the grouping of these somites into cephalic, thoracic, and abdominal. The eyes, antennulæ, antennæ, and the two anterior pairs of postoral limbs, and with them their somites, are indeed universally admitted to belong to the head; but the two following appendages are considered by some to be maxillæ, by others to be maxillæ and maxillipedes; by yet others to be maxillipedes and anterior thoracic limbs.

The simplest and most natural view appears to me to be, to regard the third pair of post-oral appendages as the homologues of the second maxillæ or last cephalic appendages, while the fourth post-oral appendages are thoracic members. In this case there will be six pairs of thoracic appendages, as in the Cirripedia. If we inquire what has become of the two thoracic somits which are unrepresented by appendages, three probabilities present themselves:1. They have remained undeveloped at the anterior end of the 
thorax; or, 2, they have remained undeveloped at the posterior end of the thorax; or, 3 , the two somites which are so closely united together as to appear as one segment, commonly regarded as the first of the abdomen, belong in reality to the thorax. This view might be supported by the position of the reproductive apertures which open behind the second of these somites, that is, on this hypothesis, in that position immediately behind or at the posterior part of the thorax, which is so common to them in Edriophthalmia, Pcecilopoda, and male Podophthalmia. If this view be correct, (but I would expressly state that it is put forth only tentatively,) it is the abdomen alone, which is shorn of its due proportions in Copepoda.

Such is the structure of a typical copepod. The modifications observable in the order, of importance for my present purpose, affect,-1stly, the form of the body ; 2ndly, the character of the eyes; $3 \mathrm{rdly}$, the form of the antennules and antennæ; 4thly, that of the labrum and metastoma; 5thly, the number of the thoracic appendages.

1. The body usually has a general resemblance in outline to that of Calanus, the abdominal somites commonly presenting a marked and immediate diminution in transverse diameter when compared with those of the cephalo-thorax. In the beautiful Sapphirince (Plate XVI. fig. 19), however, the passage from the cephalothoracic to the abdominal somites is quite slow and gradual.

2. In most Copepoda the eyes are so closely united as to appear single, and the region of the carapace which overlies them is not so modified as to deserve the name of a distinct cornea. But in the genus Sapphirina (Plate XVI. fig. 19), there are two small single cornex approximated together in the middle of the dorsal surface of the carapace; and a still more interesting modification of the visual organs is presented by Corycoeus (Plate XVI. figs. 8, 9). Here two great, oval, spectacle-like, corneæ are situated, one on each half of the anterior rounded margin of the carapace.

3 . The antennules and antennæ vary very much in form. In many Copepoda they are so constructed as to subserve prehension, either for sexual or other objects. The antennules are thus specially modified in the males of Pontella and Cyclops, while in Corycous these organs remain simple; but the antennæ (III.') are, in both sexes, converted into formidable weapons. It will be observed, however, that prehension is effected by the folding of the ultimate upon the penultimate joint, not by the biting of the apex of the ultimate joint against the prolonged distal angle of the penul- 
timate. It is a subchela such as is found in Amphipoda and Stomapoda, not a chela like that of Podophthalmia and Pacilopoda.

4. The plate, which corresponds with the conjoined epistoma and labrum of decapod Crustacea, is very large in all the Copepoda I have examined. Its form and proportions in Calanus, Corycous, and Pontella are shown in (Plate XVI. figs. 2, 9, 11). In the last-named genus it exhibits, as Milne Edwards has pointed out in his great work on the Crustacea, the remarkable peculiarity of being divided into three lobes, of which the middle is the smallest, and constitutes a kind of tongue-like projection (fig. 11).

5. The metastoma of Calanus, as has been stated above, is excavated anteriorly by so deep and wide an emargination, that it almost appears to consist of distinct lobes. In Pontella, on the other hand, the metastoma is a large flattened plate, whose terminal emargination, though wide, is not deep (fig. 11).

6. In Calanus, nine pairs of post-oral appendages have been found, the greatest number possessed by any masticating copepod. In Corycoeus and Cyclops this number is reduced to eight, and of these the last is occasionally so much atrophied as to be hardly distinguishable. We have thus evidence of a certain tendency towards a diminution of the number of thoracic appendages in this order.

The study of the development of the Copepoda shows that this is no more than might be expected, when we take into consideration how common a thing it is, for some form of a group to retain more or fewer of the characters usually found only in the young of that group; and perhaps the only subject for astonishment is that adult Copepoda, with still fewer limbs, have not yet been discovered. A Copepod just hatched is, in fact, a very different creature from the adult, as has been known since the observations of Jurine upon Cyclops.

Rathke, who has devoted particular attention to the development of the embryo in this genus, maintains that of the three pairs of locomotive appendages, with which alone, the young is endowed when it leaves the egg, the two anterior eventually become the anternules and antennæ, while the posterior are neither the mandibles nor the first pair of maxillæ, but the rudiment of the "mains" of Jurine. The young Cyclops is in addition provided with a large epistomo-labral plate. Its further changes consist chiefly in the elongation of the body, and the gradual and successive acquisition of the thoracic members. 
The resemblances of Pterygotus to the Diastylidoe do not extend to the most important and characteristic features of its organization, and even were we to combine together into one form, all the analogous peculiarities which have been noted in these, in Stomapoda, in Schizopoda, and iu larval Podophthalmia, we should not get a sufficiently near approximation to Pterygotus to justify the arrangement of the extinct genus in either of the orders of the higher Crustacea. As I hinted above, however, a stronger case might be made out for the Copepoda. Combine the body of Sapphirina with the eyes and antennæ of Corycoeus, the mandibles and maxillæ of Calanus, the epistoma and metastoma of Pontella, and the total number of appendages of a copepod larva, and something marvellously like a Pterygotus would be produced. But such an animal would not be a Pterygotus, and even if it were, it would differ so widely from any of the known Copepoda, that its association with the mernbers of that order would be a step of very questionable propriety. Confining the argument to known and existing Copepoda, the differences between them and Pterygotus are sufficiently striking.

No Copepod has truly chelate antennæ or antennules, and none present any approximation to the remarkable teeth with which the chelæ of Pterygotus are beset. All known Copepods have large thoracic appendages; no trace of such organs has yet been discovered in Pterygotus.

No Copepod, so far as I know, presents so great a number as twelve free segments behind the carapace.

No Copepod has its appendages reduced to so few as three or four pairs, nor, in any, is one pair of the post-oral cephalic appendages converted into the chief organ of locomotion.

The Pccilopoda (Plate XVI. fig. 13) are I believe the only Crustacea which possess antennary organs like those of Pterygotus, and like them, have the gnathites converted into locomotive organs, want the appendages to the sixth abdominal somite, and present on some parts of the body a remotely similar sculpture. In this order, however, we find but a small labrum,-a rudimentary metastoma,-a very differently constructed body, and a large number of appendages, both thoracic and abdominal, characters which effectually preclude the association of the extinct Crustacea under discussion with this type.*

* If the abdominal somites of the Carboniferous Bellinurus, \&c. were really free, they would present a certain approximation to the Pterygoti. Indeed, the evidence that these Carboniferous Crustacea were true Pccilopoda is, to my mind, anything but conclusive. 
The palp of the inandible of Nebalia (Plate XVI. fig. 10) is, in its :proportional size and form, not unlike that of Pterygotus anglicus, but this is the sole resemblance of importance which I can detect between the Branchiopoda and the Pterygoti.

While the relations of the Pterygoti with the great majority of other $C$ rustacea, are such as, in my mind, fully to justify their ordinal separation, there is one small and extinct group; having a similar geological range, with which they are undoubtedly closely connected. This is the genus Eurypterus of Harlan, of which many species have now been brought to light. Putting together the descriptions of Harlan, Eichwald, Roemer,* and others, with the results of a personal inspection of some species recently described by Mr. Salter, I can only arrive at the conclusion that, in its general form and structure, Eurypterus very closely resembled Pterygotus, differing from it however as Sapphirina differs from Corycoeus, viz., in having the eyes submedian instead of marginal. The ectognaths of Eurypterus appear to have been constructed upon precisely the same plan as those of Pterygotus, and its thoracic and abdominal members would seem to have been equally undeveloped. $\dagger$ Eichwald describes twelve segments behind the carapace (though only eleven are represented in his figure). Two pairs of slender jointed appendages are figured both by him $\ddagger$ and by Harlan in front of the ectognaths; but no chelate antennæ are represented, and the connexions of the jointed appendages are not made out. The characteristic sculpture is well exhibited by Eurypterus. Even if the chelate antennæ are really absent in Eurypterus, it must be remembered that these are organs particularly liable to variation among even closely allied genera of Copepoda.

Leaving the determination of the precise differences between the Pterygotus and Eurypterus to future investigators, their resemblances to one another, and their common differences from all other

* Ferd. Roemer. Ueber ein bisher nicht beschriebenes Exemplar von Eurypterus aus. Devonischen schichten des Staates New York in Nord-Amerika.-Dunker und Von Meyer's Paleontographica, b. 1, 1851, p. 190.

† Eichwald's representation of the under surface of the head is terribly diagrammatic. If it be a correct representation of an actual object, it affords evidence of only three pairs of appendages. His "two large, almost semilunar, lateral parts" appear to me to be the basal joints of the ectognaths, while the middle ovate "under lip" has just the position and general form of the metastoma. Add to these the triangular "npper lip," and the resemblance to Pterygotus becomes not a little striking.

$\ddagger$ Roemer states that his Eurypterus also had twelve free segments behind the carapace. The eyes borne by the latter were uniform and not facetted; only two appendages, both on the left side, remained. The posterior had the general structure of the ectognathary limb of Pterygotus. The anterior is slender, four-jointed, and perhaps terminated in a chela. 
Crustacea, are sufficiently important to justify their association into a distinct order-the "Eurypterida," which may be thus defined : Crustacea with numerous free thoracico-abdominal segments, the penultimate, and probably all the rest of which, are devoid of appendages; with the anterior somites united into a carapace, bearing a pair of large marginal or subcentral eyes; with a very large epistoma and metastoma; with three, or four pair of moveable cephalic appendages, the posterior of which form great swimming feet, and with the integument characteristically sculptured.

Of the mode of life of these extinct Crustacea we know nothing, but we may conjecture that it was their habit sometimes to creep along the bottom of the waters which they inhabited, like the $L$ imulus of the present day, sometimes to propel themselves by the rapid flexion of their great swimming feet, aided perhaps by the sudden extension of their free segments.

No existing or extinct crustacean has so massive a body as Pterygotus, some species of which there is every reason to believe attained a length of at least five feet; but mass, in an active animal, involves large muscles, and these require solid points d'appui. Hence we may conclude that the integument of the Pterygotus, thin and fragile as are its remains, possessed a great amount of firmness in the recent state.

That the singular thinness of the fossil test, constituting a mere papyraceous film, is not inconsistent with great solidity in the recent condition, is shown by the existing Limulus, whose leathery integumentis thick and hard enough to give firm attachment to very large and powerful muscles, and yet contains so little calcareous matter, that when dried and subjected to such pressure and decomposing influences as have operated upon the Pterygoti, it would probably be hardly more bulky.

It is not without interest to find that the skeleton was as perishable in the Crustacea as in the Vertebrata of the period in which the Pterygoti flourished.

Note, p.28.-So long ago as 1840, Milne Edwards indicated the relations of Eurypterus with the Copepoda in the following words :- "The fossil Crustacea" of which M. Dekay has formed the genus Eurypterus appear to have much analogy with Pontia (Pontella) and $C y c l o p s$, and also seem in some respects to form a link between these animals and the Isopoda," - Hist. Nat. des Crustacés, to iii. p. 422. 


\section{BRITISH FOSSILS.}

\section{MoNograpH the First.}

Part II.-Description of the Species of Pterygotus.-By J. W. SALTER, F.G.S., A.L.S., Geological Survey of Great Britain.

\section{PTERYGOTUS. GeN. Ag.}

The generic characters have already been detailed in the introductory portion of this memoir. It is only necessary here to give them in brief, and point out the two very distinct sections or subgenera into which the group may be divided. These sections are indicated by the form of the head, the position and outline of the eyes, the shape of the labrum and palpi, and probably, too, by that of the terminal abdominal segments.

Genus PTERYgotus. Agassiz, 1844. (Class Crustacea, Order Eurypterida) Carapace small, semi-oval or subquadrate, with lateral eyes, followed by 12 body segments unfurnished with appendages, the twelfth being a large telson, pointed or acuminate, or blunt and bilobed : epistoma large, deeply trilobed; antennæ of few (4) joints, strongly chelate; mandibles (and maxillæ?) with palpi of 6 or more joints ; metastoma ovate, large, notched anteriorly; a large pair of ectognaths, their terminal joints expanded for swim. ming, and the great foliaceous basal joint furnished with an inner serrate lobe or process.

Section 1. Carapace semi-oval, produced in front beyond the elongated lateral eyes; labrum with its middle lobe ovate; palpi linear, simple; bases of swimming feet foliaceous and overlapping each other; the succeeding joints attached posteriorly. [Terminal joint or telson truncate or bilobed; the penultimate not expanded.] 3 species. P. bilobus, \&c.

Section 2. Pterygotus proper. Carapace quadrate or subquadrate, seldom semi-oval or produced in front; eyes large, round, placed far forwards; labrum transverse, its middle lobe sagittate at base; palpi with tumid joints, fringed, or branched; bases of swimming feet not overlapping each other; the succeeding joints attached more forward than in the last section. [Telson ovate, apiculate, or greatly produced, the penultimate joint expanded.] 12 species. P. anglicus, $P$. gigas, \&c.

It will be seen that these sub-genera contrast in nearly all points. The production, however, of the front margin into a semicircular form in one of the true Pterygoti, $P$. gigas, and the possibly emarginate apex to the long ovate telson of that species, show that these characters are not without variation. Yet even in this case the large rounded eyes and wide expanded penultimate body joint 
indicate that the species belongs to Section 2. The forward position of the eyes is extravagantly shown in such species as $P$. acuminatus, in which, too, the telson attains its greatest degree of elongation. $P$. stylops has a similar but even more prominent eye.

The overlapping of the basal joints of the swimming feet in Section 1, and the attachment of the other joints lower down, may be characters of less importance, but they are associated in $P$. bilobus and $P$. inornatus with the characteristic elongated eyes, and the central lobe of the labrum is ovate, instead of sagittate in these species. The terminal joint or telson is also of like shape in P.bilobus and P. Banksii, the only two species of the subgenus in which it is known.

Although, therefore, Himantopterus has been restored to Pterygotus, the character in which it was formerly supposed to differ, viz., the lateral eyes, being common to both, it is advisable to keep the above two sections or subgenera distinct; and it may hereafter be necessary, when we have a more complete knowledge of the several species, to reinstate the section as a genus, in which case the name Erettopterus* will be appropriate. It is certainly more remote from Eurypterus than is Pterygotus proper, and some unpublished species of the former have the eyes so far outwards as to make a near approach to the section or subgenus here described. The shape of the antennæ, however, is quite enough to separate them; and the telson of Eurypterus, so far as it is known, is linear, $\dagger$ or linear lanceolate.

Pterygotus is known now to range from the Upper Llandovery Rock (or May Hill Sandstone) through all the overlying Upper Silurian Rocks into the Cornstones of the Old Red Sandstone, though it is but rare above the base of the last-named formation; its metropolis seems to be at the point of transition between the Silurian and Devonian formations. Fifteen species are known.

Eurypterus began not quite so early, being first met with in the Upper Ludlow Rock, and thence, becoming abundant in species (though of small dimensions) in the passage beds at the base of the Old Red Sandstone, attained its maximum of size in the upper portions of that formation and the base of the carboniferous rocks, after Pterygotus had apparently ceased to exist. (See Quart. Journ. Geol. Soc. for 1859, vol. xv. ined.) About sixteen species are known.

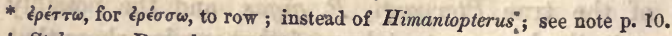

$\dagger$ Stylonurus, Page, bas a similar form, but possesses thirteen body segments and long linear swimming feet.
} 


\section{BRITISH FOSSILS.}

Plate I. Figs. 1-12.

Section 1.

\section{PTERYGOTUS BILOBUS.}

P. 8-uncialis, sublavis, capite semielliptico, corpore abbreviato antice latiori, caudâ oblonga carinatâ emarginatâ.

Synonym. Himantopterus bilobus, Salter, in Quart. Journ. Geol. Soc. vol. xii. p. 29. fig. 1. ; also "Siluria," 2nd edition, p. 155, foss. 21. PAGE, in Advanced Textbook, p. 135, fig. 1.

We have more perfect materials for this species than for any of the rest,-above twenty specimens, many of them full grown, and showing all the segments; in some the head with its elongate eyes and few-jointed antennæ; the long palpi in others; two show the serrated jaw feet beneath the carapace with the swimming joints attached; the post-oral plate is in situ in another; and there are numerous detached specimens of all the appendages except the palpi, of which last we should know but little but for the explanation afforded by the next described species.

The geological position of this and the other Pterygoti from Lesmahago has been fully given by Sir R. I. Murchison, our DirectorGeneral, in the 12th volume of the Quarterly Journal of the Geological Society, p. 23. The occurrence with them of a small spiral shell and a Lingula, identical with those of the Downton Sandstones of Shropshire, justifies the reference of the strata to the age of the Uppermost Ludlow Rocks, while not one of the species is identical with those of the border counties of Wales, either in the Ludlow Rocks or in the Passage Beds which immediately overlie them. This fact is remarkable, and may serve to indicate the probability of a vast number of species yet to be discovered. 
Description.-The general form of $H$. bilobus is elongate-oval in front and attenuated behind (resembling a good deal the outline of a Paloconiscus or other fish). The thorax is not easily distinguished from the abdomen, into which it is attenuated, the greatest width being about the third or fourth segment; its segments are widely transverse, those of the abdomen become less and less so, till the last but one is nearly square ; the tail joint is oblong and emarginate, and narrowest of all; the antennæ are slender and long, the swimming feet narrow, the palpi filiform; and these general characters, taken together with the small size (seldom nine inches long), will easily distinguish the present species from the following. The different portions may now be more minutely noticed.

The carapace, one inch and a quarter in length, is half oval, only one-fifth wider than long. The position of the long eyes is very forward on the sides, and they somewhat interrupt the general oval contour. They are broadly crescentic and convex, placed half below (fig. $4 c$ ) and half above the margin of the head, and their extreme length is rather more than half that of the head. No lenses can be seen with the naked eye, but when magnified the appearance is that given in fig. $4 d$.

Body Segments. - The body in well-preserved individuals is barrel-shaped in front, the anterior or thoracic segments, taken together, measuring about one inch and three quarters in length by one inch and a quarter broad. They are widely transverse, the anterior one being fully four times as broad as long, or even more.

The second ring, as seen in a specimen not here figured, is five times as wide as it is long, the central part gently arched forwards in the middle, and at the sides the upper angles are produced forward into blunt lobes," the outer margins being oblique, and their posterior angles are a little produced backward, particularly in the sixth or hindermost thoracic ring.

The remainder, which are here reckoned as abdominal, are gradually narrower, the seventh being only three times as wide as long, the tenth only once and a half, and somewhat narrower at the origin than the posterior edge; the penultimate (eleventh) is squareish, only a little wider than long, also contracted at the origin and with the outer angles produced to lap over the rounded anterior edges of the caudal joint. A strong carina runs down this segment upon the upper side, but for the lower half only.

* This form of the second segment is common to all the species, see fig. 13 of this Plate, and Plates IV., X, XIII., \&c. 
The caudal joint (telson) is only two-thirds as wide as long, and nearly double the length of the penultimate one. It is rather wider behind, and strongly emarginate; a deep furrow takes its origin from the notch, and continues more than half way up. There is a low keel at the upper end joining that of the preceding segment, but only for a very short distance.

The outer margins of the body and tail segments appear to be quite smooth, not serrate or crenate as in several other species.

The thickness or rotundity of the joints we have no means of ascertaining.

The sculpture is minute and characteristic, but is only visible at a few points. None has been observed on the head. On the body joints numerous small semicircular plicæ (fig. $2 a$ )-the curve open forwards-cover the surface, but are less conspicuous on the hinder portions of each segment. On the anterior narrow segment they are perhaps most prominent, and on this and some other of the front rings a raised transverse thread-like ridge runs across at about the middle, or a little in advance of it, but does not limit the conspicuous portion of the sculpture.

\section{Under Side of Head, and Appendages.}

In three or four specimens, figs. 1, 3, 4, 9, \&c. the organs of the mouth, with the antennæx, are in situ, and in others the appendages of the head occur so grouped together as to show that they were associated. Fig. 3 appears to have the parts most complete.

Antennce (fig. 6, \&c.)-None have been found more than two inches long by a quarter of an inch broad at the base of the chelæ, the free joint of which is, in antennæ of this size, about six-tenths of an inch long. The base of the fixed finger is but slender, scarcely thicker than the preceding joint, and is shorter than the chelæ, the shafts of which are linear and straight. (Fig. 7 is broader than usual, and may indicate a difference of sex.) The points of the chelæ are sharply incurved; their armature is minute, of small and larger teeth.

There are apparently but four joints in the antennæ, the basal one small, the second, fig. $7 b$ (both figs. 6 and 7 are wrongly drawn as to the length of the lower joints, from being so much broken), at least five times as long as broad, the fourth (c) is the fixed claw and its base, and the fifth the free claw. The articulations of the joints are all oblique. 
Endognaths (Mandibles, \&c.)-The under side of the carapace, of which fig. 4 . is the cast, shows the great foliaceous bases (with serrate inner lobes) of the swimming feet (c). No mandibles or maxillæ* have been discovered beneath these; but in fig. 1 , at $c$, the long filiform palpi of one pair of these organs extend right and left of the carapace. They are more elongate than in other species.

A small mandible, found since the plate was engraved, is here given as a woodcut. It is contracted in width as compared with

Fig. 1.

Endognath (Mandible), natural

size? of Pterygotus bilobus.

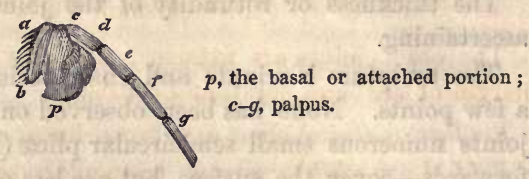

the shape in some other species. The anterior serrate lobe $a$ is narrow, and with sharp curved articulated teeth. The lamina $p$ is oblique and sub-triangular; and the palpus, set on rather far back from the serrate border, has a small quadrate basal lobe $c$ followed by a longer one $d$; the third and fourth $(e f)$ are linear, and several times as long as broad. The terminal joints are still longer, as seen in Plate I. fig. $1 c$ (compare this with Plate VII. figs. $4,5$.

Epistoma and Labrum.-Of the large semicircular piece which lies in front of fig. 1, and which has evidently been shifted from the under side of the head, we can only judge the true position by comparing it with other species (H. perornatus, for instance, fig. 16, in which the mid-lobe $a$ of the organ is seen to be of an ovate shape); also in Plate XV. fig. $2 f$, where a similar piece lies in front of the head.

In fig. 1 the semicircular outline probably corresponds to the hinder free margin (of much more angular shape) in the epistoma of $P$. anglicus, Plate III. The mid lobe $a$ is obscurely marked out, but is of an ovate shape ; its insertion not very clearly seen.

Ectognaths.-Fig. 3 shows these organs in their place at the lower angle of the carapace, drawn forward as for a stroke; the forward bend of the limb at the fifth joint $c a$, and the great serrate bases $b$ indistinctly visible through the crust. Fig. 9, with part of the carapace broken away, has both limbs in place, and figs. 1 and 2 show these natatorial feet laid backward close along the body.

* The dilated bases of the swimming feet (ectognaths) were formerly supposed to be the mandibles, and the produced neck-like portion to be jointed; Quart. Journ. Geol. Soc. 1. c. This bas been set right by Professor Huxley (see Part I.) 
Fig. 8, magnified at $8 a$, is an entire separate ectognath. The several joints of this appendage are :-

Basal Joint (coxognathite), figs. 4 c, 8 co.-The great lower lobe is wide, and of a spherico-triangular shape, the inner margins as well as the outer and base, being all convex. The neck is suddenly contracted and short, and the serrate terminal lobe transverse or oblong, greatly oblique and overlapping the opposite edge (not vertical as in $P$. acuminatus, Plate II.) Its toothed margin is curved and set with thirteen small teeth.

The other joints are attached low down, i.e. below the outer margin of the basal joint, and consist of-

b. (Basignathite) short and broad-linear.

i. (Ischygnathite) narrow triangular, produced a little at the hinder angle (but not forming a lobe as in Plate VI., fig. 1.)

$m$. (Merognathite) rudely trigonal, its binder base meeting the produced articular lobe of the large penultimate joint $p$.

[Either this or the next joint $c a$ bears the long three jointed filament $t$. The forward salient angle of the limb is formed between this and the succeeding joint.]

ca. (Carpognathite) triangular; its convex base outwards, its apex inwards against the process of $p$.

p. (Prognathite.) All the preceding joints, except the great basal one, do not quite equal the length of the penultimate joint $p$. It is oblong, but narrower at the base, which is oblique, with the hinder edge produced into a process ( 8 ), which reaches the fourth joint $(\mathrm{m})$. The outer margin is rather convex, the inner a little concave, and the apex deeply and pretty equally bilobed, to receive the terminal joint.

d. (Dactylognathite.) A regularly ovate palette, as long, measured along the middle line, as the penultimate joint, and nearly as broad; it is attached to it by a prominent tubercle.

No sculpture has been observed on the limbs.

Metastoma or Post-oral plate, figs. 1, 10.-These cordate plates (referred to the posterior margin of the mouth, p.16) occur with all the species. The piece is nearly of the same narrow ovate shape in this as in $P$. perornatus, fig. 15 , but only one-third the size, deeply cordate, with a sharp notch and rounded lobes in front, and with the base also rounded; the width is about half the length, the lobes are covered thickly with rather large semi-circular plicæ, which are absent from the other parts of the plate. 
Fig. 1 shows this plate in its natural position, and fig. 10 a detached plate as commonly found. The latter occurs in a group with a pair of antennæ, of which fig. 6 is one, and with the swimming foot, fig. 8 ; all probably therefore belong to the same individual.

Our specimens are so much altered in shape by pressure, that it is difficult to point out any real variations in form. Fig. 2 appears to have the true general shape. Fig. 1 is evidently compressed laterally, as is the caudal joint, fig. 11 ; while fig. 12 shows that joint shortened by pressure from behind forwards. Fig. 4 is reduced in length by the same cause, and appears too broad in proportion for the length.

Locality.-UPPERMOST LUDLOW BEDS, Lesmahago, Lanarkshire, with several other species, and the shells Platyschisma (Trochus) helicites and Lingula cornea. All in the Museum of Practical Geology. Collected by Mr. Robert Slimon. 


\section{BRITISH FOSSILS.}

\section{Plate I. Figs. 13-15 (AND 16, Variety);}

Plate XV. Fig. 2.

\section{P. PERORNATUS.}

P. pedalis et ultra, undique squamulis minutis ornatus, capite semi-ovali, thorace segmentis latis curvatis, oculis anticis minoribus granulatis.

Srnonym. H. perornatus. SALTER, in Quart. Geol. Journal, vol. xii. p. 31 , and 28 , fig. 6 .

One of the most distinct and well-marked species, and clearly belonging to the same section with $H$.bilobus, while it is more than double its length and width, the largest specimen being three inches and a half wide and probably not less than fifteen inches in length. We have the head and six body segments; the swimming feet, both attached and free ; maxillæ with palpi, the post-oral plate in situ, with some faint traces of antennæ; but all these show good characters.

The head (carapace*) was formerly described by me as smooth, but in better specimens it is closely and fully sculptured, the plicæ convex forwards. It is half a broad oval (fig. 13), three inches in length by three inches in breadth, and the posterior angles are acute.

The eyes are forward and rather small, not extending over a space more than two-fifths the length of the head (in H. bilobus they are much more than half), and finely granulated, the lenses visible to the naked eye (fig. 13).

The body segments are broader from front to back than in the last species, the front ones particularly, but, if fig. 16 be the same species, vary considerably in this respect. They are much arched. forwards over the wide central portion, the ends are recurved as usual, and at less than one-third from the middle $(b)$ a kind of fulcrum exists, dividing the compressed lateral area (pleura) from the more

* I take leave to use in description the term "head" for convenience' sake; carapace is of course more correct. 
convex central portions. The first segment is much more rounded off at its hinder angles $c$ than the remainder, and the space thus left filled by a projecting process of the second segment (see also Plate IV.) There is a similar but smaller process to the first joint, at least in the var. plicatissimus, fig. 16 , and it is probably so in all species.

The sculpture in the body rings, fig. $13 a$, extends over less than half their surface. The plicæ are open forwards, very small, almost linear on the front margin (the extreme margin of all the segments is rounded off and smooth) and the remainder are less than semicircles or they are subangular (more than $90^{\circ}$ ). On each side at $b$ they are not as wide. A transverse impressed line separates the anterior sculptured half from the posterior smooth portion, but this is not always present. No crenate edge has yet been observed.

\section{Appendages, Plate XY. fig. 2.}

On a specimen much distorted, and from which the swimming foot, Plate I. fig. 13*, is taken, the following organs may be detected by careful examination :-

Epistoma, $f$, reflected from the under side.

Antennæ, $b, b^{\prime}$.

Great post-oral plate or metastoma, $g$.

Two endognaths, $c, c^{\prime}$, with palpi $x$.

Endognath (mandible or maxilla) of the opposite side, $c^{\prime \prime}$.

A separate jointed palpus.

Ectognath (swimming foot), $e$, attached to the carapace.

First body joint.

$f$. The large epistomian plate resembles much in shape that seen in Plate I. fig. $1 a$, which is similarly displaced. We only see a portion of it, the termination being broken off, but it appears to have been semicircular and semioval, more than three-fourths the width of the carapace, and covered with minute prominent plicæ. Near its base, but not attached, are remains of a single antenna, $b$.

$b, b^{\prime}$, Antenna.-Only the general form can be made out; it is thick in proportion to the size of the specimen, and consists of apparently only three joints, the lower one broken (b), the fragment three times as long as wide; the second $(b)$, crossed by a line, which is probably a fracture, appears to be a long single joint, five times as wide as long, its articulation with the neighbouring joints being marked by small irregular crenulations. The penultimate joint or fixed finger $b^{\prime \prime}$ is much crushed, it seems to be contracted 
at its base, the lower part barrel shaped, about twice as wide as long, and tapering rather gradually into the serrate portion. The free claw $b^{\prime \prime \prime}$ is broad, linear, and beset with numerous small teeth, a few larger striated ones interspersed; the first only is seen on each chela, that on the fixed claw very near the angle; that on the free finger is more distant.*

$c^{\prime}, c^{\prime \prime}$, Mandibles, \&c. $\uparrow-T h e r e$ are traces of two pairs of jaws, the palpi attached or in close proximity, figured with the rest of the carapace in Plate $\mathrm{XV}$. fig. 2. One endognath is lying loose on the left hand of that figure in a reversed position, and has the usual curved striate teeth, but nothing can be determined of its shape. On the opposite side two jaws with palps lie one over the other, and a woodcut is added below, Fig. 2, to show in a diagrammatic form the arrangement of these pieces with their appendages.

The outer jaw, $g$, shows the terminal serrate lobe, with at least. seven articulated arched teeth (the uppermost largest), and about

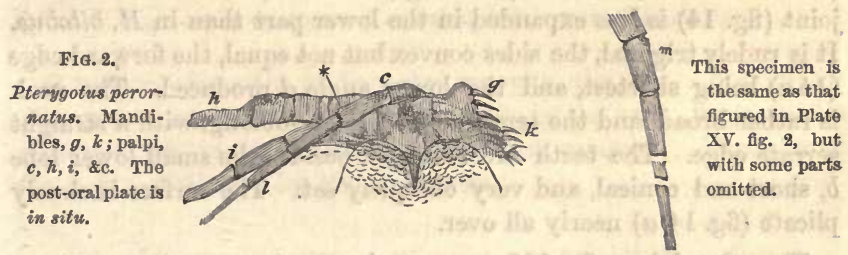

three times as long as the breadth at their base, and sharp pointed. The other, $k$, is pushed in advance of $g$; it shows a similar set, more displayed, of curved striate teeth ; about five are distinctly preserved.

The filament $c, l$, which, from analogy with that of $H$. bilobus, is presumed to be the palpus, appears to me to be connected with the mandibular piece $g$, and to cross the two others, $h, i$, which seem to form part of a branched palpus, and to belong to a second ectognath (mandible or maxilla). But the connexion of these with the serrated pieces $g$ or $k$ is not quite certain; they must therefore be described

* In Pterygotus the large teeth are very nearly opposite one another in the middle and onter portions of the forceps, and must have acted as cutting blades, not merely as prehensile forceps (see Plate VI.)

† Discovered in this species by Professor Huxley. But he does not agree with me, that there is sufficient evidence of the two pairs of jaws, one with a single, the other with a branched palpus (see p. 23). 
provisionally as belonging to them. The filament $c, l$, consists of at least four elongate sublinear joints, besides a basal one, or probably two, which are short and obscure. The first of the long joints is rather swelled and crenulate or spinose at the tip (at*); the next, which is about four times as long as broad, shows some little crenulation.

Of the branched filament (or pair of filaments) $h, i$, the junction with the maxilla is quite obscure; there are about three linear joints to each, broader than those of the palpus $c, l$. The detached fragment $m$, if it belong to this specimen at all, would from its size correspond to one of this pair ( $h$, for instance, rather than $l$ ).

5. Swimming Feet, Plate I. figs. 13*, 14.-Fig. 13* is found attached to the carapace, above described, which has the maxillæ and palpi, \&c. attached. Fig. 14 lies loose in the same slab, and as it is materially different from that of the other large Lanarkshire species (P. acuminatus, Plate II.), belongs, no doubt, to this. The basal joint (fig. 14) is less expanded in the lower part than in H. bilobus. It is rudely trigonal, the sides convex but not equal, the forward edge (14 a) being shortest, and the lower angle $d$ produced. The neck is rather broad, and the terminal lobe linear-oblong, with a straight serrate edge. The teeth are fourteen, besides the small lower lobe $b$, short and conical, and very obliquely set. The surface is closely plicate (fig. 14 $a$ ) nearly all over.

The other joints, fig. 13*, are very obscure, but constitute a linear swimming paddle, but little bent, like that of $H$. bilobus. The second joint is lost, but the third $(i)$ is linear, the fourth $(m)$ triangular, and the fifth (ca) irregular and obscure in the specimen. The penultimate joint and terminal palette $(p, d)$ are much distorted; but in a fine specimen of the carapace, with the swimming feet (ectognaths) attached, and which was discovered by Mr. Slimon since the plates were finished, the penultimate joint $(p)$ is more than twice as wide as long, with a strong process from its hinder angle running upwards, and a deeply notched termination to receive the terminal oval palette. This last is short and narrow, compared with that of P. bilobus. (See woodcut, fig. 3.) The two ectognaths are very perfect; they are attached at the outer angle, but turned outwards in this specimen by decomposition of the attaching muscles, so that the exterior margins are placed opposite to each other, and the inner serrated lobes look outwards (the dotted lines 
show what was their original position). The shape of the carapace is distinctly shown in this specimen.

FIG. 3.

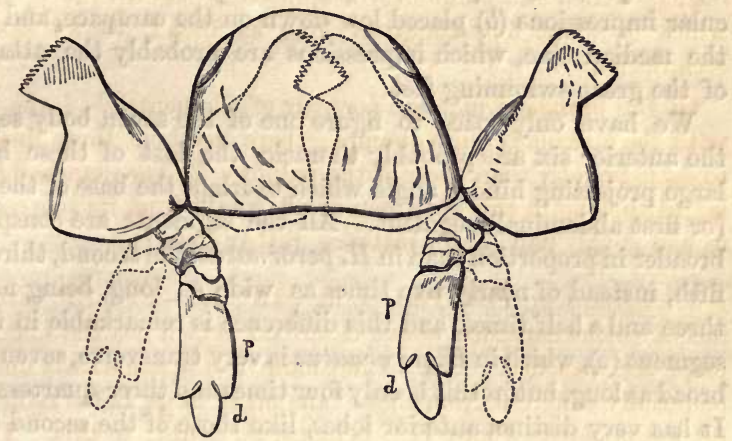

P. perornatus, carapace, and swimming feet; one-third natural size.

Locality.-Lesmahago, Lanarkshire, with the last. Besides the Pterygotus acuminatus, Plate II., this is the only large species which occurs in the locality. It is not common. Mus. Pract. Geology. Collected by Mr. R. Slimon.

P. perornatus, Var. plicatissimus, Plate I. fig. 16 .

This, which differs materially in the breadth of the segments, and somewhat also in the manner of sculpture, must be regarded, till more specimens are obtained, only as a variety. But it will very probably be found a distinct species, in which case it is only necessary to use the varietal name as a specific one.

The carapace (in fig. 16) is much compressed longitudinally, but

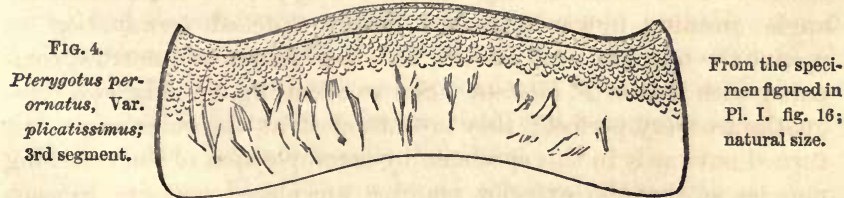

the true form would probably be a full semioval, as in the preceding woodcut; the position of the eyes is obscurely marked. The sur-

[1.] 
face is covered with semicircular plicæ, the curves of which open backwards (contrary to the usual position over the rest of the body).

In front is seen the impression of the large ovate median lobe (a) of the epistoma, shaped as usual, and behind are two radiated muscular impressions (b) placed low down on the carapace, and towards the median line, which impressions are probably the attachments of the great swimming feet.

We have only space to figure one of the seven body segments : the anterior six are probably thoracic, the last of these having a . large projecting hinder angle which overlaps the base of the seventh (or first abdominal) segment. All the segments are conspicuously broader in proportion than in H. perornatus, the second, third, fourth fifth, instead of nearly five times as wide as long, being not above three and a half times, and this difference is remarkable in the front segment (c), which in $H$. perornatus is very transverse, seven times as broad as long, but in this is only four times and three-quarters as wide. It has very distinct anterior lobes, like those of the second segment.

The sculpture of the rings differs from that of $P$. perornatus in having the plicæ narrower and longer, the angular ones being less than $90^{\circ}$, and even on the anterior margin they are not less than semicircular.

Each segment except the first is crossed by a very distinct impressed line, which bisects the anterior sculptured half, and is placed in the second segment at the anterior third (in the first segment it is absent), the rest have it very near the anterior margin.

The seventh segment is two and a half times as broad as long, and has square, not produced posterior angles.

Locality.-Lesmahago. Mus. Pract. Geology. (Collected by Mr. R. Slimon.) 


\section{BRITISH FOSSILS.}

Plate XII. Figs. 22-46.

\section{PTERTGOTUS BANKSII.}

P. parvulus, 4-5 uncialis, capite convexo, semiovali, vel parabolico, ad frontem subangulato, oculis brevibus gibbis, ad dimidium capitis: annulis trunci omnibus transversis, caudâ expansâ truncatâ bilobâ.

Sxnonyr. Himantopterus Banksii, Salter, Quart. Journ. Geol. Soc. vol. vii. p. 32, also p. 99. and pl. 2. fig. 5. [fig. 6, is the caudal joint of an Eurypterus]. Siluria, 2nd ed. p. 266. foss. 66. fig. 1.

Named in honour of Richard Banks, Esq., of Kington, Herefordshire, who has made rich collections of the Pterygoti of that locality, and has generously relinquished the publication of his materials in our favour. He has also presented to the Museum all his accurately coloured drawings and notes.

"This small neat species, of which we have many specimens in the Museum of Practical Geology, occurs with Pterygotus (P. gigas, Plate VIII.), and spines both of Crustacea and fish, in the yellow tilestone (Downton Sandstone) beds of Kington, Herefordshire. It is there associated with the Platyschisma helicites and Lingula cornea, Sil. Syst. These are the two species of shells which accompany the fossils of Lesmahago above described, a good argument, therefore, even without other evidence, for regarding these Lesmahago beds as the uppermost portions of the Ludlow rock."-Quart. Geol. Journ. l. c.

Description.-The full size must have been from four to five inches. long, but the specimens usually met with would probably not be above three or four inches. One or two show the connexion of the body rings with the head and appendages, fig. 42 , or with the tail joint (fig. 23). None are quite complete, and though we have nearly all the parts, they are usually disjointed.

The carapace (fig. 22) is a broad semioval, its length as six to seven, except when lengthened or shortened by pressure (figs. 25, 26). It is regularly convex, a little angulated in front, smooth, and bears. the small oval eyes rather more than half-way up the head. They 
are much smaller than in $H$. bilobus, being not above one-fourth the length of the carapace, and very convex.

The body is at first wider than the head and then tapers backwards. The first ring is very narrow (fig. 42), the second twice as broad and with the usual dilated extremities; the third, fourth, and fifth strap-shaped, arched in the middle and direct on the sides so that the segment appears much bent. The ends are truncate, in the anterior rings widest behind, and in the posterior ones tapering backwards.

Fig. 28 shows one of the hindermost rings, such as are seen in the more complete specimen, fig. 23. The hinder rings become gradually less transverse, the tenth only two and a half times wider than long, and the penultimate about once and three-quarters its own length.

The caudal joint (telson) figs. $23,38,45$, differs, in its expanded form, materially from that of $H$. bilobus. It is about three-fourths as long as wide, narrow at the base with two short ridges running down from either angle; then expanded with somewhat convex sides towards the wide subtruncate apex; the outer angles are rounded off, the terminal notch shallow, and a short median keel continued from it one-third up the segment.

The sculpture of the head is not known. On the body rings a transverse lineation running into open plice on the sides (fig. $43 a$ ) occupies the front margin for not quite half the segment; a few plicæo are intermixed with the lines.

[On the caudal joint, fig. 46, a lineation, parallel to the outer border $(a)$ is distinct, but it is uncertain if this specimen be of the same species; it has a strong median groove down the under side, and is less expanded in form than P. Banksii.]

The swimming foot, fig. 42 , has a characteristic shape, the upper joints (fourth and fifth) are rather narrow, and the penultimate $(p)$, instead of being simply conical as in $H$. bilobus, is ovate (more so than in our figure), with the outer border especially convex. It is notched above to receive the fifth joint, and below divided into very unequal lobes. The terminal palette $d$ is true oval, rather blunt at its origin and more pointed at the extremity. It is nearly equal to the penultimate joint in length, but considerably narrower.

Fig. 35 is a penultimate joint, probably of the same species.

Antenno.-Figs. 30 and 40 are presumed to belong to this species, as they occur with them. They are remarkably slender and straight; the base is large and broad, suddenly attenuated into the shaft, which is only a tenth of an inch wide, and three-quarters of an inch long, beset with close small teeth, and furnished with three larger 
conical ones nearly straight, the central one as long as the width of the shaft. In fig. 40, from the Ludlow Rock, the intermediate teeth are a little longer in proportion.

The basal joints, fig. 29, are flask-shaped, much more elongate in the neck than those of $H$. bilobus, and less swelled at the base. [It is possible they may not belong to the species at all, but to Eurypterus linearis, a species which occurs in the same beds; we do not yet know this joint in Eurypterus.] The base is subquadrate, quite rectangular on the outer upper margin:- the notch for attachment of the other joints is immediately beneath this angle,-and tapering into the long neck, which has a sharp ridge posteriorly, and together with the terminal lobe equals the length of the basal portion. The teeth are minute.

The post-oral plates, figs. 31 to 34 , differ a little in shape from figs. 41 to 44, but not specifically, unless the greater amount of ornament in fig. 41 may be considered sufficient to separate it. The shape is elongate oval, the greatest width at the upper third, the base (b) subtruncate, the apex with a shallow obtuse notch. At the lower fourth $(a)$ is evidently a tubercle of attachment, and such as occurs in a more linear shape in other species, Plate II. fig. 4 a. [It is desirable to find out the post-oral plate of Eurypterus; which is probably very similar.]

The sculpture is very conspicuous over the upper half; it consists of nearly straight or very slightly curved plicæ arranged in arched lines and ending abruptly against the outer margin. In the sandstone specimens the sculpture does not extend so far down, but it is identical in structure.

Localities.-UPPER LUDLOW Rock, Ludlow Lane, Whitcliffe (and Batchcot? fig. 46); Parlan, exterior slope of the Woolhope Valley (Mus. P. G.) ; Kington, Herefordshire (Mr. R. Banks' cabinet). PAssage-Beds, Ludlow Railway cutting (Cabinets of Messrs. Lightbody and Marston, at Ludlow; Museum Pract. Geol.), \&r. 


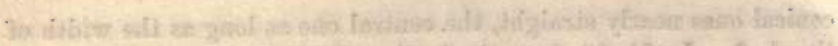

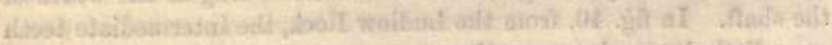

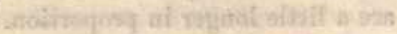
e)

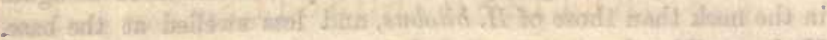

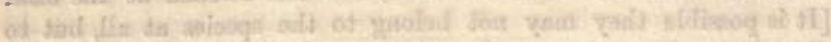

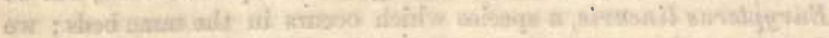

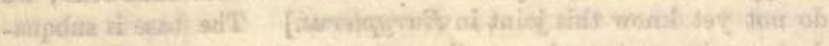

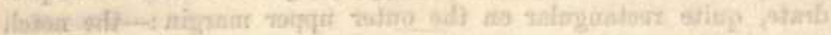

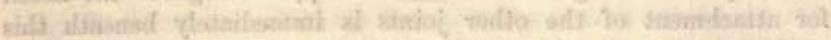

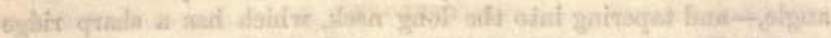

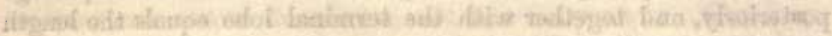

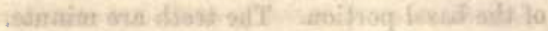

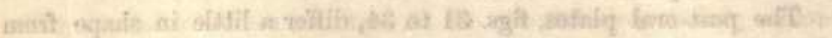

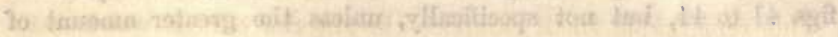

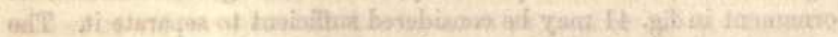

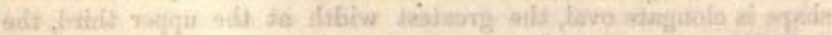

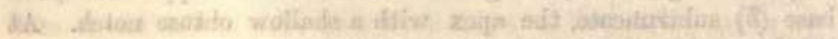

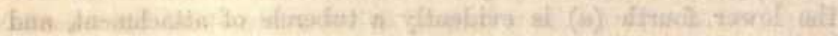

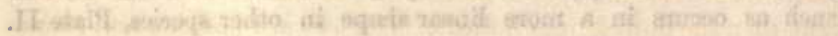

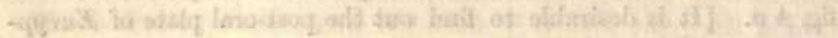

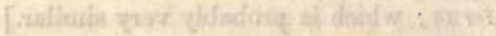

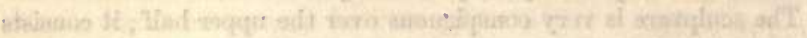

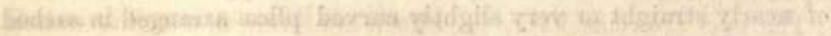

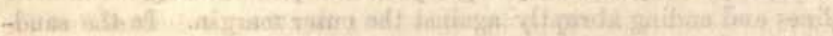

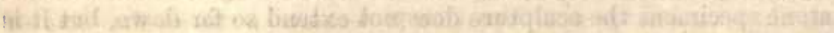

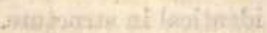

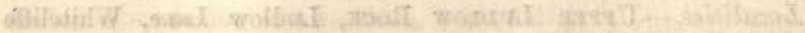

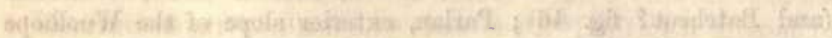

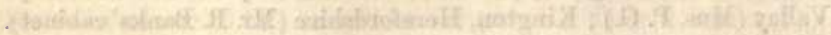

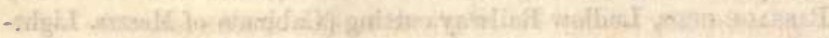

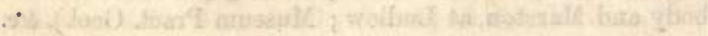




\section{BRITISH FOSSILS.}

\section{Plate XII. Fig. 47.}

\section{P. STYLOPS.}

P. parvulus, capite (parte anticâ solum asservatâ) 9 lineas lato, convexo, quadrato, fronte (fracto) producto? lateribus rectis; oculis ad angulos externos fixis, magnis, turgidis.

This remarkable small carapace, the anterior part of which only is preserved, has occurred to the assiduous search of Mr. R. Banks of Kington.

Only the anterior part is preserved, and even of this the frontal portion between the eyes is broken off; it was perhaps less prominent than the dotted lines indicate. The forward position and round form of the great eyes very much assimilate the species to $P$. acuminatus, and without doubt it belongs to the same section, or the true Pterygotus.

The eyes are remarkably prominent and turgid, a slightly raised fold of the carapace encircling them. A small tubercle, like that on the same part in P. gigas, Plate XII., occurs on the median line of the head, and rather nearer to each eye than their distance from one another. As only a single broken specimen has occurred it is useless to describe it further. There can be no doubt of the distinctness of the species.

Locality.-Kington. Coll. Mr. R. Banks, of Kington. 


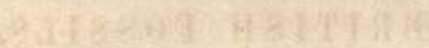 :}

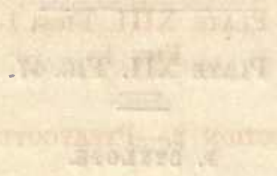

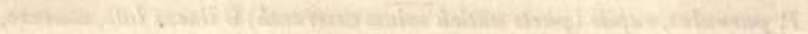

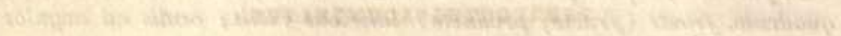

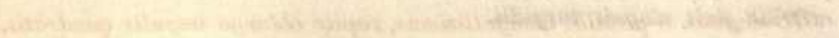

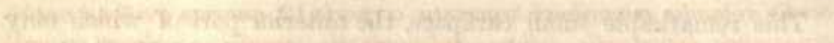

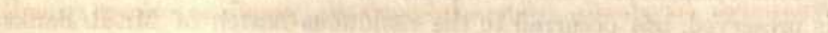

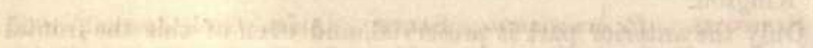

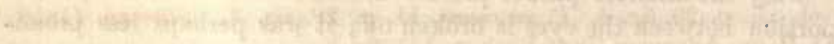

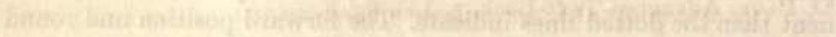

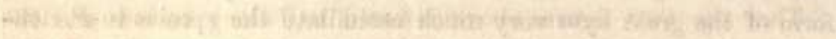

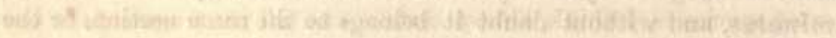

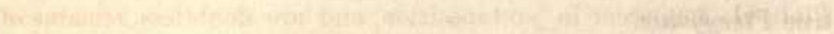

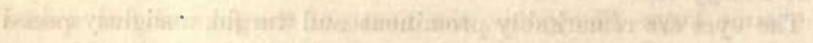

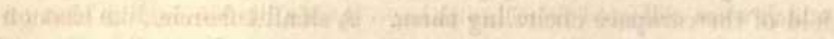

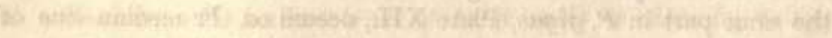

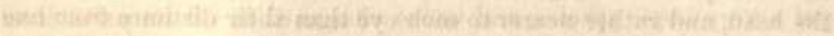

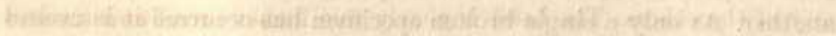

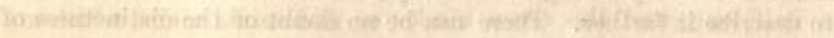

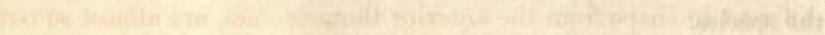

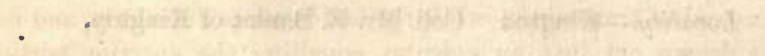

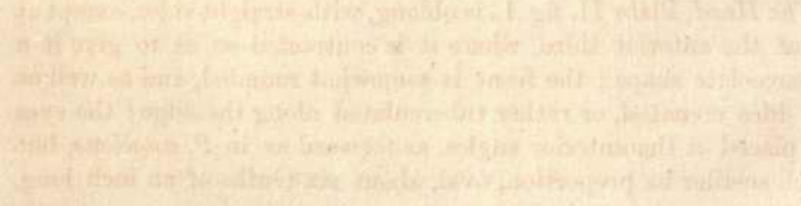

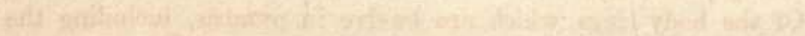

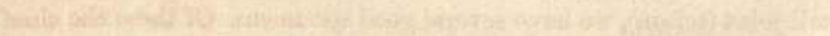




\section{BRITISH FOSSILS.}

Plate II. ; also Plate XIII. Figs. 1-4; Plate XV. FIG. 1.

\section{Section 2.-Pterygotus.}

\section{PTERYGOTUS ACUMINATUS.}

P. magnus, 3-pedalis, elongatissimus, capite oblongo angulis quadratis, oculis rotundis minoribus: segmentis corporis 12 , quorum quinque anticis transversis bicarinatis, reliquis subquadratis, penultimo oblongo; caudí ovatâ in apiculum longum productâ.

Srnonxus. P. acuminatus, SAlter, Quart. Geol. Journal, 1855, vol. xii. p. 29. fig. 4. P. maximus, id. p. 28. fig. 3. Slimonia (1856), D. PAGE, Advanced Text-Book, p. 135. fig. 3.

That the two figures above referred to belong to one and the same species is, I think, almost certain, and all the fragments in our Plate II., \&c., occur in juxtaposition, and are doubtless remains of the same large Pterygotus, the finest of the four or five species which were collected from Lesmahago by Mr. R. Slimon. Although not so gigantic as those next to be described, $P$. acuminatus is yet a very large species, and more elongated in all its parts than any of the others. The head is nearly five inches broad and six and a half long, and the seven hinder or abdominal rings, which are different in shape from the anterior thoracic ones, are almost square instead of transverse; while the tail is ovate anteriorly, and behind is drawn out into an apiculus equalling the anterior portion in length.

The Head, Plate II. fig. 1., is oblong, with straight sides, except at about the anterior third, where it is contracted so as to give it a suburceolate shape ; the front is somewhat rounded, and as well as the sides crenated, or rather tuberculated along the edge; the eyes are placed at the anterior angles, as forward as in $P$. anglicus, but much smaller in proportion, oval, about six-tenths of an inch long, and very prominent.

Of the body rings, which are twelve in number, including the tail joint (telson), we have several good specimens. Of these the chief 
are figs. 10 and 11 in Plate II. The former is of the natural size, a young specimen, showing the whole of the body rings; the two hinder ones are left out for want of room in the plate, but these are well seen in fig. 11 . The rings are arched, and were probably very convex, and both the front and back edges of the segments can be seen in our compressed specimen; the former as a segment of a circle, the latter as its chord.

The lateral hinder edges of at least some of the segments are produced (fig. $10 \mathrm{~g}$ ) into short processes, and their margins are acute.

Six segments appear to be thoracic, and are more transverse than the hinder ones, about three times as wide as long (the front ones still wider), and each is marked at its hinder extremity by two short keels* along the median space, not much raised above the surface, and about a quarter of an inch long. The hinder abdominal segments, of which fig. $10 \mathrm{~g}$ is the first, are destitute of these median keels, and gradually longer in proportion to their breadth till the tail-joint is reached. The first segment $(a)$ is only three-quarters of an inch long by one and three-quarters broad; the second and third $(b, c)$ are much narrower, about nine-tenths long. The fourth measures more than an inch in length; the fifth one inch and a quarter, but rather less in breadth, and narrowed posteriorly. It is destitute of any central ridge or keel above or below. The tail segment (telson) in this species is a large oval plate, terminated by a long apiculus; the length without the apiculus is two inches and a half, and with it four inches; the breadth is nearly one inch and three-quarters, narrowing to the base, which is thickened, (probably cylindrical,) the rest being much depressed. On the upper surface a strong carina arises near the origin of the joint, and continues to the tip of the apiculus. The lower side is flattened, or but gently convex at the base. The margin of this tail joint is closely serrate or tuberculate in a double line near the base (like that of the margin of the head), running into a single line of distant long tubercles below and along the apiculus.

This kind of double tuberculate border is conspicuous down the sides of the head, the tubercles being elongated, while on the arched front border there are three or four rows.

The ornamentation of the body rings is quite minute, and is but rarely seen in our specimens. It is confined to the anterior border of the segments; the plicæ are small, equal, and rather prominent.

* The first pair is seen in fig. 10, pushed back over the second, and is the best indication of the boundary of the segment $a$. 


\section{Appendages.}

Antenno, Plate II. figs. 2, 3.-The position of these serrated organs is settled by their mode of occurrence in the species previously described. The fragments, figs. 2, 3, being the largest chelæ in the stratum, and, occurring also with this large species, probably belong to it. The teeth are narrow, lanceolate, shorter than the width of the shaft, turned a little backward, and closely striate. The three primaries are rather more than their own length apart, and the last rather more remote from the terminal tooth, which is curved upwards nearly at a right angle. The secondary teeth are sharpconical, and five or six in each interspace. The shaft is rather broad, its outer edge quite straight, and at the tip, which is blunt and abrupt, strongly punctured for a short distance. The free claw, fig. 2, has the usual contraction at its base.

Oral Appendages.-From a number of fine specimens from Lesmahago, found since the plates were engraved, some excellent additions have been made to this species; these will be given in woodcuts. They render, I think, unnecessary some of the arguments used further on to prove the existence of two pairs of jaws with their palpi, but as those refer to the evidence as it stands in the plates, it is thought better to retain them.

Epistoma, and labrum.-A piece answering to the shape of this organ in another species (see Plate III. figs. 2, 5), and of size suitable to that of $P$. acuminatus, occurs with it at Lesmahago. It is specifically different in the great length of the central lobe $(b)$, which projects forward a long way beyond the side lobes or wings; or we may consider these latter as contracted $(a)$. The whole piece is transverse, instead of rudely triangular, and the sculpture confined to the anterior border. The median lobe $(b)$ is pyramidal, not sagittate, at the base; its tip is broken off.

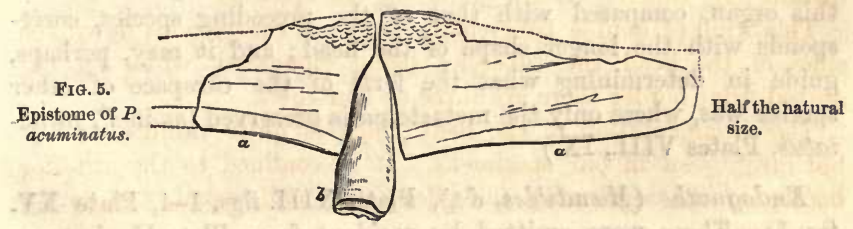

The occurrence of this more perfect specimen renders it unnecessary to suppose that Plate $\mathrm{XV}$. fig. 3 , should represent the 
central lobe of this organ. Nevertheless, it has the expanded sagittate base usual in this section of the genus, and from this base extends a narrow lanceolate piece, ridged along the centre, and shelving (to pass under the lateral lobes) on the sides. These contract near the tip, which is again expanded a little and then forms a cordate pointed lobe. The piece is one inch and threequarters long, and half an inch wide at its broadest part (below the middle). I do not know to what species it can be referred.

There is yet a third and very large plate found in the same stratum, which, from its shape and structure, appears likely to belong to an allied species, and differs from both the above described. A woodcut (fig. 6) is here given of it, half the natural length. It is keeled along the middle, and rounded near the tip.

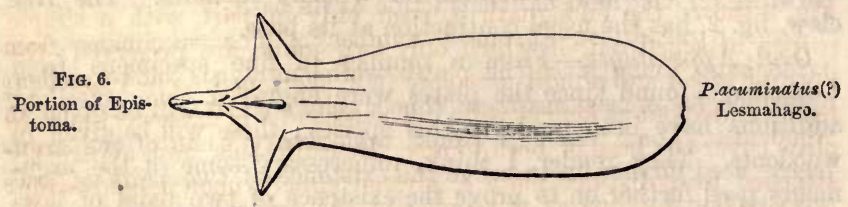

Post-oral Plate (Metastoma), Plate II. fig. 4.-This plate is seen in situ (Plate XV. fig. 1, g), and sometimes occurs of large size, above three inches long. The form is broad-linear above, then contracted at the lower fourth to half the width; this lower portion also has parallel sides, is rounded below, and furnished with a strong central keel, which is probably the line of its attachment to the head. The upper end is deeply bilobed, the lobes elliptical, and the notch very narrow; except the raised keel along the hinder portion the entire plate is flat, the upper portion marked with large and rather obscure semicircular plicæ, which are seen occasionally scattered over all the plate. The elongated'form of this organ, compared with that of the preceding species, corresponds with the longer shape of the head; and it may, perhaps, guide in determining what the form of the carapace of other species was, where only the metastoma is preserved (as in $P$. punctatus, Plates VIII., IX.)

Endognaths (Mandibles, \&c.), Plate XIII. figs. 1-4, Plate XV. fig. 1).-These were omitted by accident from Plate II., but are very important for understanding the structure of Pterygotus, since they appear to indicate that the animal possessed two pairs of 
masticating organs (exclusive of the serrate bases of the swimming feet) as before indicated for $P$. perornatus.

Fig. 1 in Plate XIII. occurs with the fragments of the species, and probably belongs to it, as its form is so elongated or compressed laterally (compared with those figured on Plate VII., which belong to a broad-headed species). The length from the serrate edge $a b$, to the end of the basal process $f$, is no greater than the breadth of the serrate margin $a b$. The general form is broad-falcate, the produced base $f$ squareish, and the insertion of the palpus $c$ very near the serrate margin. This is beset with curved narrow teeth, six or seven of which are distinct in the upper half, and there are numerous smaller ones below. The teeth are articulated with the margin, not mere processes of it, as in the serrate base of the ectngnath.

Figs. 2, 3, 4, however, belong certainly* to $P$. acuminatus. Fig. 3 shows the endognath $a$, seen only in part, with a simple palpus attached $c d$, of which only two joints are preserved; the lowest $c$ broad and almost urceolate (not shortened, as in Plate VII. fig. 9), and about as long as wide. The second $d$ is narrower; minute plicw cover the base of both joints. Beneath this, and apparently attached to a distinct plate $e$, pressed closely upon $a$, and sculptured like it, is another and broader palp, of which only the basal joint is visible; and we must refer to a more perfect specimen (fig. 2, $2 a$ ) for other details of this appendage.

In fig. 2 the endognath $a$ is seen to have a straight edge above, with which the serrate margin forms an obtuse angle (about $120^{\circ}$ ). It is rather suddenly contracted where the teeth begin; they are very oblique, narrow, conical, with a rounded base, and straighter than those of the separate specimen, fig. 1 (the latter is, however, as before said, probably the same species).

The first two joints of the single palpus $c d$ are quite distinct, and $c$ in fig. $2 a$ shows a toothed distal edge, such as is seen in the joints of fig. 4. The second palpus (probably attached to the crushed second maxillary piece) shows obscurely three or perhaps four broad joints at base, $f g$, and then divides into a pair of jointed styles $h i k l$, with tubercular or spinose joints.

Fig. 4 explains this second appendage, it has a broken and obscure basal portion $a$ (which may be part of the serrate basal joint ?) followed by three broad joints $b c d$, the second $(b)$, being

* As Prof. Huxley has described Plate XV. fig. 1, in detail, I need only refer to it here (see p. 22.) It shows, I think, the single and branched palpi; but only one mandibular piece, with teetb, is visible on each side. 
transverse, $c$ and $d$ are nearly square, thickened at their ends, which are ornamented by a crest of spiniferous tubercles. Similar tubercles occur scattered over the surface, and particularly on the outer edges and down the middle. They are also in parts ornamented with minute plicæ parallel to their length. It is not quite certain if $c$ and $d$ are single joints, or two styles parallel to one another and pressed closely together, $d$ is probably a pair of joints, as besides the crested spiny edge, it is furnished with a pair of thick curved spines (like those of the succeeding joints) on each half. e $f g$ in the longer filament are of less diameter, successively shorter, but still thickened at their ends, and furnished with thick curved spines three or four in number; the terminal joint $h, l$, in both filaments is a strong simple curved spine, without a striated surface or any serrations to the border. These terminal joints are not well seen in the large specimen figured in PlateXIV., but the proximal joints are more perfect.

The position given to the palpus in this plate, XIII., with the spiny crests directed forwards, is in conformity with the position of the much larger spines in $P$. punctatus, fig. 9.

It is difficult to prove the existence of two separate maxillary pieces from any of these specimens (Plate XIII. fig. 2, affording the best evidence on this point). But it seems pretty clear that there were two palpi on each side, one simple, the other branched from near its base :- the number of joints before branching cannot be stated with certainty. If only two filaments be admitted on each side, the alternatives will be-a single mandible with a branched palpus,-or two mandibles each with a simple palpus. We have

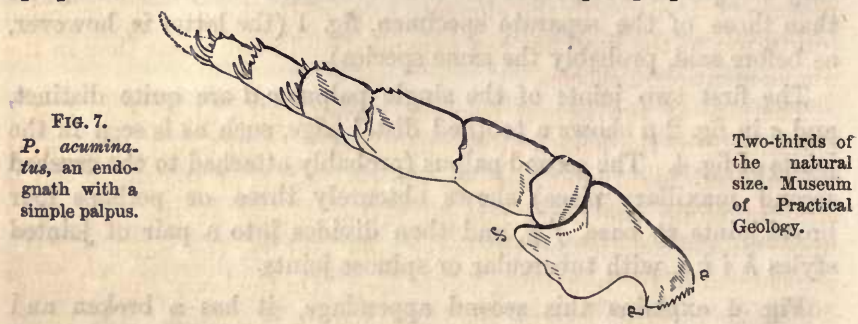

fortunately met lately with a specimen (fig. 7), tolerably perfect, and showing the basal serrate joint, with six simple joints following; the terminal uncinus is lost. There must, therefore, be two jaws, one of which has a simple palp: the other most probably a branched one. 
Lastly, we have a very perfect head of the species, here given, fig. 8, which shows the palps in situ, and there is so strong a

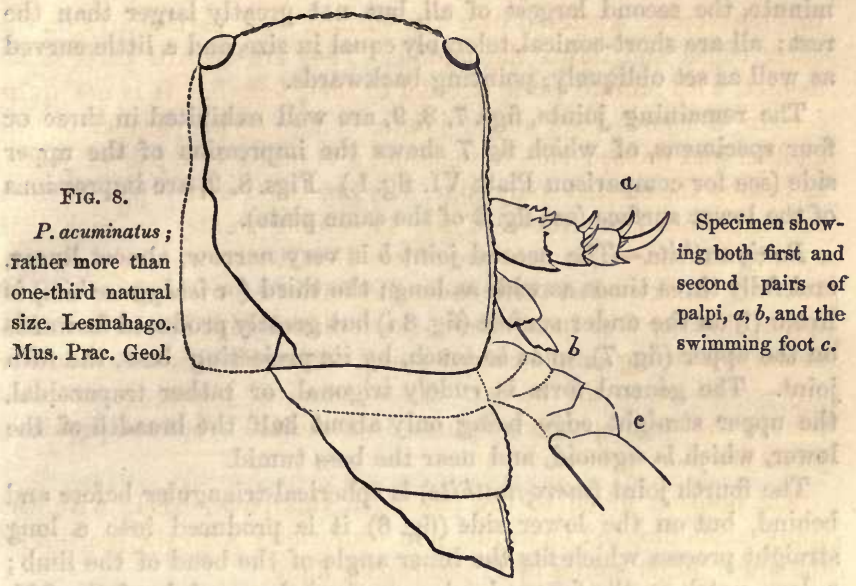

divergence between the front filament $a$, and the lower one $b$, as to render it probable they are not mere branches of the same palp. $b$ is far more imperfect than $a$. $\quad c$, is the swimming foot (ectognath) in situ.

Swimming Feet, figs. 5 to 9.-The great basal joints of these organs are squarer in outline and their serrate edges placed more vertically (i.e. more parallel to the general direction of the plate) than in $P$. bilobus, or $P$. anglicus, Plates I., VII., in order apparently to accommodate their shape to the elongate form of the head, The terminal joints, too, of the limb are less expanded and more linear than in the above-mentioned species.

The size of the largest fragments would give about four inches and a half for the length by two inches and a half broad. The great subquadrate basal joint occupies full two-thirds of the length; it is straight along the inner margin, rather square at the outer and upper angle, rounded on the outer side, and has the notch for the attachment of the remaining joints deep. On the lower third, behind which the breadth lessens, the basal margin is convex. The entire joint is thickened, and most so from the notch obliquely upwards; a ridge runs along the convexity, and another near the straight inner edge. The terminal serrate portion is narrow-oblong, and setvery obliquely on the rhomboidal neck, from which it is obscurely divided. Its upper (forward) margin is strongly arched, and the 
straight serrate edge furnished with fourteen teeth, besides a prominence on the very small basal lobe. The uppermost tooth is minute, the second largest of all, but not greatly larger than the rest; all are short-conical, tolerably equal in size, and a little curved as well as set obliquely, pointing backwards.

The remaining joints, figs. $7,8,9$, are well exhibited in three or four specimens, of which fig. 7 shows the impression of the upper side (see for comparison Plate VI. fig. 1.) Figs. 8, 9, are impressions of the lower surface (see fig. 2 of the same plate).

Basignathite.-The second joint $b$ is very narrow, almost linear, and fully three times as wide as long; the third (or ischygnathite) is linear (?) on the under surface (fig. $8 i$ ) but greatly produced forwards on the upper (fig. 7), so as to touch, by its projecting boss, the fifth joint. The general form is rudely trigonal, or rather trapezoidal, the upper straight edge being only about half the breadth of the lower, which is sigmoid, and near the boss tumid.

The fourth joint (merognathite) is spherical-triangular before and behind, but on the lower side (fig. 8) it is produced into a long straight process which fits the inner angle of the bend of the limb; a deep notch on the forward edge receives the condyle of the fifth joint. The outer or front margin is very convex, almost gibbous, and forms the prominent forward angle of the foot, which is more strongly bent than in any other species.

The fifth joint (carpognathite) is narrow-linear on the upper side, but much broader beneath, about seven lines long by ten or eleven broad, with a rounded boss anteriorly about midway along the joint, and a deep sinus at the hinder edge to admit the great process from the-

Sixth joint (prognathite). This is broad-linear, or oblong, (the sides straight and parallel) not quite twice as long as broad, exclusive of the lobes above and below. The upper lobe is rounded, fitting into the posterior concavity on the margin of the preceding joint, the lower lobes are unequal, the hindermost being largest and most pointed, the forward one rounded and shorter, the notch deep, rather wide and straight edged at the point of attachment of the last joint (d).

(d.) (Dactylognathite.) This is two and a half times as wide as long, contracted at the base, widest above its middle part, and ending in a blunt point. The margin of this and the preceding joint are minutely serrate.

Locality.-Lesmahago, an abundant species. Collected by Mr. R. Slimon. The specimens are all in the Museum of Practical Geology. 


\section{BRITISH FOSSILS.}

\section{Plate I. Fig. 17.}

\section{EURTPTERUS LANCEOLATUS.}

Gen. Char.* Eurypterus, Dekay, 1826. Body as in Pterygotus, with 12 segments, eyes subcentral, antennæ without chelæ.

E. elongatus, postice attenuatus, articulis 12, quorum 10 transversis, penultimo oblongo; caudâ acutâ productâ, ad basin tumidâ.

Srnonym. Himantopterus lanceolatus, SAlter, in Quart. Journ. Geol. Soc., 1. c., p. 28, fig. 5 (tail joint).

Perfect, except the carapace, which, when the plate was engraved, was supposed to have resembled that of $P$. acuminatus. It is, however, almost certainly an Eurypterus, from the elongate-linear candal joint, but the shape of the swimming feet is more linear than usual in the genus. It is here figured because of its association with the Pterygoti in my former notice.

Body two and a half inches long, by three-quarters wide in the broadest part, which is about the fourth segment; from thence it tapers very gradually to the last. The anterior segment is narrow (short), not above one-fifth as long as wide, with its ends recurved; the next, not much broader, is straight posteriorly. The last thoracic ring (sixth) is three and a balf times as wide as long, with the posterior angles a little produced ; from thence the joints are larger and less transverse, the tenth being only half as wide again as long. The penultimate joint is about as long as wide, but narrowed posteriorly.

The terminal joint (telson) is three-quarters of an inch long and only two-tenths wide; it is regularly conical and acute, has a median keel (apparently tumid at the extreme base) nearly all the way down, and also one along each edge.

* For remarks on the generic character of Eurypterus, see pp. 35. 38. It differs from Pterygotus chiefly in the subcentral eyes, but also by the want of the large chelæ to the antennæ.

It is hoped to illustrate this genus in a future monograph, meanwhile the reader is referred to the Quart. Journ. Geol. Soc., vol, xv., for information on the species. 
The sculpture is rather obscure, strong on the anterior half of each segment, and faint over the rest; the borders are smooth.

Swimming F'eet.-These are the only appendages found with the present species; they resemble those of Pterygotus bilobus, and, when laid back, reach the end of the fifth segment. The third joint is very obscure; the fourth trigonal with the longer side outwards, and but little convex; the fifth irregular, its produced outer edge overhanging the oblong penultimate joint.

This latter $(d)$ is about twice and a half as long as wide, rather broadest at the bilobed end, the notch deep; lobes rather acute, the inner much exceeding the outer in size. Terminal palette ovate, its length (measuring from the notch) equal to the penultimate joint without the lobes. Margins minutely crenate.

Locality.-Lesmahago; only one specimen known. (Museum of Practical Geology.) 


\section{BRITISH FOSSILS.}

\section{Plates III. to VII.}

\section{PTERYGOTUS ANGLICUS.}

Spec. Char. P. gigas, 6-8?-pedalis, capite transverso, anticè angustiori truncato, segmentis corporis transversis, penultimo percarinato (subtus carinâ brevi subcentrali), vix expanso, caudâa ovatâ breviapiculat $\hat{a}$, carinâ medianâ paullo elevatâ.

Srnonyms. P. anglicus, Agassiz (1844), Poissons Foss. Vieux Grès Rouge, pl. 1; $\mathrm{M}^{\circ} \mathrm{Cox}$ in Lyell (1855), Elem. Manual, 5th ed. pp. 419, 420 (restored). Salter in Murchison's Siluria, new edition (1859), foss. 21, fig. 1, restored ; Trans. Brit. Assoc., 1856, Rep. Sections, p. 75. Palcocarcinus alatus (Agassiz olim) fide Page, in Trans. Brit. Assoc., 1855, vol. xxiv. Rep. Sections, p. 90.

The liberality of Lord Kinnaird and of the officers of the Watt Institution, Dundee, has placed at our disposal a magnificent series of this well-known species, including most of the fragments from which Agassiz drew up his original description. We have also to thank Colonel James, Director of the Ordnance Survey, and Mr. David Page, of Edinburgh, for their kind co-operation.

Until the carapace, Plate III. fig. 1, was obtained, no very complete notion could be formed of the probable size of the fossil. It was a less elongated species than $P$. acuminatus, but taking the proportions of the head and the widest body rings as a guide, and comparing these with such species as $P$. bilobus, the entire length could not have been less than six, and from the size of the epistoma. and some other parts probably reached eight feet in length! There are no living Crustacea which can match this in bulk.

And it was apparently of considerable thickness, almost cylindrical ; the crust, however, appears to be very thin and paper like, and only thickened where requisite for the attachment of strong muscles, as in the swimming feet; or along the ridges and margins,-the serrated parts of the mouth, \&c.

The carapace, now first described from a young specimen, measures six inches and a half long and fully nine inches wide at the broad base, but narrows considerably towards the front, where it is less than five inches and a half broad. 
Our figure shows it compressed a little obliquely, but, allowing for this, it is not far from the true shape, and it is probable that not much of the margin is lost on the right-hand side, while enough remains of the other to indicate that the outline was somewhat curved. Two other specimens in Lord Kinnaird's cabinet show the curved outline. The eyes are distinctly visible on each side, and are as large as crown pieces.

The head must have been considerably more convex than at present, since in our flattened specimen it is corrugated all over; it is sub-pyramidal in shape, truncate or but slightly arched in front between the eyes, and concave posteriorly. The side margins (so far as visible) and the front are strongly crenate, but not tubercular; the general surface appears smooth or minutely punctate, but not anywhere marked by plicæ. The eyes occupy the outer angles of the head; they are oval, an inch and a half in the largest diameter, and about an inch broad. The lenses are rather large, about eight rows in one-tenth of an inch, and in this pressed specimen are rhomboidal rather than hexagonal, at least in arrangement; this may be due to pressure only.

The entire head, compared with that of $P$. acuminatus, is broad and short, and much narrowed in front, so as to be intermediate in shape between that square-headed species and the forms with semioval carapaces. The eye is much larger in proportion.

Epistoma and Labrum, Plate III. figs. 2-5 (6 ?).-This piece, which is the epistoma or under side of the front of the head, occurs in tolerable plenty, and is the portion formerly supposed to be the carapace itself (see p. 6). From a very perfect and large specimen in the British Museum, a reduced figure (fig. 5) is added, which justifies the inference above drawn as to the great size of the animal. The figured specimen, 2 , is the same as that figured by Agassiz, and is nearly three inches from back to front, but we have other specimens which measure four inches and a half long, and were probably sixteen or eighteen inches wide.

The "seraphim," as the piece is called, is straight or only sinuous in front, but broadly wedge-shaped behind; its extremities are unknown, unless fig. 6 be the lateral termination on one side. It consists of a central arrow-shaped piece and two widely-expanded wings or lateral lobes which project backwards nearly as far as the shaft or central lobe, forming with it the broad salient angle of the posterior margin. These lobes are not, however, united with the shaft but overlap it with thickened edges on each side, giving it an appearance of contraction in the middle; it is, when detached, a 
linear piece, somewhat dilated at the base, convex along the median line, deflexed at the sides, and expanding at the base into a broad arrow-headed plate, the point acute, subtending a variable angle (generally about sixty degrees), and reaching nearly to the front. This portion is divided from the general surface by sutures, but not quite separable. The apex of the central lobe is expanded, rounded, and marked with radiating plaits. As in all other parts of the crust the plicæ which closely cover the surface are transverse and but little curved in front, but become semicircular further back, and then semi-ellipses, and even cones, closely tiling over one another. It is this feather-like arrangement, combined with the shape, which must have suggested the term "seraphim." The extreme margin is smooth. The plicæ on the arrow-headed central piece of the labrum follow the same order from before backwards, and become elongate and prominent along the central ridge, forming tessellæ rather than scales.

Body Joints, Plates IV. and V.-The segments of the thorax and abdomen may easily be arranged in their right order, from comparison with those of the preceding more perfect species. Plate IV.

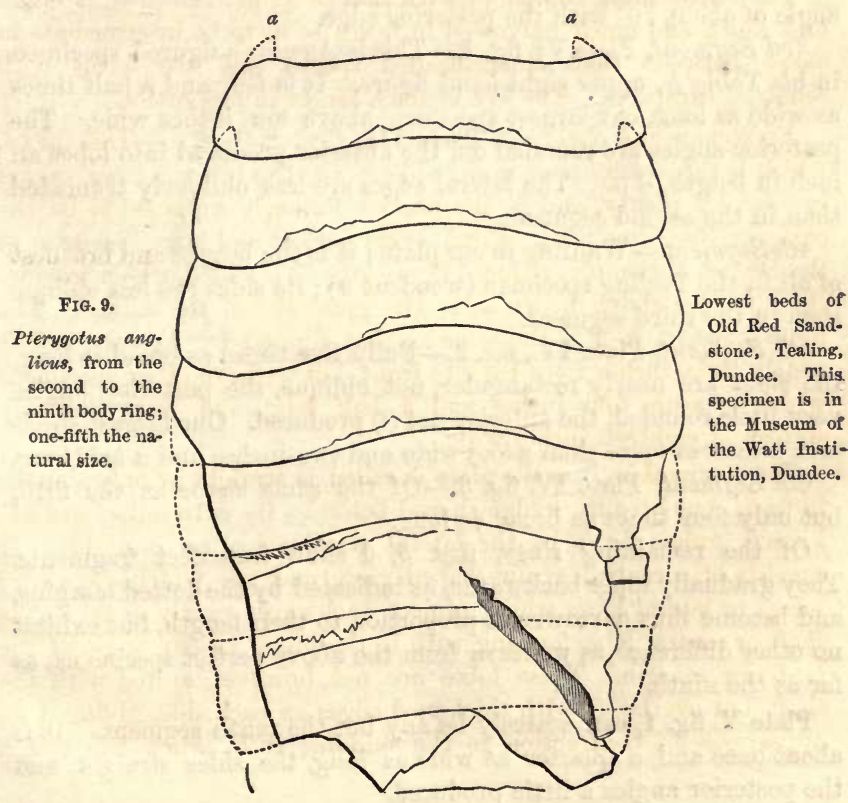


represents all the anterior segments we had observed when the plates were engraved. But since their completion, a cast (agreeing very nearly with the figures in Plate III.) of a fine specimen of the anterior body rings, and nearly a foot wide, has been sent up by our correspondent, Mr. W. Miller of Dundee. It is from a new quarry at Tealing, Forfarshire. The specimen is in the Museum of the Watt Institution, Dundee, and a woodcut, one-fifth the natural size, is given of it in p. 67. From the second to the ninth, the segments are all united, and the anterior ones have slipped a good deal over one another so as not to present quite their full dimensions.

1st Segment.-This appears to be wanting both in the Tealing specimen, and in the specimens figured in Plate IV. It was, probably, narrower than all the rest and had the outer posterior angle much rounded off.

2nd Segment. (Woodcut, No. 9).-This is five times as wide as long, somewhat arched in the middle, and much bent forward at the sides, with indications of lateral processes $a, a$, similar to those in the third segment. The lateral edges are very oblique : forming an angle of about $70^{\circ}$ with the posterior edge.

3rd Segment, Plate VI. fig. 1.-This is Agassiz's figured specimen in his Table A, upper right-hand figure. It is four and a half times as wide as long, our largest specimen above ten inches wide. The posterior angles are rounded off, the anterior produced into lobes an inch in length, $a a$. The lateral edges are less obliquely truncated than in the second segment.

4th Segment.-Wanting in our plate; it is the largest and broadest of all in the Tealing specimen (woodcut 9 ); its sides are less oblique than in the third segment.

5th Segment, Plate IV., fig. 2.-Fully five times as broad as long, the sides are nearly rectangular, not oblique, the posterior angles very little rounded, the anterior not (?) produced. Our largest specimen measures more than a foot wide and two inches and a half long.

6 th Segment, Plate IV. fig. 3.-Of the same shape as the fifth, but only four times as broad as long.

Of the remaining rings, figs. 5, 6 show imperfect fragments. They gradually taper backwards, as indicated by the dotted margins, and become thus narrower in proportion to their length, but exhibit no other difference, as we learn from the above perfect specimens, as far as the ninth.

Plate V. fig. 1, can scarcely be any but the tenth segment. It is about once and a quarter as wide as long, the sides straight, and the posterior angles a little produced. 
The 11th segment, figs. 3,4 , suddenly changes shape, it is half oval, with both ends truncate, and its length is rather more than three-fourths of the width. The base is contracted, the sides curve boldly outwards, and again contract at the produced and hooked posterior angles. The segment is thus much broadest behind. We have both upper and under surfaces, the former is carinated all the way down by a strong median ridge, wider and less prominent at first, then sharply elevated and covered with coarse squamæ. The under side, fig. $3 b$, has no median ridge except for its middle third, and this, which begins by a gentle elevation, ends abruptly rather more than two-thirds down. It is closely covered with large squamæ, and probably indicates the place of the anal opening. The lateral and posterior margins are also bordered with tubercular squamæ, largest and most conspicuous on the sides. Our finest specimen is three inches and three-quarters long, and four inches and a quarter wide behind the middle, where the width is greatest; at its upper end it is only two inches and a quarter broad.

In the same beds, near Forfar, penultimate joints occur, which are probably of the same species, but show a marked difference from those in the plate. An upper and under side is here figured.
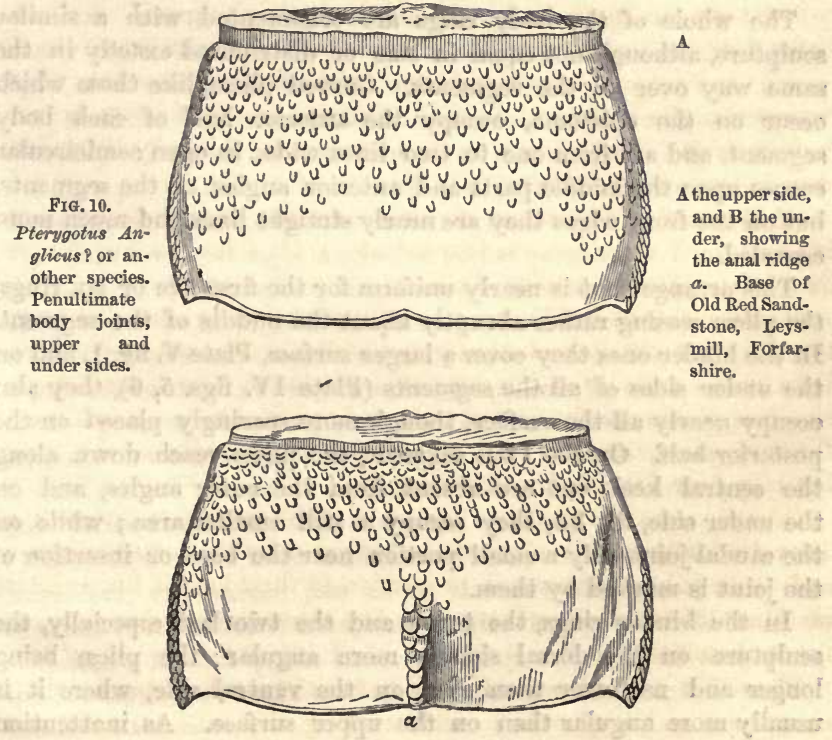
The former is destitute of any carina; on the latter an abbreviated (anal ?) ridge exists, but on the posterior third only (exactly as in $\boldsymbol{P}$. gigas, Plate VIII. figs. 6,7 ). The proportions also of these joints are different from that of the corresponding part in Plate V. figs. 3, 4, being greatly more transverse ; two-thirds as long as wide in fig. 1, and about three-fifths in fig. 2. This proportion is not very different from that of $P$. gigas, though the shape is so different. May these not be differences of sex, instead of indicating a second species? The ridge (a), supposed to be anal, is present in all the species, either subcentrally or on the hinder edge of the segment.

Telson, Plate V., figs. 5, 6.-The tail joint (12th) is a broad oval, contracted at its base of insertion, widest posteriorly below the middle, and shortly apiculate at the tip. It is but little carinate on the dorsal view, fig. 5 , and flat or with a very slight median ridge below fig. 6 . In a specimen six inches long the apiculus does not project half an inch from the general margin, which is squarnate and serrate, but not strongly so. The apiculus itself is not serrated.

\section{Sculpture.}

The whole of the body rings are ornamented with a similar sculpture, although not equal in size or distributed exactly in the same way over all the segments. Curved plicæ, like those which occur on the epistoma, occupy the anterior half of each body segment, and are from one to two lines wide, in open semicircular curves upon the middle parts and anterior angles of the segments, but on the front edges they are nearly straight lines and much more crowded.

This arrangement is nearly uniform for the first five or six rings, the plicæ ceasing rather abruptly about the middle of the segment. In the hinder ones they cover a larger surface, Plate V. fig. 1, and on the under sides of all the segments (Plate IV. figs. 5, 6), they also occupy nearly all the surface, though more sparingly placed on the posterior half. On the 11 th segment, the plicæ reach down along the central keel, but are absent from the outer angles, and on the under side, fig. $3 a$, they occupy a still smaller area; while on the caudal joint only a small portion near the base or insertion of the joint is marked by them.

In the hinder rings, the tenth and the two last especially, the sculpture on the dorsal side is more angular; the plicx being longer and narrower than even on the ventral side, where it is usually more angular than on the upper surface. As inattention 
to this point might mislead in comparing with other species ( $P$. gigas, for instance, Plate VIII.), it is of consequence to note this difference in the ornamentation of different portions.

\section{Appendages.}

Antenno, Plate VI. figs. 4, 6.-They were of great size. Plate VI. fig. 5, shows the largest we have seen, but a somewhat smaller size (fig. 4) is not at all unfrequent. There are four joints, including the free terminal claws.

Of the first articulation only short fragments remain, it is narrower than the second, which is linear, scarcely contracted at either end, and in the largest specimen must have been four inches and a half long and one inch and a quarter broad. The penultimate joint, which is produced into the fixed claw of the chela, is rather suddenly swelled, and increases in width outwards to the insertion of the terminal joint. The produced portion is fully four inches long, rather narrowed at its insertion (so as to be a little fusiform), and thence tapering to the abruptly curved tip, which bends up at a right angle, and is frequently half an inch long and pointed. The opposed free claw is of the same shape, but more equal in breadth, generally longer, fig. 2 , than the other, but sometimes the two are nearly equal (fig. 1). Occasionally the moveable joint is largest, fig. 6 , and overhangs the other considerably.

It is difficult to say which was anterior, but from the curvature probably the free joint was forward, as in our figure. Each half of the forceps similarly armed with about four primary and ten or eleven secondary teeth, three or four between each pair of primaries. These are set on at right angles, or rather pointing a little forward on the fixed finger, but on the moveable claw decidedly backwards. They appear to have been much compressed, and were so long that when the chela was closed they shut side by side like the blades of a pair of shears; and they are placed opposite to one another as if for the purpose of cutting as well as seizing. The middle pairs are longest, sometimes measuring half an inch. The pair next outwards from these are nearest in size, and the outermost and innermost pair (when the latter are present) are smallest.

The shape of the large teeth and of many of the smaller is ovatolanceolate, constructed just above the immediate base, and then expanded into a lancet form, and longitudinally striated, the striæ radiating a little from the base on the forward edge. Some of the smaller teeth are simply conical, and the striation of all is about equally coarse. 
Endognaths, Plate VII. figs. 4 to 7.-There are five or six specimens in the Scotch collections more perfect than that figured by Agassiz (middle left-hand figure), and of larger size, fully four inches and a half long. The palpus, $c d e$, was probably five or six inches in length, and of considerable thickness. Some fragments even indicate a still larger size for the jaw.

The mandible is of an oblong form, the front and back margins nearly parallel. The serrate termination of the lamina scarcely at all expanded into a lobe, and the posterior or basal portion $(p)$ which occupies nearly half the entire length is produced obliquely backwards at a wide angle. This portion is straight in front and only slightly sinuous along the hinder edge, which shows traces here and there of strix perpendicular to the edge, probably due to the insertion of muscular fibres.

The serrate edge is nearly straight and very oblique forming an angle of about $120^{\circ}$ with the front margin. There are about twelve strong teeth, of which the upper six or seven are free, lanceolate, curved, and dilated below, with a constriction as if articulated, and the remainder are connected so as to form ridges upon a thin plate. Minute intermediate ridges occur between these. The posterior angle of the serrate edge is produced a little into a small lobe $b$, covered with deep punctures as if for the insertion of stiff hairs or setæ. The upper edge is not at all expanded or overhanging as in $P$. acuminatus, the teeth starting at once from the upper angle in a line continuous with the front margin (this is not the case with fig. 7 , in which there is an overhanging lobe).

The general surface of the mandible is covered with obscure plicæ, which become distinct and large along the front margin, which is thickened; the rest of the lamina is rather flat, the base is thin and almost membranous at the edge.

The palpus is long and stout, directed straight outwards, and consisting of at least five, and probably more joints, of which the basal one $(c)$ is more than twice as wide as long. The next $(d)$ unceolate and thickened at the distal end, rather longer than wide. The third takes an elongate form, but is still broad, and its end thickened and somewhat bilobed $(e)$. The next $(f)$ is still longer in proportion, swelled, and a little crenulate or spiny at the tip (compare with Plate IX. fig. 7.) We have no more joints, but in Agassiz's figure the succeeding joint, the fifth, is clearly shown.

The surfaces of all these joints are covered with transverse plicæ.

Maxilla? fig. 7. - It is probable that fig. 7 indicates a second pair of endognaths, since the proportions of the plate are so different, fig. 7 being considerably longer before the insertion of the palpu 
than fig. 4, and having an overhanging rounded lobe in front above the insertion of the teeth. Some specimens agreeing with this in proportion have the basal lobe of the palpi broader.

Swimming Feet (Ectognaths), Plate VI. figs. 1 to 3, Plate VII. figs. 1 to 3.-The large basal joints of these organs are among the most characteristic parts of Pterygotus, and were at first supposed to be the mandibles or maxillæ, as they are most frequently found detached from the other joints of the limb. Agassiz figured a portion as a part of the tail flap, and we reproduce his original specimen, Plate VII. fig. 3. It will be best to describe this portion first. It is the-

Basal Joint (Coxognathite), Plate VII. figs. 1 to 3.-These are six inches and a half and even seven inches long! and not less than three inches broad, gently curved (flask-shaped) convex, with the outer or forward edge thickened, and concave on the inner or hinder side, with the large basal portion almost orbicular, but narrowing into the neck, and the terminal lobe again somewhat broadened and subrhomboidal, with the serrate border placed obliquely to the general direction of the entire joint.

The teeth are twelve in number, gradually longer from behind forwards, the first often five lines long, and three broad at base. They are conical, a little curved and grooved down the middle, but not at all articulated to the base. Being set on a straight margin and regularly increasing in size forwards, they present a serrate edge along the points, rounded off a little behind into a very small basal lobe $b$. There are the same number of teeth in young as in mature specimens.

Large tubercular plicæ cover the whole surface, except the inner thin margin of the terminal lobe, and these are concave everywhere to the border, except towards the inferior angle behind the attachment of the foot (Plate VII. fig. $2 c$ ), where they present their convex side to the margin; and hence this portion is easy to identify, even in fragments.

The limb beyond the large basal joint is very suddenly contracted. The point of attachment for these is very conspicuous, as a deep notch in the foliaceous base, about half way up on the outer side, and from this point to the upper angle of the serrate tip is the line of greatest convexity. The basal edge is rounded below, but angular where it joins the inner margin.

The other joints of the limb are represented in Plate VI. figs. 1, 2 ; and we are able to give a more complete account of them in this than in any other species; fig. 1 represents the upper and fig. 2 the lower surface of the limb. 
b. The second joint (basignathite) is transverse, more than twice as wide as long, and furnished anteriorly with a large rounded boss occupying the exterior third of the joint (see fig. 2), broken off from the limb and left attached to the coxal segment in fig. 1 at' $b^{*}$. Its hinder articulating border is somewhat concave, its inferior angle rounded and produced.

$i$. The following joint is subtrigonal with rounded sides on the upper surface, and with an obtuse angle projecting over the centre of the following joint, but on the under surface it is rhomboidal, more than twice as wide as long, and with the distal and proximal edges nearly parallel (ischygnathite.)

$m$. The fourth joint is trigonal, the outer edges wide, convex, and forming the angle of the limb, terminating in a rounded process extending half way down the following joint. On the upper side, fig. 1, the distal articulating edge is produced; on the under side, fig. 2 , deeply emarginate to receive a process from the fifth joint c a. The inner side of this joint (merognathite), which is rather a difficult one to describe, is much narrowed, and terminates in an acute angle opposed to the wide basis of the outer margin.

ca. Of the next joint (carpognathite) it is equally difficult to give a clear idea ; its shape is irregular. It is somewhat crescentic on the upper surface, its outer side much the longer, and its distal margin oblique, nearly straight for the greater part of its length, but the outer angle truncated, and the inner notched. On the under side it follows the shape of the preceding joint, and has a prominent median process above to fit into the notch of it. Its distal margin, too, on this surface is sinuous, and less oblique than on the upper side.

$p$. (and fig. 3.) The penultimate joint (prognathite) is flattened (to form with the last, $d$, a swimming palette.) Our largest specimen measures two and a half inches in length, by one and a half at its broadest part. It is somewhat quadrangular, but one-third brcader below than above. Its outer edge is perfectly straight, longer than the inner, and terminating above as a narrow rounded lobe, behind which is a deep emargination, continuous with the curved outline of the inner margin. The latter is produced inferiorly into a subtriangular lobe $(3 \mathrm{c})$, broader than the superior process of the outer margin above described. The rest of the inferior border $(d)$ is nearly straight, and forms almost a right angle with the straight outer margin.

d. The terminal palette (dactylognathite) is broadly ovate, twice as long as broad, its apex rounded, its outer margin quite regular; the inner a little flattened above, leaving room for the play of the palette against the penultimate joint, as in the swimming crabs. 
The surface of the great basal joint is nearly covered with large plicæ or squamæ, the convexity of which is outwards over the lower and hinder half, and inwards along the front margin. The other joints are more strongly ornamented, the plicæ coarsest on the exterior margin; on the three or four terminal joints they are only obscurely visible except on the margin.

The margins of at least the two last segments are beautifully crenulated all round, with appressed serratures; these are largest at the apex and inner edge of the terminal swimming palette.

Metastoma, Plate VI. fig. 7.-The only piece which remains to be described is this large oval plate, deeply notched at the broader anterior extremity, regularly rounded on the sides, and very slightly truncate at the posterior end. These plates are sometimes four inches long and three broad, and are oval, the greatest width being less than half way from the notched end; flat on one side and of but slight convexity on the other, except at a point on the median line about one-third distant from the smaller end, where there is a prominence (probably the point of insertion). They are more covered with sculpture than in the species previously described.

Fig. 11.

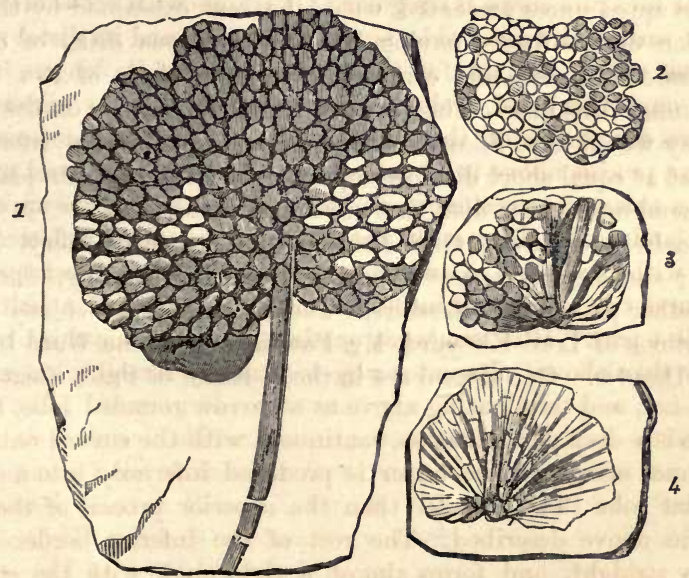

Packets of eggs or ovisacs (Parka decipiens). No. 1 is from a specimen in the cabinet of Lord Kinnaird.

(Parka decipiens, Fleming. See Siluria, 2nd ed. chap. 10.) These occur too often with Pterygotus not to be suspected as part of its 
structure, and are found with the $P$. anglicus in Forfarshire and Perthshire; also, with $P$. ludensis at Kidderminster, and $P$. problematicus at Ludlow.

Four fine specimens lent us by Dr. Balfour, of the Botanic Gardens, Edinburgh, show clearly that the bodies in question cannot be referred to seed vessels or receptacles, or indeed any other portions of a plant. There is no trace of a style on any of the carpels of the supposed fruit, nor of a leafy involucrum below it.

They are rounded masses, one to two inches broad, and composed of numerous oval or hexagonal areæ, a line or two in diameter, which are now flat, but appear as if they had been compressed from a nearly globular shape, not crowded over each othcr, but arranged in nearly one plane so as to form a disk.

A long pedicle, fully a line broad, is attached near the centre of the disk so formed, or sometimes nearer its margin; and from the point of attachment the surface of the general enclosing membrane is radiated or plaited to the margin, but only on one side of the disk. The plaits are depressed lines, dichotomising and inosculating a little, but seem to have no reference whatever to the arrangement of the ova, which they cross without being interfered with by them.

The appearances presented would be best explained by the supposition of the fossils having been membranous disks of only a moderate thickness, and containing a single series of ova in the thickness of the disk. They are not superimposed one on the other, as they would have been had they been contained in a pyriform sac, but set at equal short distances apart, as if kept in their places by the membrane of the disk that enveloped them.

Localities. - Lower OLD ReD SANDstone, Balruddery, Perthshire; and Leysmill near Arbroath, Reswallie, Tealing, Carmylie, and other places in Forfarshire. The specimens are chiefly in the collections of Lord Kinnaird, Mr. Powrie, and of the Watt Institution, Dundee. One or two are in the Museum of Pract. Geology. 


\title{
BRITISH FOSSILS.
}

\author{
Plate XIV. Figs. 1 to 13 ; Plate IX. Fig. 18 ?; \\ Plate XII. Figs. $]$ to 5 (and 6 ?).
}

\section{P. LUDENSIS.}

P. major, segmentis corporis omnibus transversis, decimo bis quam longo latiore, penultimo subquadrato vix expanso, supra carinâ percurrenti; caudâ ovali breviapiculatâ obtusicarinatâ : superficie toto plicis curvatis simplicibus ornato.

Under this name I would now describe, with but little doubt of its specific distinction, the fragments of a fine species very abundant indeed in the transition beds of Ludlow, shown as they are in the railway cutting near that town. All the specimens are in the cabinets of Mr. Lightbody and his son. The same species is found at Trimpley near Kidderminster, and we are indebted to Mr. G. E Roberts for the means of illustrating some points not clear in the specimens at Ludlow.

The materials consist of several body rings of large size, Plate XIV. fig. 2, 3, 4, 11; a fragment of the caudal joint, fig. 12; the epistoma; a specimen, fig. 1 , showing nearly all the body joints and telson in position, but a good deal obliterated; the serrate bases of the swimming feet, figs. 8,9 ; mandibles with palpi, figs. $5,6,7$; antennæ, fig. 10 ; and to these must be added certain figures in Plate XII., showing the antennæ, figs. 1, 2; the post-oral plate, fig. 3 ; the bilobed (abdominal ?) appendages, figs. 4, 5; and possibly the portion of the swimming foot, fig. 6 ; together with the imperfect caudal joint in Plate IX. fig. 18. The two last may, however belong to $P$.gigas, a species very nearly allied, and to which for some time I believed the whole of the specimens referable. Again, there is so much resemblance in certain points to the Scotch species, $P$. anglicus, that it requires nice discrimination to separate the three forms. The characters of the antennæ, and also of the caudal joint, will, I think, be sufficient. And if subsequent observation 
should tend to show that this "Tilestone" species is the opposite sex of the $P$. gigas, it will still have been worth while provisionally to separate them.

Body Joints.-The complete specimen, Plate XIV. fig. 1, shows that the body was not greatly elongated, the segments being all rather widely transverse, the seventh, for instance, being fully four and $a$ half times as wide as long; the eighth and ninth are gradually narrower, but the tenth still shows a width two and a half times greater than the length, while in $P$. anglicus the corresponding joint appears so have been no more than one and a half times the length (see Plate V. fig. 1).

The penultimate joint is squareish, or rather inversely conical, not much expanded below. It is about one-fourth wider than long (as in $P$. anglicus), and this at the hinder part only. A strong central keel runs down its whole length, covered with large squamæ, and the margins are similarly ornamented.

If the caudal joint, Plate IX. fig. 18, be of this species, it has lost the terminal apiculus. It is nearly elliptical, the base truncated. It is fully four inches long.

The sculpture of the body rings consists of open semicircular squamr, flattened along the anterior border and more convex behind, occupying the anterior half of the segment in the front rings, and more in the hinder ones, till, in the eighth and ninth, they nearly cover the segment. On the sides they are more elongate, and, as in other species ( $P$. gigas, for instance, Plate VIII. fig. 5), those on the upper side are more elongate and pointed than those on the lower. All the plicæ are prominent and sharp-edged. There are very few intermediate ones, Plate XIV. figs. 2, 11, but the surface of the cuticle is generally roughened between the plicæ. Some segments show the plicæ very large, fig. 2 , and must have been at least fourteen inches broad. Other specimens in the Ludlow Museum show four or five rings overlapping, and some are subcylindrical, and with sharp edges. The caudal joint (twelfth) is broad-oval and shortly apiculate, less abruptly so than in $P$. anglicus, which, too, has a less regularly oval form, the greatest breadth being below the middle. It is marked all the way down dorsally by a strong carina covered with broad squamæ, and the edges are also squamate, in two or three rows. In the specimen from Trimpley, fig. 12, the sides are marked by oblique radiating interrupted lines.

Epistoma and Labrum (not figured).-This plate is as large as that of $P$. anglicus, Plate III., and nearly like in all its parts to it. 
Antennce, Plate XII. figs. 1, 2; Plate XIV. fig. 10.-These resemble in general form those of $P$. anglicus, but have a more slender shaft, tapering more quickly, and narrower and more conical teeth. The teeth are intermediate in form between the species above mentioned and $P$. problematicus, the central one being long-lanceolate, and the secondaries narrow, conical, and with coarse striæ. The base of the fixed claw, Plate XIV. fig. 10, is furnished with a set of stiff spines, as in $P$. problematicus, but the whole chela is proportionably much shorter.

Endognaths, Plate XIV. figs. 5, 6, 7.-Of these there seem to be two pairs, as in P.anglicus, and of very similar shape. The one pair (fig. 5) resembles in all respects Plate VII. fig. 5, except that it has the teeth more bent down. The joints of the palpus, like those of $P$. gigas, have a squamose ridge along each side, and the ends of the joints are bilobed. The second joint is three and a quarter times as long as broad. This is nearly the proportion in $P$. anglicus, where it is three times the breadth.

The other pair of jaws (fig. 7) have their anterior margin more curved, and the teeth set on a more convex edge than in $P$. anglicus. The first tooth $a$ is set more backward, thick, and curved at its base, and all are more curved than in the Scotch species.

The Post-oral Plate (Plate XII. fig. 3) may belong either to this or to $P$. gigas.

Base of Swimming Foot, Plate XIV. figs. 8, 9.-These portions are very characteristic in all the species. In this the shape most nearly resembles that of $P$. gigas, Plate IX. fig. 8, and the teeth are short and blunt, as in that species, but the neck is shorter. From $P$. anglicus, the shorter form, the short neck, blunt teeth, and convex upper lobe $(a)$ overhanging the teeth, distinguish it; but the sculpture raised into thick, prominent, boss-like plicæ is almost identical. The lower edge is tuberculate, and even spinous; our figure does not show this part. A little comparison of this specimen with Plate VII. fig. 2, will show that both in the upper or front edge (a), and on the lower or hinder edge (b), the terminal lobe is more prominent in $P$. ludensis. We do not know the other joints, unless Plate XII. fig. 6 , be the penultimate one. It has exactly the form of that of $P$.gigas.

Thoracic? Appendages? Plate XII. figs.4, 5.-The nature of these is not understood, nor do these specimens show the characteristic irregular base. But they differ specifically both from the similar appendages in P. problematicus, Plate XII. fig. 16, and from the more perfect one figured in Plate XIII. fig. 16, by their deep ter[1.] 
minal notch. The outer edges are thickened, and the substance of the whole appendage is thick. The lateral plicæ run down in oblique rows on the inner (?) surface, becoming more and more linear, till they become straight lines like the pennæ of a feather; and on the outer side, impressed distant converging striæ cut up, as it were, the whole surface into narrow bands, the terminations of these bands being serrated projections in $P$. problematicus, but in this species they come to an even edge on the notched border.

Ovisacs (?), Plate XIV. figs. 13, 13*.-The egg-packets (Parka), found in plenty with this species at Trimpley, show the membranous veil in several cases. The ova are of considerable size, generally oval, and placed a little apart in the younger packets, fig 13, but they become hexagonal or polygonal, from mutual pressure, in the older ones, figs. 13*.

Localities.-Base of the OLd RED SANDSTONE, at Ludlow Railway Station (abundant); at Trimpley, north of Bewdley, associated with Pteraspis Banksii. (Mr. G. E. Roberts' Cabinet.) 


\section{B RITISH FOSSILS.}

\section{Plates VIII aNd IX.}

PTERTGOTUS GIGAS.

Spec. Char. P. maximus, 6-7 pedalis (?), capite haud truncato, semiovato; oculis anticis rotundis; segmentis corporis ut in $P$. anglico,-penultimo expanso emarginato, insuper plano, subtûs carinâ medianâ posticâ : caudâ magnâ ovali, cristâ elevatâ centrali (apice emarginato?).

Srnonym. P. problematicus, Banks, Quart. Journ. Geol. Soc., vol. xii. pp. 93 , \&c.

For some years a large Pterygotus has been known in the beds of Downton Sandstone (Uppermost Ludlow Rock), worked for building purposes at Kington, Herefordshire, and a description of many of its parts was given by Mr. R. Banks, of Ridgbourne, in the Quarterly Journal of the Geological Society for 1856. Since his description was written, he has continued to labour assiduously to collect the fragments, and has been fortunate enough to discover nearly all the parts of this fine species. He has generously placed these fragile specimens in our hands, and presented a series of excellent drawings, which were formerly exhibited at the Geological Society.* In the paper quoted above, the fragments were all considered to belong to the $P$. problematicus of Agassiz, a species for which there is unfortunately very scanty material, but which, as originally described (see below, Plate XII.) is a Ludlow Rock species identical with one of the Kington fossils, but not apparently with the principal and largest of them, here described, and which in many respects is very like $P$. anglicus.

$P$. gigas has, in common with the latter species, the open scalelike sculpture on the body rings, and the thick tubercular scales on their margin; the shape of the epistome and head is very similar, but the latter is rounded and not truncate in front. The penultimate body ring is wider and has a short keel on the upper surface only (while $P$. anglicus has one on both sides above and below), ana

* See Quart. Journ. as above, note to p. 97. It ought to have been named after him, had not a much smaller Kington species been already distinguished by his name. 
the tail joint or telson appears to be emarginate instead of pointed. But if this character should be deceptive, there can be no doubt of the specific difference, since this joint is furnished with a most remarkable elevated crest or ridge nearly half an inch high, which is quite absent in the Scotch species.

As the fragments indicate a species of the largest size, the above specific name will not be inappropriate. The size of the chelate antennæ exceeds that of any known species.

There are two species in the Kington beds, $P$. gigas and $P$. problematicus, and it was of course possible that some of the parts assigned to the former might belong to the latter species. The subsequent discovery of nearly all the parts of $P$. problematicus shows that in this instance the fragments have been rightly collocated.

Head or Carapace, Plate VIII. fig. 1.-Nearly semioval, convex, the width three inches and three quarters at the broad base, probably greater than the length. The specimen being imperfect behind, the true length is not known, but the portion preserved is three inches and a quarter long. The eyes are very large, three quarters of an inch long, oval and prominent beyond the margin. They are placed very near the anterior end, and the space between them on the margin is about an inch and three quarters, while between the convex inner edges of the eyes it is about an inch and a half. The anterior border is arched and very slightly angular in front, with a crenulate edge. The sides are convex (their margin not visible).

In the centre of the carapace, and forming an equilateral triangle with the eyes, is an elongate tubercle. The general surface appears somewhat rugose.

Epistoma, fig. 2.-The proportions of this plate and its sculpture are very like those of $P$. anglicus; and the specimen figured indicates this part to be quite as large as that in Plate III. fig. 7. The plice on the upper or front portion (a) are crowded, and but slightly curved; those further back are semicircular or even semioval, while thcse near the apex of the side lobes are narrower and pointed as in the cognate species. Similar but smaller plicæ occur down the centre lobe, which does not appear to have prominent elongate scales, nor is it convex as it is in $P$. anglicus. Its base $c$ is broad and spear-shaped.

Body Rings.-The anterior body rings, fig. 3, bear the squamæ only on their front half, and these are less curved and less crowded than in the corresponding segments of $P$. anglicus. The edge of the plicæ is thickened. Figs 4 and 5 must represent large segments 
from a portion of the body further back than fig. 3 , for the squamæ cover the whole lower surface of the segment (fig. 5), and the greater part of the upper side (fig. 4). They are greatly more couvex than in the Scotch species, the posterior ones especially being parabolic or even pointed in form, frequently three-tenths of an inch long and broad. Fig. 5 shows the closely squamate lateral edges of the segment, which are convex and rounded in the forward portion and sharply keeled behind. The front margin in both of these segments is contracted, for articulation with the previous joint, and has a broad groove running along its whole length. The hinder angles are a little produced.

Penultimate segment, figs. 6, 7, 8, 9, and Plate IX. fig. 15.-This joint is much wider than long, in the proportion of four inches and a half to two inches and a half; some specimens must have been fully five inches long, and therefore nine or ten broad. The segment is widest and flattest at the hinder end, the margins are conipressed and keeled, except at the thickened and contracted base, and the angles (fig. 9) pointed and produced. The upper surface (fig. 7) is gently convex, but without any ridge, while the lower (?) fig. 6 has a short thick keel extending half way up. It terminates on the hinder margin of the segment, which is rather deeply notched at this point. The surface is thickly covered with plic:, both above and below, but they are much more prominent on the lower (keeled) surface than on the other, where they are mere surface markings and often obliterated. They cover the whole of the segment, but are less thickly placed towards the hinder margin, at least on the under side (fig. 6). The margin itself is tubercular.

The squamate keeled lateral borders are ornamented with several (about four or five) rows of oblique thick plicæ, more prominent and larger on the lower side ; these are continued from about the anterior fourth of the segment, where the keel commences, to the pointed hinder angle. Similar, but still larger, plicæ cover the central keel, Plate IX. fig. 15a, and numerous shallow folds run obliquely backwards from the sides to the keel.

Telson or Tail-Joint, Plate IX. figs. 16, 17.-The dimensions of this joint give the best indication of the size to which the species grew; its length was full five inches and the width four and a half. The largest specimens of this part in P. anglicus, Plate V. fig. 5, are rather longer but narrower. The general shape was that of a broad and pretty regular oval, but truncated at the base, and emarginate at the apex.* The under side, fig. $15 b$, is flat, except

* Plate IX. fig. 15, is the only specimen which shows the apex. Perhaps there may have been a short central apiculus, as in $P$. anglicus. 
at the origin of the joint, while it is somewhat convex; the median line is even concave. Oblique folds or lines, like those on the penultimate segment, occur on the forward half. The upper side is also flattened, but furnished along its whole length with a great central keel, rather thick at its origin, but becoming narrower and more elevated (six-tenths of an inch high in the centre), and then decreasing towards the tip.

Sculpture as in the preceding segment. The blunt ridge of the central keel is covered with small squamate plates, and the margins have four or five rows of oblique elongate ones. The general surface is bare of plic:e, except near the base, where they are numerous and prominent both on the upper and under sides.

\section{Appendages.}

Chelate Antenno,, Plate IX. figs. 1, 3.-Fragments only are yet found ; the large base of the fixed claw, fig. 1 , is about five inches long to the first tooth (in the largest $P$. anglicus it is not more than three inches and a quarter), and one inch ten lines broad (nearly of equal breadth throughout). The articulating edge ( $a)$ is long and oblique, the joint narrowing considerably into the serrate claw. Of this portion $(b)$ there is but little preserved, but it shows the chela to have had broad (probably subovate) cutting teeth, as well as numerous close set smaller ones. These last are short-conical near the base of the fixed claw, and coarsely striated parallel to their sides, the striæ branching from above downwards. Further out (as shown in the separate specimen, fig. 2 , which may be the free claw) the smaller teeth are lanceolate and narrow, and the striæ parallel. These striæ are very closely set, much more so than in any other species. These teeth appear to have been irregular in size, and much crowded; a third specimen (fig. 3) shows three kinds,- the small lanceolate one $a$, larger subovate secondary ones $b$, and one a great striate tooth $c$, * apparently the median one (see Plate VI. fig. 5), which is coarsely ribbed, and is besides serrate on the inner edge.

The endognath has somewhat broader and shorter teeth than that figured in Plate VII.; and the second maxillary piece is more curved anteriorly. Mr. Banks' cabinet contains both.

Of the palpi (Plate IX. fig. 5-7) only fragments are left. Fig. 5 shows four joints connected, but all compressed in a direction perpendicular to their length. Their diameter is half an inch, and

* A similar tooth (?) has been figured in P. problematicus. See Quart. Geol. Journal, vol viii. pl. 21. fig. $2 b$. 
their proportions may be compared with those shown in Piate VII. fig. 4. The second joint $d$ is rather longer, and the third $e$ not quite so.long as in $P$. anglicus. The other figured fragments are less distorted; fig. 6 shows the fourth joint fully one inch and a half long, with the tip expanded and bilobed. In fig. 7, one of the lobes bears a fringe of spines. All the joints show elongate squamæ on their outer side.

Swimming Foot, Plate IX. fig. 4-9. - The great basal joint, fig. 8, with its serrated tip, closely resembles in form and sculpture that figured in Plate VII., the chief difference being the greater width of the foliaceous base, and the more backward position of the notch at the point of attachment for the succeeding joints. The serrate terminal lobe, figs. 4 and 9 , has broad stout teeth, as usual, thirteen in number, slightly curved, the uppermost broader and shorter than the rest, the lowest $b$ a rounded lobe as broad as the two preceding teeth taken together. The teeth are shorter than in $P$. anglicus, especially the upper ones, so that the outline of the serrate edge is more curved. The perfect specimen is only three inches and a half long by two and three-quarters broad, but fragments. indicate a size equal to the largest specimens of the Scotch species.

Of the other joints of the swimming foot only two or three specimens (fig. 10-12) have occurred. Fig. 10 shows the upper surface of the right-hand swimming foot, with two complete joints; the fourth $(m)$ and fifth $(c a)$, with a portion of the great penultimate joint $p^{*}$. The latter joint is better shown in another fragment, fig. 10, which is in close juxtaposition, and has a fragment. of the fifth joint $c a$ attached to it.

The fourth and fifth joints closely resemble those of $P$. anglicus (see Plate VI.), but the form of the penultimate or propodite is as usual characteristic. It is oblong, two inches and a half in length by one and a half broad, and is but little broader at one end than the other. The upper or proximal end is deeply bilobed, as in P.punctatus, the lobes being apparently equally prominent, and the distal or outer end is trilobed; this is partly seen in fig. 10, but much better in fig. 11, where the outer lobe $a$ is pointed and prominent, the middle one rounded and shallow, and the inner $c$ truncate: the last forms nearly a straight line ending in a sharp angle against the straight inner margin.

Both outer and inner margins of the penultimate joint are serrate with elongate appressed squamæ, and the surface of the preceding joints (the fourth especially) has close and rather elongate plicæ. 
Of the terminal palette we have no trace; its probable shape is given in the dotted outline.

Only the metastoma, fig. 13, remains to be described. It is greatly like that of $P$. anglicus, Plate VI., and chiefly differs in the more contracted base, and large open plicæ of the surface. The notch is somewhat deeper. It may have been smooth over the hinder portion, as in Plate XII. fig. 3, which is the same or a closely allied species, and may be noticed here, though possibly it belongs to $P$. ludensis, above described.

Plate XII. fig. 3.-This post-oral plate, in its anterior portion, a good deal resembles that figured in Plate IX., the notch being a little less deep only. The shape is much more elongate than in $P$. anglicus, the length being as seven to four ; the width is greatest at the anterior third, and the general shape ovate. The plicæ are large and open, and are confined to the anterior portion about the notch.

The basal joint of the swimming foot (fig. 6), found at the same locality, is in almost every respect like that of $P$. gigas, having the teeth broad and short.

Locality.-Downton Sandstone (UPPERMOST LUDLOW Rock) of Kington, Herefordshire. (Cabinet of Mr. R. Banks, of that place.) Some specimens, presented by that gentleman, are in the Museum of Practical Geology. Plate XII. figs. 3, 6 are also specimens in the Museum, collected by Mr. A. Marston, of Ludlow. They were found at the Ludlow Railway Bridge, in the passage beds at the base of the Old Red Sandstone. 


\title{
BRITISH FOSSILS.
}

\author{
Plate XII. Figs. 7-16, 20, 21 ; AND Plate XIV. \\ FIGS. 16-18.
}

\section{P. PROBLEMATICOS.}

P. magnus, segmentis corporis ornatissimis,-plicis minutis creberrimis inter majores mixtis (segmento ultimo transverso, nec expanso, subtûs cariná brevi medianâ ?): antennis dentibus longis, rectis, remotis.

Srnoxyar. P. problematicus, AGass., in Sil. Syst. (1839), p. 606, pl. 4. figs. 4, 5 (? Sphagodus pristodontus, AG., tooth only, ib.fig. 6). StrickLAND and SAlter, Quart. Journ. Geol. Soc., vol. viii. pl. 21. figs. 1, 2 ; Siluria, 2nd ed. pl. 19. figs. 4-6.

As this is the principal, if not the only species in the true Upper Ludlow Rock which has the usual semicircular ornamental plicæ, it is to this that the name problematicus should be given, and, fortunately, on one of the minute original fragments figured in the "Silurian System," the small intermediate plicæ are to be seen marking the species more definitely.

The large chela, figured as above under this name, by the late Mr. Strickland and myself, proves to be really an appendage of this same species, at least it is always associated with it in the same bed. Again, the antennary portions, fragments of body rings, bases of the swimming feet, post-oral plate, \&c., figured on Plate XII., are all found in the Whitcliffe, Ludlow, or other localities of the Upper Ludlow Rock, and clearly differ from the corresponding parts in $P$. punctatus, the only other large species occurring with them, as well as from those just described, which are characteristic of the beds of passage above the top of the Ludlow series. P.problematicus may now, therefore, be considered an established species, and the cabinets of our Ludlow friends, Messrs. Cocking and Marston, have furnished many of the materials. It occurs, too, in plenty, as Mr. Lightbody's researches show, in the transition beds beneath the Old Red Sandstone, Plate XIV.; and Mr. J. Harley, to whom we are 
indebted for much valuable help, has been fortunate enough to detect its fragments far up in the cornstones of the Old Red itself, a higher limit than the genus had been known before to attain.

[If the large fragments from the transition beds above quoted, and figured on Plate XIV., be of the same species, as the sculpture indicates, the body segments attained a very large size, nearly three inches from back to front. As it is possible these may belong to a different species, I will describe these portions first.

Carapace(?), Plate XIV. fig. 16.-A fragment, three inches by two and a half, has the surface sculptured, unlike the body rings, i.e., much more finely marked, and without the regular increase in size and curve of the plicæ backwards. The anterior ones are nearly as much bent as the hinder ones though smaller-all are but slightly prominent, and are covered by numerous smaller plicæ.

Body Rings, Plate XIV. fig. 17.-One of the broad abdominal rings, two inches and three quarters from back to front: the articulating front margin is rather deeply concave, and its edge is obscurely striate longitudinally (like fig. 3 ). The plicæ are very numerous and close-set, not so large as in $P$. anglicus, or so straight. on the forward edge, where, however, they are very closely packed. They are more open posteriorly, and cover more than half the segment, interspersed with very numerous minute semicircular plaits.

Another piece (fig. 14) is here considered as belonging to this species, but it only shows the interspersed plicæ over part of the surface : and it quite possibly belongs to $P$. ludensis, or even to a new species.

Penultimate Joint, Plate XIV. fig. 18.-Of this we have only the lower surface; and as the plicæ are restricted to the upper portions, and only a few small ones are interspersed, it is possibly not $P$. problematicus, but of the same species as fig. 15, mentioned above. The width is greater than that of the same joint in $P$. anglicus or $P$. ludensis, being three inches and a half, while the length is only two and a quarter, (or as fourteen to nine,) which is. about the proportion in $P$. gigas. The joint is not expanded posteriorly as in that species, and the plicæ are semicircular, not pointed, on the lower side.]

In the true Ludlow rock but few body joints bave been met with, the two best are figured from Mr. J. Harley's collection, viz., Plate XII. fig. 20, must be one of the thoracic rings, and fig. 21, 
probably the tenth or last but two of the segments. Both show the minute interspersed plicæ very clearly, and these small plicæ extend over nearly all the segment, while the larger ones are confined to the anterior half.

Telson, as yet unknown, as also is the epistomian plate.

Antenno, Plate XII. figs. 7-10.-Fig. 10 is most probably part of the stem, and shows the large and small plicæ in perfection. Figs. 7 to 9 , the large characteristic chelæ, which can scarcely be confounded with any other species, the teeth being so much elongated. Fig. 7 is the fixed claw, with a widely expanded and largely dentate base.* The shaft is parallel-sided (not tapering as in P. ludensis), and the teeth long-lanceolate, the large one being much longer than the diameter of the shaft, (in fig. 7, fully three-quarters of an inch long, the secondaries three or four on each side of it, with small teeth interspersed, all linear-lanceolate, erect and remote, not crowded at their bases. In the fixed ramus they are either erect or (fig. 8) point forward a very little.

- The striæ on the teeth are very fine and close, + oblique somewhat on the great tooth, and more direct in the smaller ones. In $P$. gigas and P. ludensis they are coarser, and the teeth broad. The great terminal mucro is as broad and long as the primary tooth, or even longer, and is bent at right angles to the shaft.

Swimming Feet, Basal Joint, Plate XII. figs. 11-14.-Several fragments have been found of the great basal joint, and one tolerably perfect from the Whitcliffe, Ludlow, fig. 11. It shows a wide-expanded basal lobe, and the whole extent of the serrate tip, with the usual number of teeth (thirteen, or rather twelve in this specimen); and in fig. 14, the upper tooth being obsolete. Fig. $13 a$, from Ludlow, shows the full number.

The lobe in front of the teeth is arched and thickened in all the specimens, (a character in which this species differs widely from $P$. anglicus,) and the second tooth is more than twice the breadth of any of the others, conical, and but little curved; the remaining teeth are long, straight, narrow, and separated by about their width from each other in large specimens. These elongate teeth are very

* See P. ludensis (Plate XIV. fig. 10) for a similar chela.

† See also Strickland's figure, quoted above. There is one lanceolate fragment $(2 b)$ in that figure, here reproduced, fig. 9*, which is striated finely like the teeth. It is serrated all down one side. Its nature is quite doubtful; but it is associated with the antenna; and as the large primary tooth in $P$. gigas (Plate IX. fig. 3 ) is serrated posteriorly, it is possible this may be the case in one of the chelæ of the present species. There is a small conical uncinate appendage in the same figure, Geol. Journ., that is yet unexplained.-Quart. Journ. Geol. Soc., 1. c. 
distinctive of the species. I believe I am not mistaken in referring Agassiz's figure of the Sphagodus tooth to this portion.

Metastoma (Plate XII. fig. 15, Plate XIV. fig. 19) is cordate-ovate, narrower at the bilobed end, and has its greatest width below the middle (our figure does not express this well), becoming angulated at that point. The notch is deep, the lobes rounded (the base is broken off), surface marked with open squamæ, but only near the upper end and about the notch. This post-oral plate is the broadest of any species known.

Fig. 16 is a plate of the same nature as those found with $P$. ludensis, and is possibly a thoracic or abdominal appendage, though, as no species are known with any such attached, its nature is quite doubtful. The small crenate fragment, fig. 17, probably belongs to it; a similar piece is attached at $c$ to fig. 16. [The entire form is better seen in $P$. arcuatus, Plate XIII. fig. 16, viz., a lobed broad emarginate plate $(d)$, in the wide notch of which is attached the truncated sub-oval plate $a, b$.] A more perfect specimen is here added in a woodcut, showing the thickness of the plate on the one side of it. The obscure converging lines ending in serrations on the

Frg. 12.

Pterygotus problematicus, Ag., thoracic or abdominal appendage? nat. size.

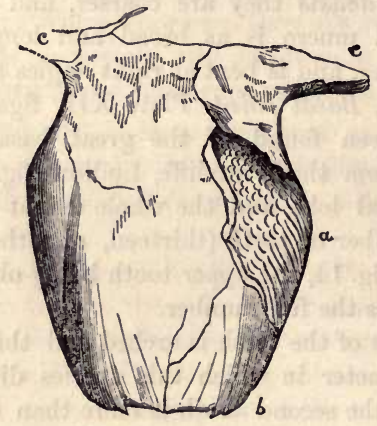

Comus Wood, Ludlow, in Upper Ludlow Rock (Cabinet of Mr. J. Harley, King's Coll.)

border are exhibited on one surface; on the opposite, the oblique close plicæ running into parallel lines towards the margin, very like the segments of a feather.

The base $a a$ is much extended on each side, and in this respect seems to be different from the figure above quoted, Plate XIII., which probably belongs to $P$. arcuatus.

Localities. - UPPER LUDLOW Rock, Whitcliffe, and many places near Ludlow (Ludlow Museum and Museum of Pract. Geology ; Cabinets of Messrs. Lightbody, Cocking, J. Harley, and A. Marston.) Kendal, Westmoreland (Museum of Pract. Geology). 
Ludlow Bone Bed, Ludlow: Downton Sandstone of Bradnor Hill, Kington. (Mr. R. Banks' Cabinet.) Base of Old Red Sandstone, Ludlow Railway Station (Museum of Pract. Geology). Cornstones of Hopton Gate (Cabinet of Mr. J. Harley).

One of the most widely spread species; it is probably this which occurs in the Upper Llandovery Rock or "May Hill Sandstone" of the Obelisk, Eastnor Park. A woodcut of it is subjoined.

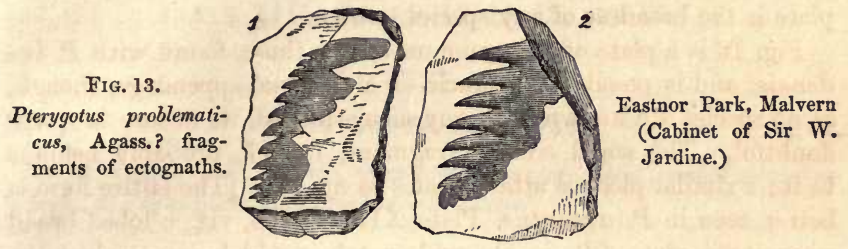





\title{
BRITISH FOSSILS.
}

\author{
Plate XIII. Figs. 8, 12, 13, 15, ANd 16.
}

\section{PTERTGOTUS ARCUATUS.}

Spec. Char. P. major, segmentis arcuatis, plicis semicircularibus parvis, nec squamulis minutioribus intermixtis.

The name is applied to a large and fine species, of which several fragments occur in the Lower Ludlow Rock of Leintwardine, along with the more common $P$. punctatus, Plates X., XI. It is clearly distinct from that species, but except for the total absence of any minute interspersed plicæ, the body segments might be easily mistaken for those of $P$. problematicus, to which it is closely allied; and with it, in the same beds of Lower Ludlow Rock, occur antennoe (fig. 8), the obscure appendages (fig. 16), swimming feet, maxillæ, and other oral apparatus, differing specifically from those of $P$. problematicus, and yet more distinctly separated from the portions of $P$. punctatus, found in the same beds. Of these fragments the body segment must receive the name, the other pieces being only provisionally arranged with it. They all resemble the corresponding parts in the Upper Ludlow species.

Body Segments.-Fig. 12 is clearly, from its shape, the second body segment, seven inches broad and more than one inch and a half deep. It is curved, and more oblique laterally than in $P$. angli$c u s$, the sides forming an angle of $65^{\circ}$ with the base. The anterior edge is much more sinuated than the posterior, owing to the deep excavation to receive the first segment; but the central part is strongly arched forward on both margins. The lateral anterior process $a$ is broken off, but enough remains to show it was prominent. The sides are oblique, inclined forward at an angle of $80^{\circ}$ from the posterior angle, which is rounded off. The margin is crenulated, the prominent minute sculpture confined to the anterior third, but continued more faintly over a large part of the segment. (The sculpture in the thoracic segments of $P$. punctatus, Plate X. 
though not carried over a much larger part of the surface, is far more prominent and remote).

A specimen, crushed longitudinally (fig. 13), shows that the species was rotund in section, as in $P$. punctatus and others.

Antennce.-In all probability Plate XIII. fig. 8, represents the antenna of this species. Its resemblance to those of $P$. problematicus is very close. The shaft is linear, the long end turned abruptly up, and the teeth straight, narrow, and remote, as in that species; but the chela is much more slender, three inches and a half to four inches long, and the larger central tooth is scarcely longer than the diameter of the shaft itself; while the secondary teeth, some of them at least, approach it more nearly in size. The tooth at the base of the large terminal mucro is appressed against it, and the mucro itself (Plate XI. fig. 3) is sometimes oblique. All the teeth are finely striate, the striæ tending obliquely backward on the principal teeth. There are numerous sharp, conical, minute teeth between the secondaries.

Endognaths (Maxillae?)-Most probably Plate XIII. fig. 15, represents the first or second pair of these organs, and it is pretty clearly referable to $P$.arcuatus, and not to $P$. punctatus, which has much shorter and blunter mandibles. (Plate XI. fig. 6.) It is elongate, or even falcate, the upper lobe $a$ greatly convex, the posterior portion $(f)$ drawn out laterally instead of backwards; the surface closely sculptured all over. The teeth are not oblique, straight, and conical as in P. punctatus, but lanceolate and curved, and directed outwards. About ten or eleven are free, the rest confused, either in a horny plate or mixed with setæ. In this particular, and in the production of the lower lobe $b$, it resembles $P$. punctatus, but the great curvature and elongation of the plate distinguish it.

Base of Swimming Foot, Plate XI. fig. 10.-Most probably, from the very convex form of the anterior edge, and the greatly elongate teeth, this belongs rather to the present than to $P$. punctatus. [Plate XIII. fig. 14, may, perhaps, represent this part in the latter species.]

Post-oral Plate, Plate XV. fig. 5.-Found at Leintwardine, by Mr. Alfred Marston. It differs from the corresponding plate in all the species, having the lobes of the apex narrow, and nearly their own width apart, the sinus between them being very wide and shallow, instead of a simple deep notch. The plate is cordatolanceolate, for the upper two-thirds it is oval, the greatest width 
being rather below the upper third; the base is rather suddenly contracted, and tongue-shaped.

Thoracic (?) Appendage, Plate XIII. fig. 16.-This has been already alluded to (p. 92), as probably belonging to the species. It is more perfect than any other specimen, though only the impression of one side. The large ovate terminal plate $a b$, shows well the gradation between the ordinary plicæ and the long lateral plaits, the middle line is bare of any ornament. At the apex are seen two or three of those impressed lines, which are so much more conspicuous on the opposite surface, and which seem to divide the plate into laciniæ, $a$. The plate is indented at its basal end, corresponding to the central depression (ridge in the cast) of the preceding joint. This joint is very irregular in shape, the lobes on one side, $d$, being single, on the opposed side $c$ double. Both are marked with minute plicæ near the edges.

Locality.-The above-mentioned fragments have all successively come to light during the active researches of the Ludlow geologists in the quarries of LOWER LUDLOW ROCK at Leintwardine, particularly in one at Church Hill. There are many new Crustacea to be described from the same quarry, of one of which the head portion has been accidentally introduced into this plate. Plate XIII. fig. 17. See also p. 25, suprà. 


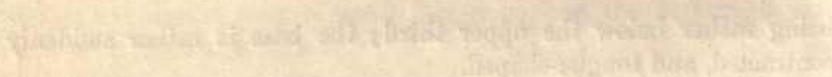

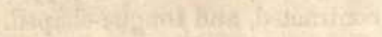

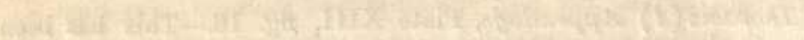

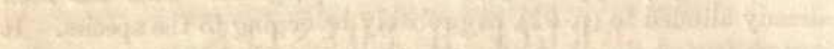

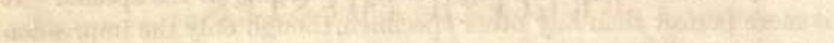

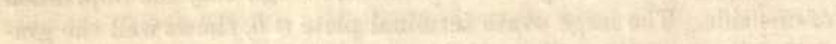

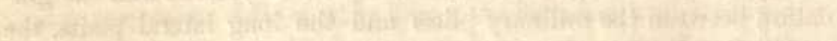

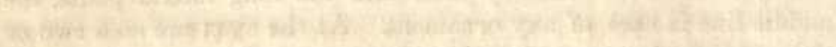

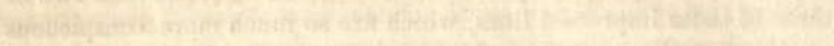
Withith

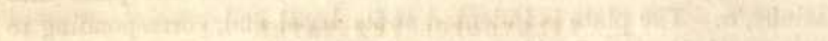

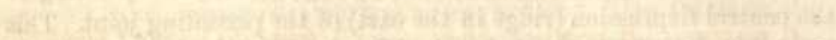

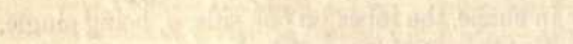

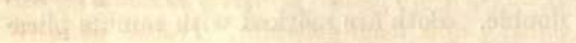

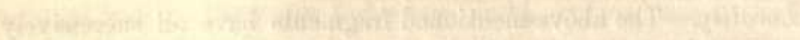

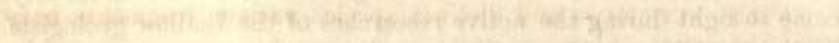

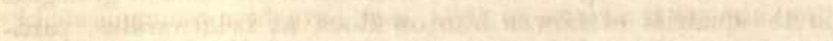

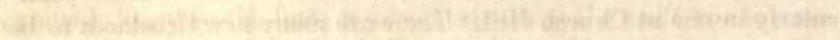

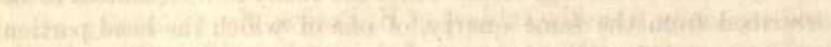

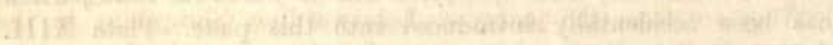

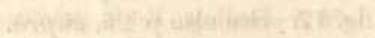

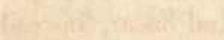

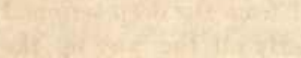




\title{
B RITISH FOSSILS.
}

\author{
Plates X., XI., AND PART OF XIII.
}

\section{PTERTGOTUS PUNCTATUS.}

P. magnus, (5-6 pedalis?) capite - (?), segmentis omnibus squamulis remotis prominulis ornatis, -in articulis posticis per totum annulum sparsis; chelis antennarum elongatis; palpis longi-fimbriatis. Pedibus natatoriis articulo terminali elongato, penultimo expanso.

Of this very large and distinct species various fragments have from time to time come to light, and have been communicated by our friends Messrs. Lightbody, Cocking, and Marston, of Ludlow, and especially from the cabinet of $\mathrm{H}$. Pardoe, Esq.

They are from the quarry at Leintwardine, Shropshire, in the Lower Ludlow Rock, where many fine starfish and other rarities have been newly discovered. (Siluria, 2nd edition, p. 140.)

There is evidence of at least three, if not more, of the thoracic rings. The hinder segments were decidedly longer in proportion to their width than in the $P$. anglicus or $P$. gigas. We have also the swimming paddles, which, without the great coxal joints, were seven inches long, expanded in the penultimate joint and attenuated at their tips; of the mandibles, the palpi of which are strongly fringed with long curved processes, and of antennæ, with slender pincers at their terminations, and armed with numerous small conical teeth. As all these parts present distinctive peculiarities from other species, and as the tuberculatiou on the various specimens found in this bed agrees in character, it is fair to combine them as a single species, and figure them all upon one plate.

Of the carapace or eyes we have yet no trace. But the epistoma (fig. 1) presents us with a singularly neat character for the species. The upper portion of this organ is broadly sagittate or spear-shaped as in other species, and offers a wider basal angle than that of $P$. anglicus, but the outer portion, which is quite straight and linear, (instead of being clavate,) is bilobed at the tip; and from the deep terminal notch a raised central line is continued nearly all the way up the 
linear portion, and terminating in a slight prominence. The whole piece is smooth.

Of the first body ring a fragment an inch and a half long and one inch wide is figured (Plate X. fig. 2). It is the semi-circular sweep of the outer edge of the segment, where it fits into the scooped out portion of the succeeding (second) one. The rounded margin $a$ is serrated, the serrations pointing backward. The sculpture is very minute, prominent, and confined to the forward half, except a few marginal plicæ on the hinder edge. All are longer than wide. Fig. $2 a$ shows them magnified. Fig. 3 is without much doubt the second thoracic segment. It is wider at the sides than in the middle, and turns up abruptly at the forward angle to form the characteristic process. Fig. 4 appears to be a larger specimen of the third ring, it has the same characters of ornamentation. In both the central portion is less arched than in $P$. anglicus or $P$. arcuatus, and the sides less oblique and minutely crenulate. A narrow (articular?) furrow runs along the middle portion of the anterior edge, followed by a convex ridge, which is bounded by a row of prominent minute tubercles extending a good way out, and nearly to the lateral margins. Behind this the anterior third of the segment is occupied by the sculpture, which is much more prominent and tubercular, and less scale-like than in the large Scotch species.

The occurrence of this line of tubercles enables us to connect with the species some very curious fragments, one of which is here figured (fig. 8) with one or other of the body rings. When first viewed the piece appears quite anomalous, the extended ends giving the general form much the aspect of the epistoma, but a closer examination shows that it has an upper surface $b$, and the impression of the lower side $c$, each with the sculpture pointing backwards, and with no room for a median lobe. Of the epistoma we have now obtained specimens (fig. 1, as above described), and it remains therefore to explain this piece as one of the body rings, obliquely pressed, (probably the exuviated crust only,) the angular edge being indicated at $a$, and one surface (the inferior) $c$, being less disturbed and altered in shape than the other, $b$. The dotted lines will give a notion of what was probably the complete form. Fig. 9 is probably a similar fragment. Figs. 10 and 11 have as yet no explanation. Fig. 7 shows the true outline of another ring, which has been compressed vertically in the rock, instead of laterally. These specimens of course give the true idea of the convexity, which was very great. The form was almost cylindrical. 
Of the intermediate rings we have very few fragments, but several hinder rings, which must have been near to the extremity both from their form and their being quite covered with the elongate tubercular plicæ.

Plate IX. fig. 7, from the cabinet of Mr. Marston, represents probably the penultimate ring. It is two inches and a quarter long by two inches at its truncated extremity, which is rather wider than its base. The shape is thus nearly square, the sides are but very slightly (perhaps not at all) curved, nor is the base $a$ contracted or the distal end $b$ expanded or produced, as in $P$. anglicus. The edge is crenate. Plate XIII. fig. 5 is from the Upper Ludlow Rock.

The caudal joint (telson) is yet wanting and should be sought for, as in all probability it was not unlike that figured on Plate VIII. fig. 11 has possibly something to do with it.

Mr. J. Harley, of King's College, has found a small specimen, doubtless of this species (Woodcut, fig. 14), since the plate was finished. It has the second to the sixth rings united, and the pyramidal form of the front ring is very marked.

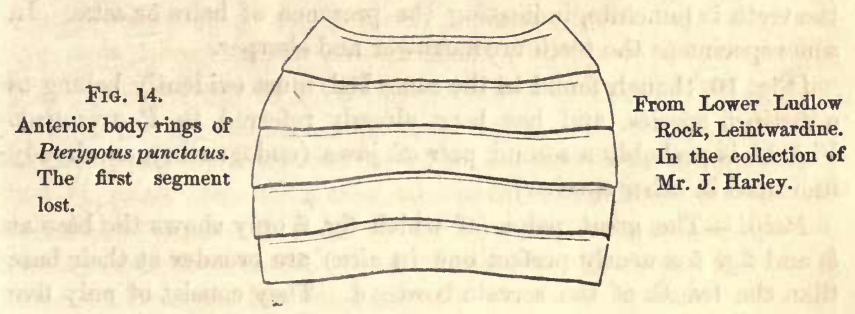

Appendages.

Antennoc.-Of these great pincer-like organs only two chelæ have been found, one three inches and a half long, but these are quite different in proportion from that of $P$. anglicus. The shaft is much longer and slenderer, being quite eight times as long as wide, and not much thicker at the origin than near the tip. The teeth are much shorter, the central one is as long as the diameter of the chela itself, and placed beyond the middle; two other primaries nearly equal in size and a secondary tooth are outside it, while only minute teeth with a single primary near the hinge occur on the proximal half. As many as twenty of these small conical teeth may be counted in the inner half, and eleven or twelve on the outer. The primaries are broad-conical (not ovate), striated and directed back- 
wards, and are not crowded at their bases by the smaller teeth which vary much in size, but are all of them more or less conical in shape like the larger ones. The terminal mucro is lost in both the specimens; a few tubercles occur on the shaft near the end, fig. $2 a$.

Endognaths and Palpi, figs. 5-8, and Plate XIII. figs. 9-11.There are several specimens and they present some strong characters for the species. Plate XIII. fig. 9, and Plate XI. figs. 7 and 8, show portions of the palpi, and fig. 5 an endognath with its entire palp attached, and in the proper position in respect of the great swimming foot $c$. From this specimen it would appear that the remarkable spines of the palpus were directed forward. Figs. 8, 9, show the great size these appendages obtained.

The teeth of the maxillary piece (fig. $6 a a^{*}$ ) are small, short, and obliquely conical, not curved, and as in some other species striate; there are about seven distinct, and six smaller ones, which last are either connected by a horny plate (as in $P$. anglicus, Plate VII. fig. 5 b), or are confused with setæ; the state of preservation does not permit us to decide which. The margin near the teeth is punctate, indicating the presence of hairs or setæ. In some specimens the teeth are narrower and sharper.

[Fig. 10, though found in the same bed, must evidently belong to a distinct species, and has been already referred to $P$. arcuatus. Fig. 11 is probably a second pair of jaws (endognaths), as already indicated in other species.]

Palpi.-The great palpi (of which fig. 6 only shows the base at $b$, and fig. 5 a nearly perfect one in situ) are broader at their base than the length of the serrate border $a$. They consist of only five joints, all except the basal one bearing (a pair? of) curved processes, while the terminal one, $g$ in fig. 8 , might even be considered as an additional joint.* The specimen (Plate XIII. fig. 9), obtained since Plate XI. was completed, shows all the joints complete, and these resemble Plate XI. fig 7. in their elongate form. Fig. 5 has much shorter joints and may very possibly belong to a different pair of maxillæ. In this figure, the first joint is very broad and large, subquadrate, tapering but little, rather longer than broad, and bears apparently no curved process. Its edge is spinose, fig. $6 b$. The third, fourth, and fifth are, in figs. 5 and 8 ,

* Although the specimens from Church Hill look as if there were only a single process to each joint, yet, as in the palpus of this species, figured in Plate XIII. fig. 11, there is a pair of these organs, it is most likely all the other specimens had two. In this view the two processes $f, g$, would belong to the terminal fift joint. 
not very different in size and nearly square, while in fig. 7 the proportions are longer. All have the great curved spines placed about the middle of the joint.

In the perfect palpus (Plate XIII. fig. 9) the proportions of the joints are as follows. The basal one is smaller than the second, about two-thirds its length, and of a roughly triangular or trapezoidal shape, the base smallest. The second is longest-half as long again as its breadth; the third and fourth much shorter, the fifth only half as long as broad, and bearing one curved spine at its outer angle, and the other $(g)$ at its tip. The second, third, and fourth joints are subcylindrical, convex on their outer margin, and bear the curved spines about the middle of the joint.

The terminal articulation $(g)$, if it be a separate joint; consists only of the curved process; but it is probably only the opposite spine of the fifth joint, seen obliquely, and in this view there would be five joints only to the palpus, each joint bearing a pair of processes, as is certainly the case in Plate XIII. fig. 11.

The processes themselves are directed obliquely outwards and forwards; they are long, curved, sabre-shaped, and much compressed, fully three times as long as the width of the joints, to which they are attached by a swelled base. They are striated longitudinally, the striæ, eleven or twelve in number, sharply impressed, not continuous except near the tip, but interrupted alternately (Plate XIII. fig. 10) for wide spaces, so that the number of striæ appears little more than half what it really is. Nor are the striæ quite parallel to the sides, for they abut obliquely against the concave side towards the tip of the process. Here and there some striæ are stronger than the rest.

Near the base of the processes the striæ are still more interrupted and run into short impressed lines or puncta.

Plate XIII. figs. 5, 6, 7, 11, and 18.-These are from the UPPER LUDLOW ROCK. Fig. 11 is a very perfect joint of the palpus, with both spines attached; and figs. 5 and 6 show the characteristic long plicæ; fig. 7, part of a chela probably of this species. Fig. 6 at least would answer best to one of the long joints of the antennæ; it is but a cylindrical fragment of the proximal end, and has the contraction which is visible in the corresponding joint of $P$. anglicus, Plate IV. fig. $4 c$. At this part the plicæ are very numerous and small; in the body of the joint they are large, prominent, and elongate, and with the channel-like depression and its bounding ridges, fig. $6 a$, magnified. They are somewhat unequal in size, and set at more than their diameter apart from one another. 
Plate XIII. fig. 18. -There is one other fragment in the Upper Ludlow to which a place cannot be yet assigned, and yet belongs apparently to $P$. punctatus. It is a long strap-shaped piece, two inches and a half long and half an inch broad, and narrowed and rounded at one if not both ends. At $b$ it is imperfect. The surface shows the peculiar long tubercular plicæ of the species, at least near the base ( $a$ ) and the opposite end $b$, and the margins are deeply incised by short slits forming nearly square serrations (like those on the edge of the carapace of a crab). This is not exactly the structure of any part of the margin of Pterygotus, the usual ornament being that of prominent superficial plicæ or tubercles. The terminal (?) portion $b$ differs in not having (so far as the impression shows) this serrate edge, but only a thickened crenate margin, and is probably a distinct joint, or may even be accidentally placed where it is. The surface shows elongate plice of various sizes, rather thickly scattered.

The Metastoma (Plate XI. fig. 4) is nearly three times as wide as long, widest above the middle, and tapering backwards with straight sides from this point to the blunt posterior extremity; the anterior end is broadest, rounded, and not even emarginate; much less bilobed as in other species. It is thus quite different in shape from that of any other species; its long oval form, blunt ends, and straightened sides enable us to recognize it at once. It occurs three inches and a half long; and in specimens of this size, the width is one inch and a quarter.

The Swimming Feet (Plate XI. figs. 12-15) are very different in proportion to those of $P$. anglicus, the terminal joints occupying a considerably greater length, and being abruptly wider than the rest. Of the great basal joint ( $c o$ in fig. 5 ) but little is preserved, but a larger specimen, fig. 12, shows it to have been roughly squamose, especially along its basal edge, the narrow squamæ projecting as small spines, the rest of the surface is closely imbricated with smaller plicæ. Pl. XIII. fig. 14, is very possibly the serrate inner lobe of this joint. The second joint $b$ is large in proportion to the rest, and widens from the base to its truncated apex. The third $i$ is subtriangular, the blunt apex of the triangle being anterior, and the edge articulating with the next joint nearly straight or but slightly curved. The fourth joint, on the contrary, is an obtuse triangle, of which the broad base is forward and moderately arched, but not projecting as in P.anglicus. It contracts rapidly behind, where it has a narrow deep notch to receive the articulating process of the next joint. This, $c a$, is the fifth, a remarkably short wide articulation, almost buried in the 
concave edge of the great penultimate joint, and curved to follow the convex border of the triangular fourth joint. It is marked by a strong transverse ridge. All these joints may be seen in figs. 5 and 13, but in a far less perfect state than in the fine specimen, fig. 13, presented by my young friend Mr. R. Lightbody, jun., of Ludlow. The penultimate joint $p$ is very large, nearly three inches long, and about half as broad. It is oblong, with two rounded unequal lobes, and deeply notched at each end (the distal notch at the end being the deepest), so that the joint overlaps the proximate joints at either end. The hinder margin of the joint is more convex at first, then somewhat excavated, while the anterior margin is straight, or nearly so: the hinder lobes at both ends are larger than the anterior ones, the proximal one, which overlaps the small fifth and fourth joints, being broader and rounder, and the distal one, which abuts against the terminal palette, being long and narrow.

The terminal joint $(d)$ is very long, nearly three inches by ninetenths of an inch wide, elongato-lanceolate, but rounded at the tip, its anterior margin a little convex, and plain-edged half way down, the posterior slightly concave and rather strongly serrate,-the serræ are shallower on the anterior margin, and deepest round the tip.

Locality.-Church Hill, Leintwardine, in Lower LUDLOW RocK; Whitcliffe, Ludlow, UPPER LUDLOW RocK ; Kendal, Westmoreland; fragments in UPPER LUDLOW ROCK.

January 22, 1859.

J. W. S. 


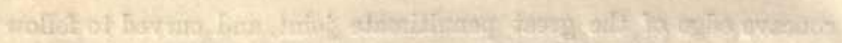

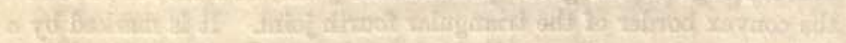

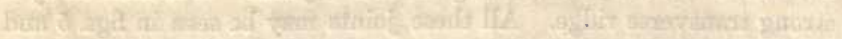

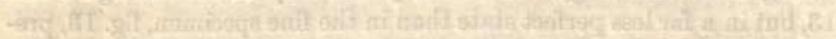

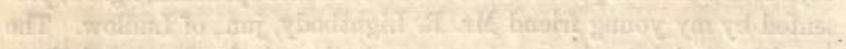

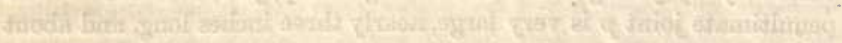

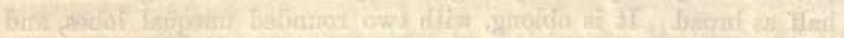

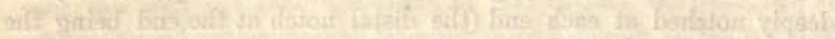

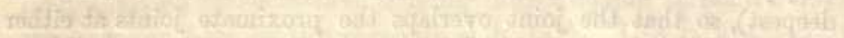

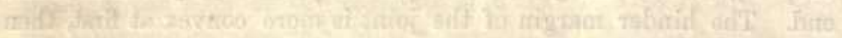

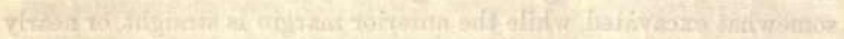

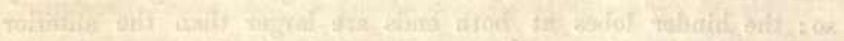

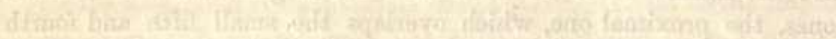

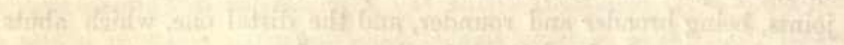

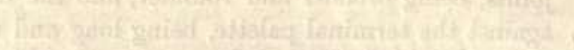

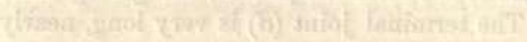

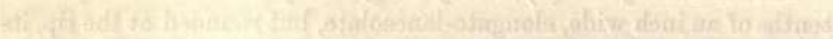

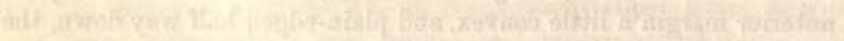

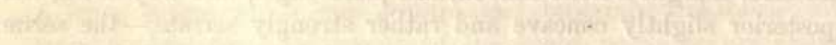

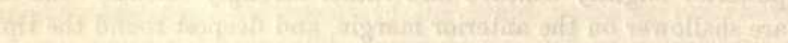

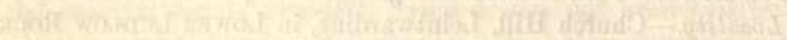

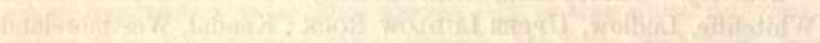

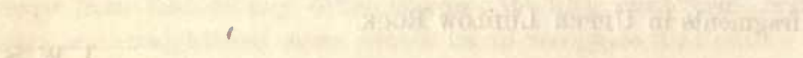

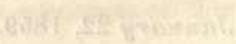

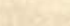

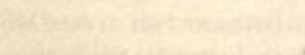

II , 



\section{LONDON :}

Printed by George E. Exre and William Spotriswoode, Printers to the Queen's most Excellent Majesty. For Her Majesty's Stationery Office. 


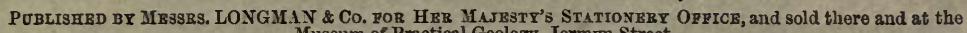
Museum of Practical Geology, Jermyn Street.

?ar Maps are those of the Ordnance Survey, geologically coloured by the Geological Survey of Great Britain and Ireland, under the Superintendence of Sir RODERICK IXPRX MURCHISON, F.R.S., Director-General. The various Formations are traced and coloured in all their Subdivisions.

\section{GREAT BRITAIM:- The Counties of which the Geological Survey is completed, are -}

BRBCKNOCKSH IRE, Sheets $36,41,42,56$ (NW \& SW), 57 (NE \& SE). 1l. 12s.

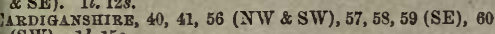
(SW). 1l.15s.

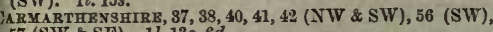
57 (SW \& SE). 1l, 13s. 6d.

ARRNARVON, 74 (NW), 75, 76, 77 (N), 78, 79 (NW \& SW). 1l. 15 s.

ORNWALL, including Sheets $24,25,26,29,30,31,82, \& 33$.

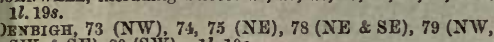
$\mathrm{SW}, \& \mathrm{SE}), 80(\mathrm{SW}) .1 i .10 s$.

OBVONSHrRE, including Sheets $20,21,22,23,24,25,26,27, \&$ $29.2 l .2 s$.

ORSRTSHIRE, including Sheets $15,16,17,18,21,22.11$. 16s. LNT TSHIRE, 73 (NW \& SW), 74 (NE), 79. 17s. $6 d$. iLA TORGANSHIRE, including Sheets $20,36,37,41$, \& 42 (SE
\& SW). 1l.9s.

Isle of Wight. $3 s$.

Devizes, Middle Wiltshire. $6 s$.

5 Salisbury, East Dorset, South Wilts, West Hants. $6 s$.

6 Poole, South East of Dorset. 6s.

7 South West of Dorset. $6 s$.

Northern half of Dorset, and SE. part of Somerset. $6 s$.

3 Half of Somerset, and part of West Wilts. is.

0 West Somerset and part of South Glamorgan. $6 s$.

SW. Somerset, NE. Devoll, and part of West Dorset. 6 s.

Part of SE. Devon. 6s.

3 Devon between Torbay and Start Point. $3 s$.

4 Part of South Devon and of Cornwall. 3s.

5 SW. Devon aud East Cornwall. $6 s$.

6 West Devon and NE. Cornwall. Gs.

7 Part of North Devon. $3 s$.

8 Lundy Island. $3 s$.

The North of Cornwall, showing the Coast line from Hartland Quay to Cambeak. 3s.

Part of Cornwall. 6s.

1 Part of Cornwall. 6s.

2 Part of Cornwall. $3 s$.

3 Part of Cornwall. $6 s$.

4 Part of Wilts, Gloucestershire, Berks (Swindon, Cirencester). $6 s$.

Western Gloucester, the SE. of Monmouth, part of North Somerset and West Wilts. $6 s$.

6 The greater part of Glamorgan on the West, and Monmouth on the East. $6 s$.

7 West Glamorgan and South Carmarthen. 6s.

South Pembroke. $3 s$.

Small's Light, Pembroke. $3 s$.

0 North Pembroke and West Carmarthen. 68.

Most of Carmarthen, parts of North Glamorgan, South Cardigan, and East Pembroke. os.

NW. West Brecknock and part of East Carmarthen

NE. Part of East Brecknock and West Hereford.

3 SW. SW of Brecknock, part of North Glamorgan and East Carmarthen.

SE. NE. of Glamorgan and Monmouth Coalfield.

NW. The Old Red Sandstone and part of the Silurian Strata of Woolhope.

$3 N E$. Silurian District of Woolhope, with the Malvern Country as far North as the Wych.

$3 \mathrm{SW}$. The West of Dean Forest Coalfield.

SE. The greater part of Dean Forest Coalficld.

1 Cheltenham, East Gloucestershire. $6 s$.

NW. Part of Warwickshire - Coventry.

SW. Southam. Part of Warwickshire.

NW. Part of Worcestershire.

NE. Part of Warwickshire.

SW. Part of Worcestershire

SE. Part of Warwickshire.

NE. Part of Shropshire and Worcestershire.

NW. Part of Hereford, Worcester, and Shropshire.

SW. Part of Hereford.

5 SE Part or Hereford and Worcester.

3 NW. Part of Brecon, Cardigan, Radnor, and Mont-

3 NE. Part of Radnor, Montgomery and Shropshire.

3 SW. Part of Radnor, Brecon, and Carmarthen.

3 SE Part of Radnor and Hereford.

NW. Part of Cardiganshire.

? NE. Part of Cardiganshire.

SW. Part of Cardiganshire.

SE. Part of Cardiganshire, including Lampeter to Tregarron.

N.B.-An Index to the Colours and Signs employed on the Geological Survey, price $5 s$.

The price of the Quarter Sheets is now uniformly 2s. $6 d_{.,}$with the exception of 57 NW. 76 N, and 77 NE.,
GLOUCFSTRRSHIRE, 34, 35, 43 (NE, SE. SW), 44. 1l. $5 s .6 d$. HRREPORDSHIRE, 42 (NE \& SE), 43, 55, 56 (NE \& SE). 12.108 .

ERIONETHSHIRE, 59 (NE \& SE), 60 (NW), 74 (NW, NL, $\& \mathrm{SW}), 75$ (NE \& SE). $1 l$.

(SW) (SW). 19s.6 $d$.

MONTGOMERYSHIRE, 56 (NW), 59 (NE \& SE), 60, 74 (SW \& SE). $1 l .2 s .6 d$.

PEMBROKESHIRE, $38,39,40,41,58,1 l .1 s$.

RADNORSHIRE, 42 (NW' \& NE), 56,60 (SW \& SE). $1 l$.

SHROPSHIRE, 55 (NE, NW), 60 (NE, SE) $61,72,74$ (NE, SE). 1l. $15 s$.

SOMERSETSHIRE, $18,19,20,21,27,35.12 .13 s$.

(NE), 44, 54, 55, 62 (SW \& SE), 61

(SE). 1l. 16.

WILTSHIBE, 12, 13, 14, 15, 19, 19, 3ı, 35. 2l. 2s.

58 Part of the Coast of Cardiganshire (Cardigan) and $\mathrm{N}$. Pembrokeshire. 3 s.

59 NE. Part of Cardigan, Montgomery, and Merionetl.

$59 \mathrm{SW}$. Sea. (No Geological Colouring.) $6 d$.

$59 \mathrm{SE}$. The North of Cardiganshire; part of the West of IIontgomery and the South of Merionethshire.

60 NW. Part of Montgomery and Merioneth.

60 NE. Part of Muntgomery and Shropshire.

60 SW. Part of Cardigan, Montgomery, and Shropshire.

60 SE. Part of Montgomery, Radnor, and Shropshire.

61 NW. Part of Shropshire.

61 NE. Part of Shropshire and Staffordshire.

61 SW. Part of Shropshire.

62 NE. Lichfield, part of Staffordshire.

62 SE. Birmingham part of Warwickshire.

$62 \mathrm{SW}$. Part of Stafiordshire, including the Coalfield.

62 NW. Part of Staffordshire, including the Coalfield.

63 NW. Ashby-de-la-Zouch, part of Leicestershire.

63 NE. Leicester.

63 SW. Hincklcy, part of Leicestershire and Warwick shire.

71 NW. Nottingham, part of Derbyshire.

71 SW. Derby

71 SE. Part of Nottinghamshire.

72 NW. Hanley. Part of Staffordshire.

$72 \mathrm{NE}$. Part of North Staffordshire and of $\mathrm{SW}$. Derby shire.

72 SW. Central Part of Staffordshire.

72 SE. Part of Staffordshire and SW. Derbyshire.

73 NW. Part of Cheshire.

78 SE. Part of Shropshire and Staffordshire.

74 NW. Part of Denbigh, Merioneth, and Cacrnarvon.

74 NE. Part of Denbigh, Flint, Shropshire, and Merionetl. 74 SW. Part of Montgomery, Denbigh, and Merioneth.

74 SE. Part of Shropshire, Montgomery, and Denbigh.

75 NW. Part of Caernarvon.

75 NE. Part of Caernarvon, Merioneth, and Denbigh.

75 SW. Part of Caernarvon.

75 SE. Part of Merionetl.

76 N. Part of Caernarvon.

76 S. Part of Caernarvon.

77 N Part of Holyhead island.

$78 \mathrm{NW}$. N. part of Anglesea, and part of Holyhead Island. 78 NE. E. corner of Anglesea. 78 WS. S. of Holyliead Island and of Anglesea, with part

78 SE. Part of Anglesea on Menai Straits, NE. of Caernarvonshire, and W. of Deubighshire.

79 NW. Part of Flint, Denbigh, and Caeruarvon.

79 NE. Part of Flint, Cheshire, and Lancashire.

$79 \mathrm{SW}$. Part of Flint, Caernarvon, and Denbighshire.

79 SE. Part of Cheshire, Flint, and Denbigh.

$80 \mathrm{SE}$. Northwich.

$80 \mathrm{SW}$. Chester, part of Cheshire. 81 NE. Part of Derbyshire and of the West Riding of York

81 SF Part of Derbyshire and of N Staffordshire.

82 NW. Chesterfield, part of Derbyshire.

82 SE. Mansfield.

82 SW. Chesterfield, part o? Derbyshire.
59 NW. Sea.

$71 \mathrm{NE}$. Nottingham.

73 SW. Part of Shropshire. 


\section{HORIZONTAI SECTIONS,}

\section{Illustrative of the Survey's Geological Maps.}

These Sections are drawn to a scale of six inches to a mile, horizontally and vertically, and describe in detail the Gcolog? of the Country over which they are drawn. Descriptions are engraved on each plate, thus rendering each Section a concisi Report on the district it traverses. The size of each plate is $3 \mathrm{ft} .3 \mathrm{in}$. by $2 \mathrm{ft} .3 \mathrm{in}$. They are engraved on Copper by Mr. Lowry and coloured in accordance with the Maps. Sheets 1 to 55 , price $5 s$, each.

\section{VIRTYCAI SECTIONS,}

\section{Illustrative of the Horizontal Sections and Mraps of the Geological Survey.}

These Sections are arranged, in the form of Vertical Columns, to a scale of $40 \mathrm{ft}$. to an inch, and illustrate such details a it is impossible to give in the Horizontal Sections above described. In the Coal Measure Sections, for instance, the Thicknes of cach Bed of Coal, the Mineral Strueture and Thickness of the Strata with which they are associated, and the kind an Amount of Ironstone, are given in the greatest detail. Sheets 1 to 25 , price $3 s .6 d$. each Shieet.

\section{MAPS OF IRELAHD.}

On the one-inch scale.

WICkLow includes Sheets 36 (NW., NF., SW., and SE.) and 41 (NW., NE., SW.) WBXFORD includes Sheets 41 (NW.. NE., SW., and SE.), 46 (NE. and $S E$.), 47 (NW., NE., SW., and SE.), 52 (NE.)

WATRRFORD includes Shects 45 (SE.), 46 (SW. and SE.), 51 (NW., NE., and SE.), and 52 (NW., NE., and SW.)

Price 2s. 6d. cach Quarter-Shect.

BOOKS Published under the Superintendence of the Geological Survey and Museum of Practical Geology.

REPORT on CORNWALL, DEVON, and WEST SOMERSET. By Sir II. T. DE LA BECHE, F.R.S. \&c. 8vo.14s.

FIGURES and DESCRIPTIONS of the PALAOZOIC FOSSILS in the above Countics. By Propessor Prillips, F.R. 8vo. (Out of print.)

THE MENOIRS of the GEOLOGICAL SURVEY of GREAT BRITAIN, and of the MUSEUM of ECONOMIC GEOLOG of LONDON. 8vo. Vol. I. 21s.; Vol.I1. (in 2 Parts), $42 s$.

BRITISH ORGANIC REMAINS. Forming a portion of the Memoirs of the Geological Survey. Decades I. to IX., wit 10 Plates cach. Royal 4to. 4s.6d.: or royal 8vo. 2s.6d. each Decade.-Other DeCADEs are in the Press.

RECORDS of the SCHOOL OF MINES and of SCIENCE applied to the ARTS. Vol. I. Part I. Inaugural and Introductor Lectures to the Courses for the Session 1851-52. Royal 8vo. price 1s. $6 d$. cloth. Vol. I. Part II. On the Geology of th South Staffordshire Coalficld. By J. BEETE JUkzs, M.A., F.R.S., \&c. (2d Edition). Vol. I. Part III. On the Mines Wicklow and Wexford. By WARINGToN W. SMrTI, M.A., \&c. Vol. I. Part IV. Statistics of the Produce of Coppe Tin, Lead, and Silver from the IIines of the United Kingdom, with the Exports and Imports of these Metals, frol 1848 to 1852 inclusive. By ROBERT HUst, F.R.S., Kecper of Mining Records.

CATALOGUE of SPECIMENS in the Museum of Practical Gcologv, illustrative of the Composition and Manufactur of British Pottery and Porcclain. By Sir HENBY DE LA BECHE, and TRENHAX RBEKB, Curator. 8vo. 1s Woodcuts. Price 1s. (Out of Print.)

A DESCRIPTIVE GUIDE to the IIUSEUM of PRACTICAL GFOLOGY, with Notices of the Geological Survey of th United Kingdom, the School of Mines, and the Mining Record Olfice. By Rosert Hext, F.R.S. Price 6d.

$\Lambda$ DESCRIPTIVE CATALOGUE of the ROCK SPECIMENS in the MUSEUM of PRACTICAL GEOLOGY. B A. C. Ramsar, F.R.S., Local Dircetor, H. W. Bristow, F.G.S., and H. BaUERManN. Price 6d. (2d Edition).

CATALOGUE OF THE CONTENTS OF THE MINING RECORD OFFICE. Pricc $6 d$.

Memoirs of the Geological Survey and of the IMuseum of Practical Geology.

"MINING RECORDS." MINERAL STATISTICS for 1853-1854, cmbracing the produce of Tin, Copper, Lead, an Silver for both years; of Irour ; of Coals and other Minerals for 1854; the Exports and Imports ; the Populatio employed, and a list of the Collieries of the United Kingdom. By ROBBRT HUNT, F.R.S., Keeper of Minin Records. Price 1s. $6 d$.

The IRON ORES of GREAT BRITAIN. Part I. The IRON ORES of the North and North Midland Counties of Enylau (Ont of print.) Part II. The Iron Ores of South Staffordshire. Price $1 s$.

"MINING RECORDS." MINERA L S'TATISTICS for 1855 and 1856, embraciug Tin, Copper, Lead, Silver, Iron, Coals, Zin Salt, and other Minerals produced in the United Kingdom. Their Exports and lmports, de. By RoBUBT HUN: F.R.S., lieeper of Mining kecords. Price 1s. $\mathrm{c} d$. each.

"MINING RECORDS." MINERAL STATISTICS for 1857. Price 1s.6el.

On the TERTIARY FLUVIO-MARINE FORMATION of the ISLT of WIGHT. By EDWARD ForBEs, F.R.S. Illu trated with a Map and Plates of Fossils, Sections, \&c. Price 5s.

On the GEOLOGY of the COUNTRY around CHELTENIIAM. Illnstrating Sheet 44 by EDWABD HCLL, A.B., F.G. Price 2s. 6d.

GEOLOGY of PARTS of WILTSIIRE and GLOUCESTERSHIRE (Sliect 34.) By A. C. RAMSAI, F. R.S., F.G.S W.T. A VisLix, F.G.S., and EDWARD HULL, B.A., F.G.S. Priee $8 d$.

These IMaps, Sections, and Books may be obtained at the Mruseum of Practical Ceology Jermyn street, Iondon.

N.B.-To prevent the confusion arising from different titles, as above, all further publications will appear under th general title of "Mexolrs of THE Geologrcal Surver, and of the Mfuseum of Practical Geology;" the woro "Monographs," "Decades," "Mining Recurds," "Reports," d'c. Ueing employed as subordinate titles, as in the la works of the list. 




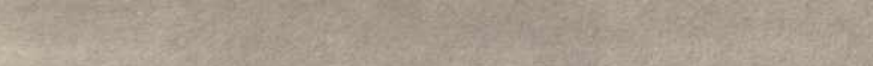




\section{Date Due}

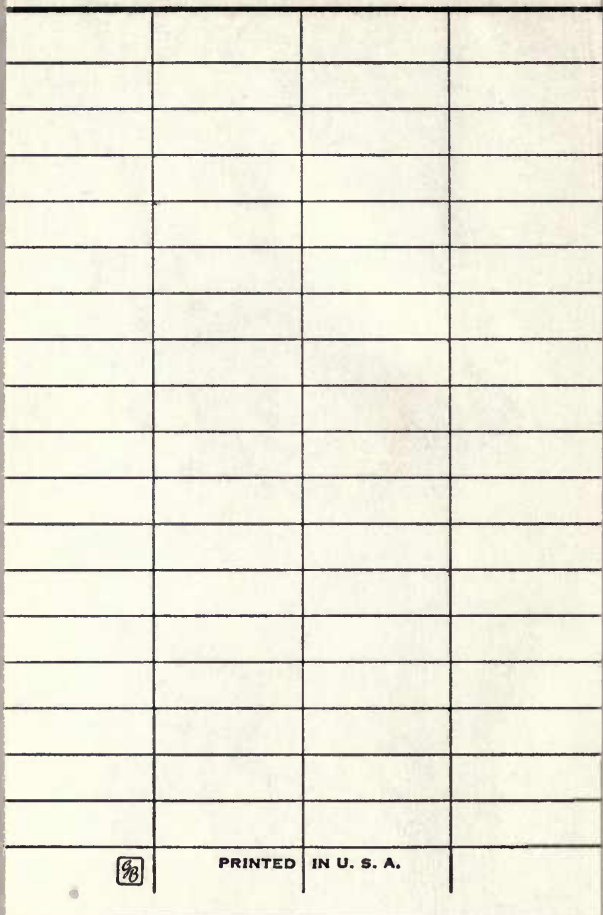

圆

PRINTED IN U. S. A. 
UC SOUTHERN REGIONAL LIBRARY FACILITY

AA $001172046 \quad 3$ 
